\title{
DESIGN, COOKING, AND OLDER MEN \\ by
}

Samantha Paige Schneider

A thesis submitted to the Faculty of Graduate and Postdoctoral Affairs in partial fulfillment of the requirements for the degree of

Master of Design

in the

School of Industrial Design

Carleton University

Ottawa, Ontario

(C) 2021, Samantha Paige Schneider 


\section{Abstract}

Many older men do not cook or only participate in very basic food preparation, which may create challenges for those who might be required to prepare their own meals out of necessity in the future. By developing an understanding of older men's cooking experiences, designers may have the insights needed to develop design interventions to support this population with their cooking experiences. This preliminary study worked with two different participant groups, older men (ages 65 years and older) who do not cook or who only participate in very basic food preparation, and designers from product, service, and healthcare design fields. Three qualitative and exploratory design research methods were used: semi-structured interviews with the older men; journal-based cultural probe kits with the older men; and focus groups with designers using personas derived from the first two methods. From these methods' insights, an understanding into the perspectives of older men cooking was produced; including three primary themes relevant to design. Additionally, two recommendation categories, recommendations for design process and recommendations supporting cooking experiences, were created through insights produced for designers aiming to facilitate older men's cooking experiences through design intervention. 


\section{Acknowledgments}

\section{To my co-supervisors:}

Lois Frankel, thank you for your encouraging words, steady guidance, and invaluable insights. I am so greatly appreciative for your willingness to go above and beyond in your support.

Mike Mopas, thank you for your support and thoughtful perspective, which always challenged me to think outside of my discipline.

\section{To my family:}

Thank you for always being there to love and support me through the thick and thin of my academic journey. Thank you Mom, for always being a willing listener and a last minute editor; Dad, for all your advice and tech support; and Christopher, for passing along your knowledge of academia and all of your jokes. Thank you Kevin for brightening each day with your loving patience and support.

\section{Special thanks:}

To all of the wonderful study participants, who generously volunteered in the middle of a worldwide pandemic and made the time to provide their insights to me. My research would not be possible without you. Thank you. 


\section{Table of Contents}

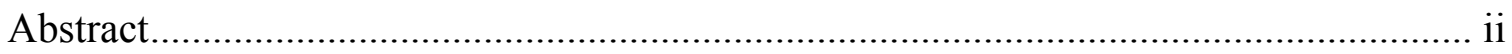

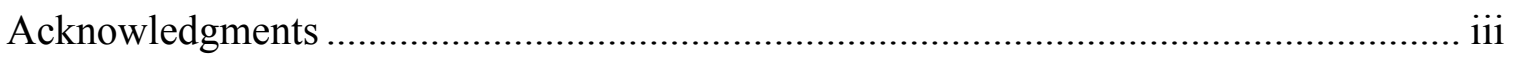

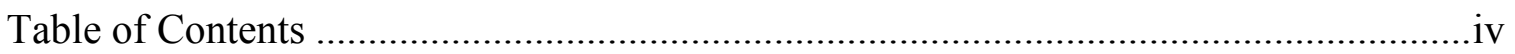

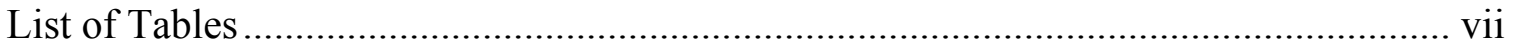

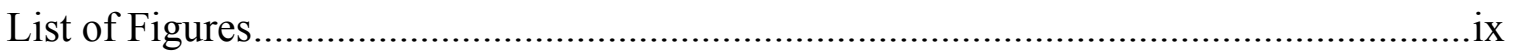

List of Appendices................................................................................................

Preface: A Personal note from the Researcher................................................................

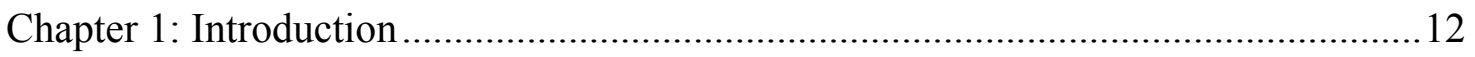

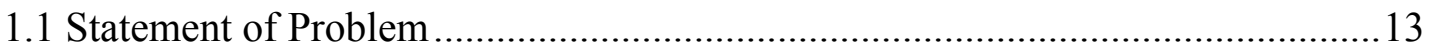

1.2 Background and Needs ............................................................................... 14

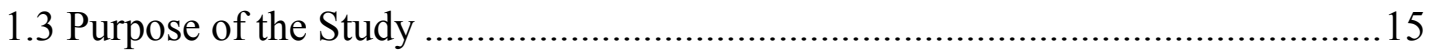

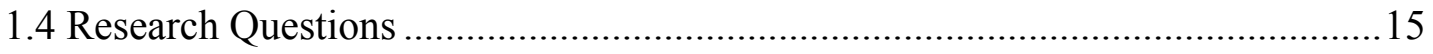

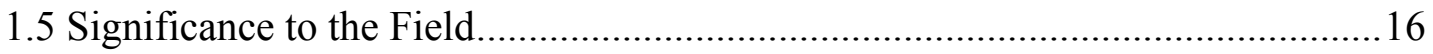

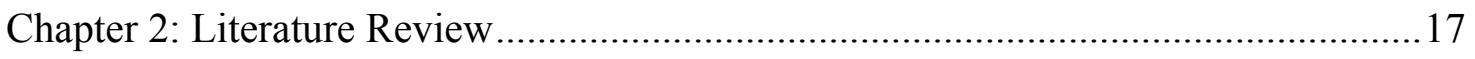

2.1 Gerontology Literature .....................................................................................

2.2 Literature about Older Men Cooking ............................................................2.

2.3 Gender Studies Literature ……………………….......................................2

2.4 Cooking Motivation Literature ………………………..................................2

2.5 Design of Ritual or Routine in Literature ……………..................................28

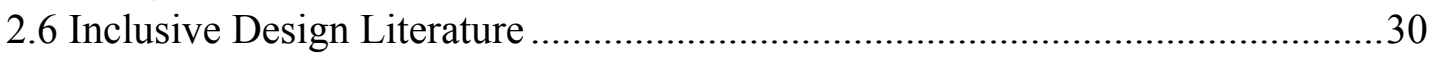

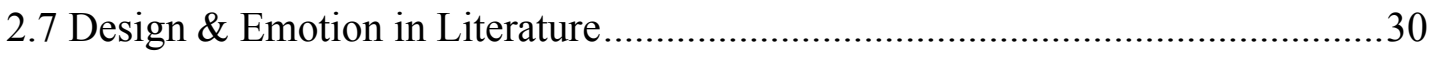

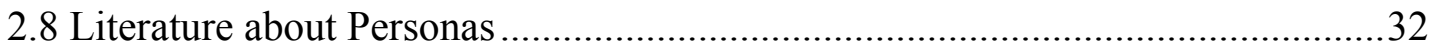

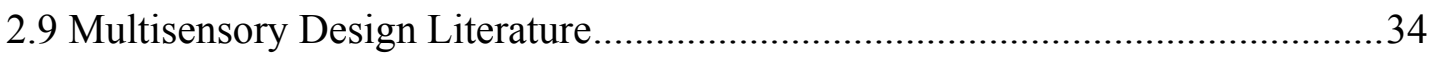

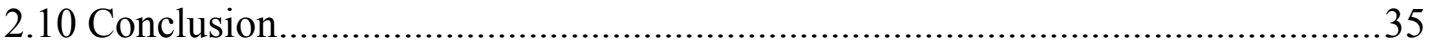

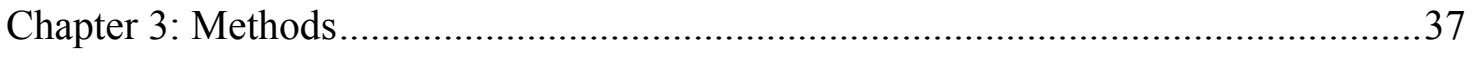

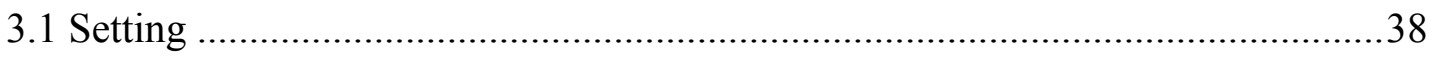

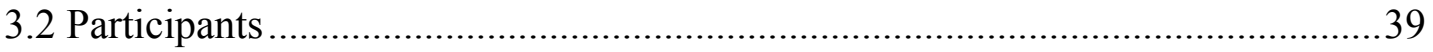

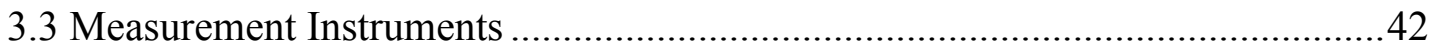

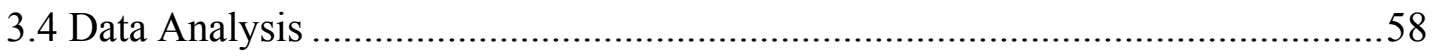

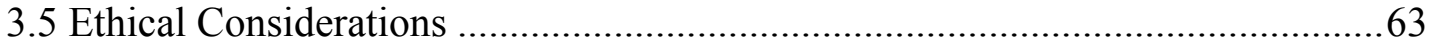




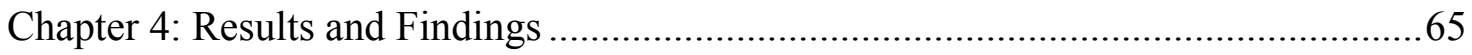

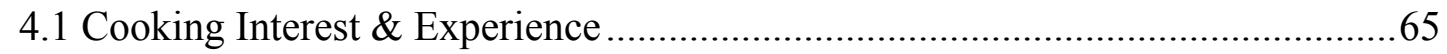

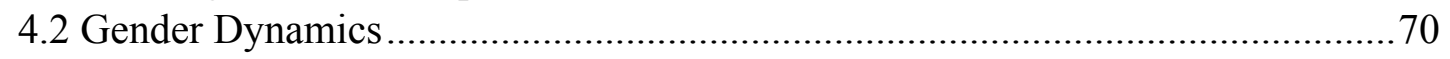

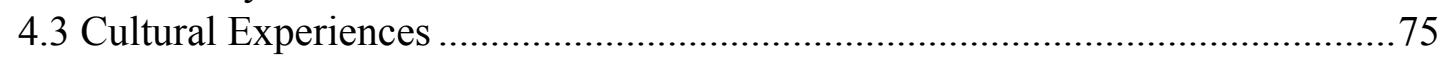

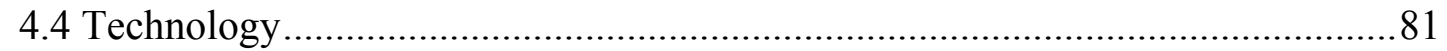

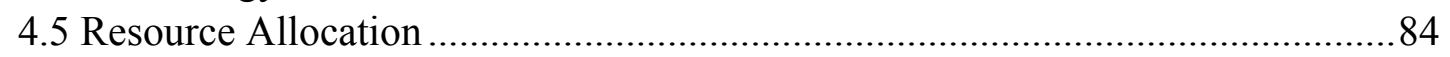

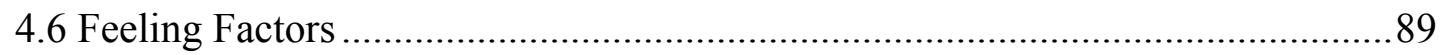

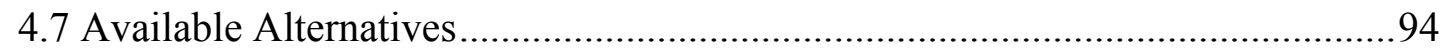

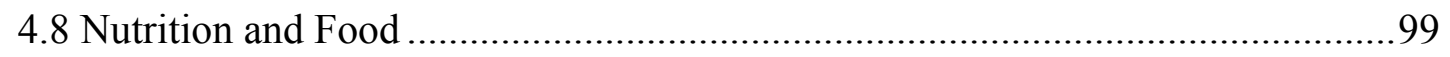

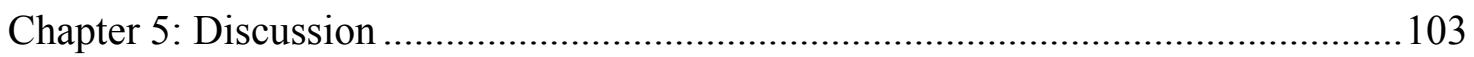

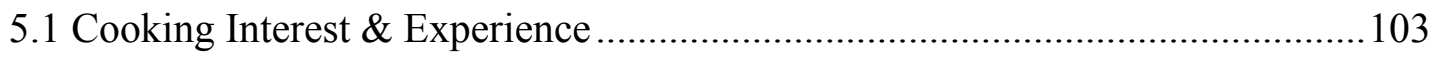

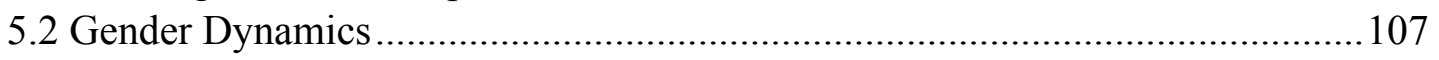

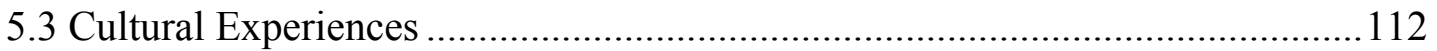

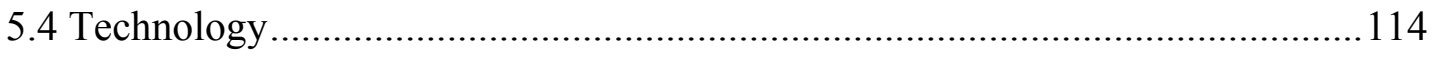

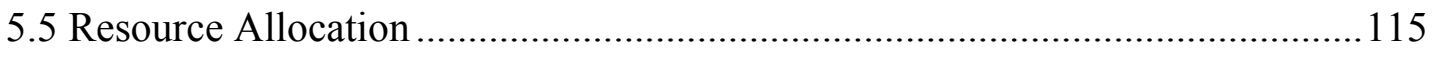

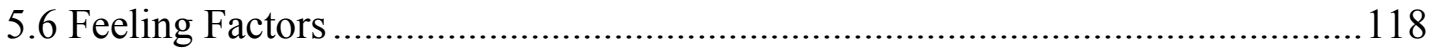

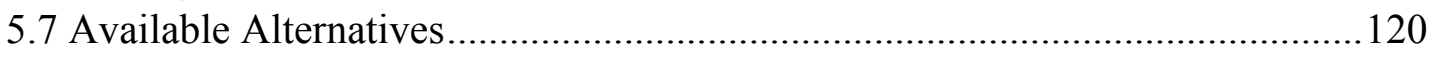

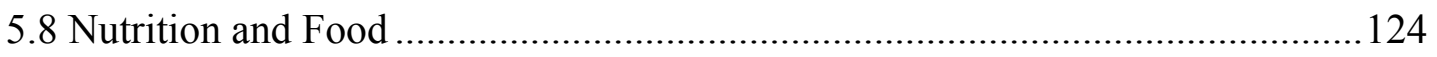

5.9 Interest as a Support for Designer Empathy ............................................... 125

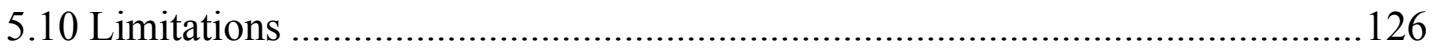

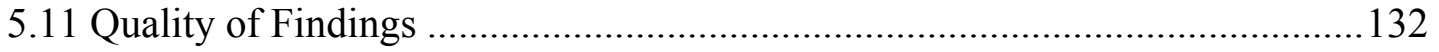

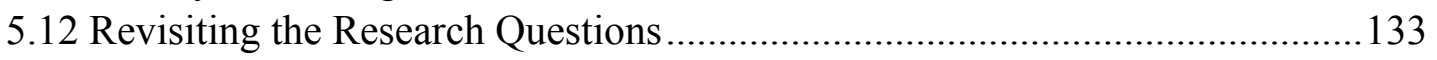

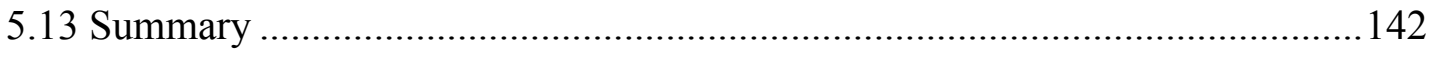

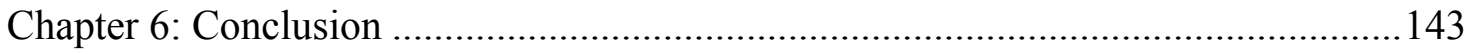

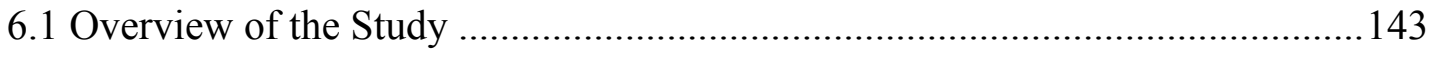

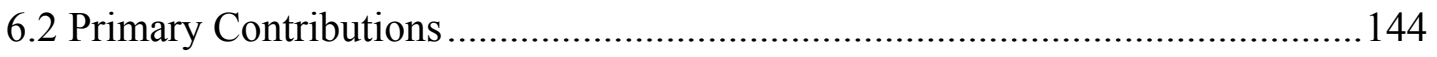

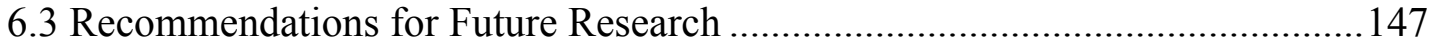

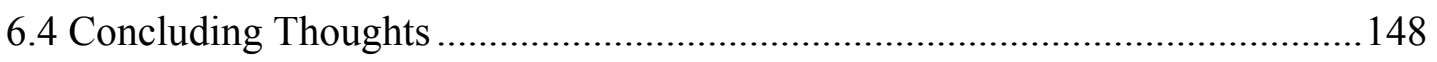

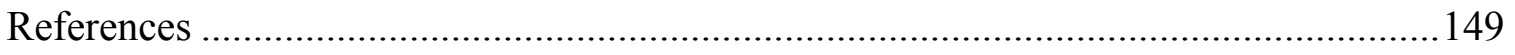

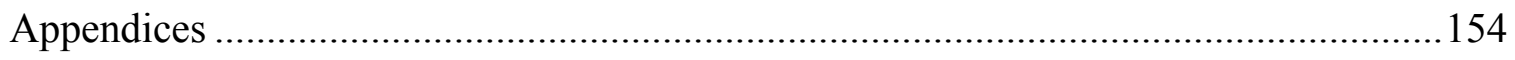

Appendix A Cultural Probe Kit Journal ............................................................. 154

Appendix B Mind-Mapping Activity Templates .................................................. 178

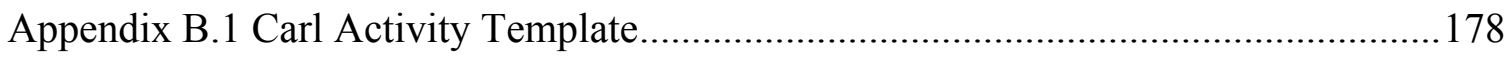

Appendix B.2 George Activity Template ........................................................... 179 


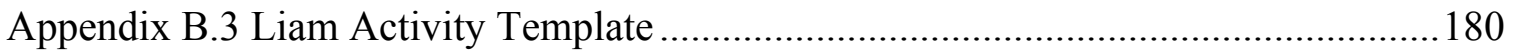

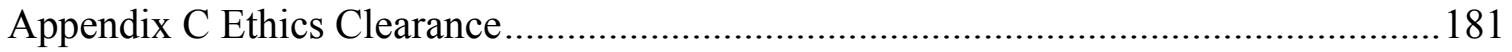




\section{List of Tables}

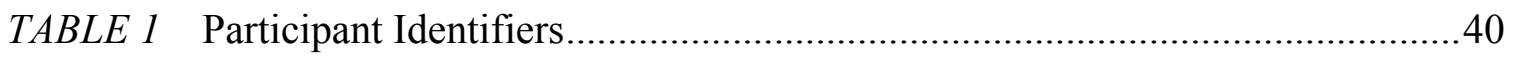

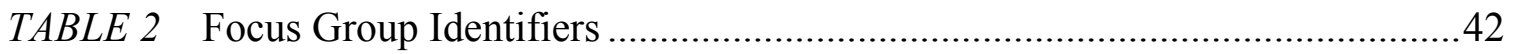

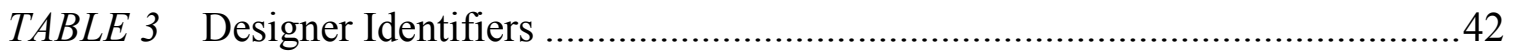

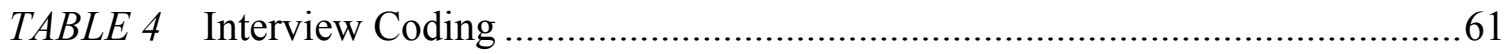

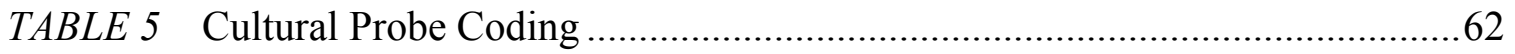

TABLE 6 Designer Focus Group Coding ………………………………………...63

TABLE 7 Men reporting their cooking experiences (Participants specified) .................66

TABLE 8 Men reporting their cooking interest (Participants specified) …………........66

TABLE 9 Past experiences as influencing factors in cooking attitudes and experiences

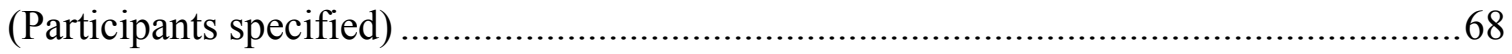

TABLE 10 Dinner preparation experiences (Participants specified) ...............................69

TABLE 11 Dinner preparation connected to men interested in learning to cook, as identified during the interviews (Participants specified)..................................................69

TABLE 12 Solutions proposed for facilitating cooking experiences (Groups specified) 70

TABLE 13 Numbers related to gendered dynamics (Participants specified)..................72

TABLE 14 Breakfast and lunch preparation experiences (Participant specified)...........72

TABLE 15 Gender as an acknowledged consideration by designers (Designers specified) 75

TABLE 16 Social experiences reported during interviews (Participants specified) .......77

TABLE 17 Social factors related to food experienced by older men (Participants specified) 79

TABLE 18 Enjoyable activities related to or embedded within food activities (Participants Specified)

TABLE 19 Proposed design solutions involving social factors or enjoyable/hobby

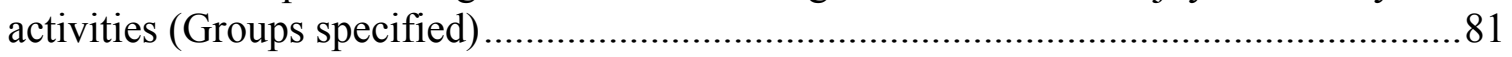


TABLE 20 Comfort with technology (Participants specified) .......................................82

TABLE 21 Technology as a barrier to design solutions (Groups Specified) ...................84

TABLE 22 Resource allocation concerns in interviews (Participants specified)............86

TABLE 23 Resource allocation influencing daily meal or food experiences (Participants specified) $\quad 87$

TABLE 24 Allocation of time-based resources as a design factor (Design participants specified) $\quad 88$

TABLE 25 Feeling factors impacting cooking attitudes (Participants specified) ...........91

TABLE 26 Feelings impacting daily cooking experiences (Participants specified) .......93

TABLE 27 Emotions as a part of the design process (Design participants specified)....94

TABLE 28 Available alternatives to traditional cooking discussed by older men (Participants specified)

TABLE 29 Reported use of available alternatives to traditional cooking in daily life

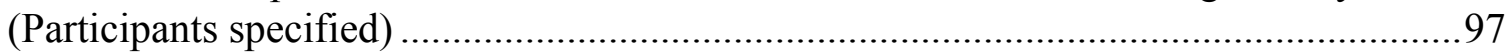

TABLE 30 New or reimagined design solutions......................................................98

TABLE 31 Preexisting options recommended supporting food activities ......................98

TABLE 32 Older men's diets in relation to nutrition (Participants specified)..............100

TABLE 33 Dessert or goodies in older men's diets (Participants specified) ................102 


\section{List of Figures}

FIGURE 1 Contents of the cultural probe kit................................................... 45

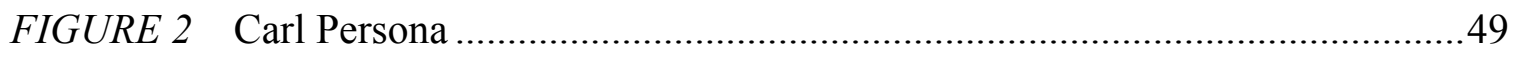

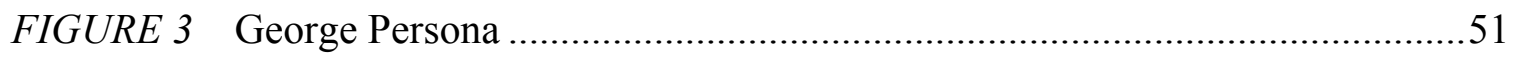

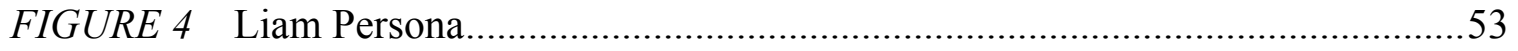

FIGURE 5 Layout for the digital Mural template ..................................................55

FIGURE 6 Photograph from P6's cultural probe kit titled "TV Table in Family Rm”.78

FIGURE 7 Photograph from P7's cultural probe kit titled "Preparing Ham"................79

FIGURE 8 Photograph from P4's cultural probe kit titled "These are the vitamin supplements I take to hopefully get a reasonable diet." .......................................... 101 


\section{List of Appendices}

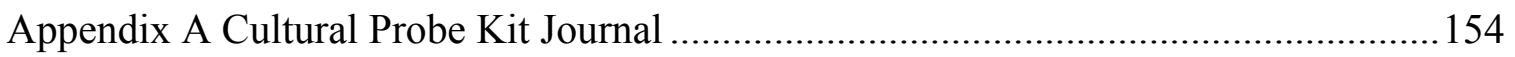

Appendix B Mind-Mapping Activity Templates ...........................................................178

Appendix B.1 Carl Activity Template .......................................................................178

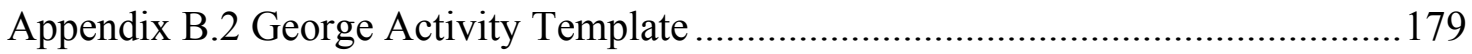

Appendix B.3 Liam Activity Template ............................................................. 180

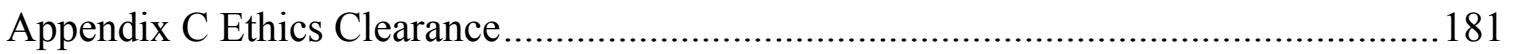




\section{Preface: A Personal note from the}

\section{Researcher...}

My own grandfather struggled to adapt to the need to feed himself after the passing of my grandmother. My grandfather was a proud man who loved good food and his own independence, and my immediate family (mom, dad, brother, and myself) lived on the other side of the country, making it difficult to support him. At one point my grandfather ate exclusively restaurant food, and right up until his death he still enjoyed meals his doctor told him were not nutritionally appropriate for a man beyond 80 years of age. As I was beginning to examine the topic of older men cooking and was identifying the gap in research on older men and cooking activities I thought of my grandfather often.

Furthermore, as I began to mention the research gap and my thesis topic to others, I began to hear more and more stories of elderly fathers and grandfathers who struggled to adapt to cooking their own meals in old age - bringing me to the conclusion that my grandfather's story was common and more research into this topic was potentially very important. 


\section{Chapter 1: Introduction}

In North American society age-based discrimination, known as ageism, is commonplace and helps perpetuate negative stereotypes (Angus \& Reeve, 2006., \& Morgan, 1979). In turn, many people in the older age brackets of North America experience a deep-rooted fear of aging and the perceived loss of independence and autonomy that may come with it (Angus \& Reeve, 2006., \& Morgan, 1979). Some of the negative stereotypes spread by ageism include the idea that elderly people are unsociable, dependent, and burdensome on society (Angus \& Reeve, 2006). While these stereotypes are largely untrue, social policy is oftentimes shaped by societal beliefs and assumptions, meaning many of the systems in place to support the elderly run under the same misconceptions that fuel fear of age (Pelham \& Clark, 1986., \& Fisk, 1986). Older people who are able to maintain their independence help to counteract ageism while experiencing a rich and wellbalanced life (Morgan, 1979).

Understanding what challenges older people face as they advance in age can help designers to develop ways to support the adaptations needed to face daily age-related challenges. Cooking is a significant daily ritual for many reasons and may benefit from design support. The first reason cooking is significant is as a basic need; humans need food to survive. To be able to support one's basic needs contributes to a sense of independence (Shephard, 1997., \& Trees \& Dean, 2018). Second, food is linked to culture, memories, and emotions, so having control over what food is made and how it is prepared can provide positive emotional experiences (Desmet \& Schifferstein, 2007., \& Elrich, Yngve, \& Wahlqvist, 2012). Last, the act of cooking, when associated with 
positive experiences, may become an enjoyable activity and also holds the potential to facilitate various social experiences.

While cooking as a daily ritual may have a positive impact on its practitioners, there is very little research into how these rituals might be encouraged and developed for elderly male populations. Traditionally, in many cultures around the world, domestic cooking tasks have been predominantly viewed as feminine. As a result, men have less experience cooking and there seems to be a reduced focus placed on understanding their cooking experiences. An interdisciplinary design research approach across design and sociology disciplines may provide a fuller understanding of older men, their cooking experiences, and how to support them.

\subsection{Statement of Problem}

How can design support older men with little to no cooking skills, who may struggle to adapt to the challenges of preparing their own meals if their spouses or partners are no longer able to prepare the household's meals?

\section{Gerontology Considerations}

The experience of aging can create new challenges that impact the way a person experiences activities of daily life. For older men who suddenly need to cook for themselves, the challenges of aging in combination with learning a new skill may make the process of adaptation difficult. Being unable to fulfill a basic need by one's self can foster fear for the loss of independence and autonomy. Additionally, potential product solutions may need to consider design challenges pertaining to old age, such as how grip capabilities might impact the design of food packaging, such as a twist-capped jar (Yoxall, Langley, Musselwhite, Rodrigues-Falcom, Rowson, 2010). 


\section{Sociological Influences}

Sociological influences, such as gender and culture, impact how cooking as an activity is perceived and who has experienced it. Due to cooking being traditionally viewed as a feminine activity, older men typically have not developed cooking skills (Sidenvall, Nydahl, Fjellström, 2000., \& Charles \& Kerr, 1988). On top of lack of experience, social and cultural opinions may also impact older men's readiness to learn to cook.

\section{Design Interventions}

Design methods create a structured way of exploring older men's cooking abilities and developing a clear understanding of key problematic areas to support. In order to intervene in older men's cooking abilities, the most optimal design methods for the task must first be understood and explored.

\subsection{Background and Needs}

This study focuses on gaining knowledge and understanding in the areas of gerontology, sociology, and design can help to develop recommendations that will support older men learning to cook.

\section{Gerontology Considerations}

This study begins by searching the gerontology literature to develop an understanding of what the experience of aging may look like for older men living independently is key in order to better understand how to support this demographics' daily cooking abilities.

\section{Sociological Influences}

Understanding the culture and traditional influences impacting older men's experiences in the kitchen and surrounding food is pivotal to understanding how to support them moving forward. 


\section{Design Interventions}

Understanding how designers might approach the problem of designing to support older men cooking may help to develop a successful set of design recommendations.

\subsection{Purpose of the Study}

The purpose of this research was to develop a fuller understanding of the potential significance of daily cooking rituals, and experiences for elderly men who don't cook or who only participate in very basic food preparation and how design may be able to support positive cooking experiences and/or rituals.

Many older men depend on their wives to cook their meals for them and are ill prepared for any scenario where they may need to prepare their own meals (Trees \& Dean, 2018., Daniels, Glorieux, Minnen, \& van Tienoven, 2012., Short, 2006., \& Sidenvall et al., 2000). While there are many benefits to being able to cook, the challenges of learning a new skillset as well as age related barriers might instead foster negative cooking experiences if proper support is not available.

This preliminary study explores older men who only have very basic to no skills related to food preparation as well as the designers that may work with this demographic in the future. Through this exploration a better understanding of how designers can best approach design problems related to older men and cooking has been developed.

The expected outcome of this research is the production of a set of design recommendations for the future of cooking and kitchen supports for older men.

\subsection{Research Questions}

This research seeks to answer the following questions: 
Main Question: How might design interventions support the facilitation of positive cooking experiences for older men?

Sub-question: How might insights into older men's daily cooking rituals or routines further support independence for this population?

Sub-question: How might the design of kitchenware further support older men's independence?

\subsection{Significance to the Field}

Due to the limited amount of research that has been produced in regards to older men and cooking skills in the past, this research is significant for its contribution to the basic foundation of knowledge on the subject. Additionally, this research is significant in its call for designers to set focus on the potential increasing need for cooking supports for older men. 


\section{Chapter 2: Literature Review}

Due to the multitude of perspectives and disciplines that influence topics of aging, gender, and food and cooking experiences there are many research facets (including: gerontology, sociology and gender studies, and industrial design) that are relevant to this study. Design is a primary approach to this research because its core goal is to develop further understanding into how design can contribute to and support the daily cooking rituals of older men. Sociology also serves as a major approach due to its perspectives on societal challenges and needs, of which this research seeks to address several (i.e. ageism, autonomy in aging experiences, and a need for inclusivity in accessibility design).

\subsection{Gerontology Literature}

Before beginning to research anything remotely related to cooking or daily rituals it's important to understand elderly populations and how the experience of old age might influence this research. In his gerontology book, Becoming Old, John Morgan seeks to explain the process and experience of becoming old. In doing so, he covers a wide range of topics such as the variety of potential physical, sociological, and emotional losses that can be experienced through the process of aging (1979). Something key that he covers within this work is the concept of "aging successfully," also known as the ability to "adapt and grow within the later years of life" (Morgan, 1979). Successful agers are linked to having higher self-esteem levels, which Morgan explains is likely tied to a higher level of independence (1979). Being a successful ager essentially boils down to having the ability to lead a well-balanced, independent (but not necessarily solitary) lifestyle, something that all age groups, young and old, tend to seek to do. 
Decreased physical capabilities and changes to social circles may challenge the way older people experience daily life (Palmore, 1970., \& Fisk, 1986). With advanced aging comes an increase in the experience of loss; the ability to navigate loss and adapt one's social network is important to maintaining a high quality of life later in life (Morgan, 1979., Fisk, 1986., Smith \& Ryan, 2016). Many independent elderly adapt to loss and shifts to their social circles by maintaining or strengthening remaining familial relationships and/or developing new friendships (Fisk, 1986., \& Smith \& Ryan, 2016). Not only does this social adaptability improve mental wellbeing and provide pleasure, after all, humans are social creatures by nature, it provides a more personal source of care or support where needed (Smith \& Ryan, 2016., \& Svanborg, 1984).

Decreased physical capabilities may impact ability to carry out daily chores and hobbies in the same way as when young, thus challenging the way older people experience daily life (Palmore, 1970., Morgan, 1979., \& Shephard, 1997). In his book, Aging, Physical Activity, and Health, Shephard breaks down physical activity into 3 categories of activities in order to describe how physical activity impacts quality of life (1997). The categories are as follows: basic activity (encompasses the ability to eat, dress, bathe, and move about independently), intermediate activity (encompasses activities such as housekeeping and shopping), and advanced activities (encompasses voluntary pursuits, such as travel, hobbies, recreational exercise, and participation in religious and social gatherings) (Shephard, 1997). Intermediate and advanced activities are of equal significance to basic activities and a balance of at least some capabilities from each of the activity categories are needed to support what might be considered a higher quality of life (Shephard, 1997). 
Elderly people who decline in physical abilities must adapt to the new challenges in their lives. Part of this adaptation may require an evaluation into what support is needed if the elderly individual wishes to continue to live independently in their own home. This evaluation can tie back to the importance of social support, which, as mentioned above, may provide a more personal form of care and support where needed.

Domestic care services, which may be used for those elderly people unable to receive full support from their social network, must also be examined. It has been found that domestic care services often perpetuate socially constructed stereotypes that assign elderly people as dependent and helpless (Pelham \& Clark, 1986., \& Fisk, 1986). One example of this stereotyping is seen in an elderly home care book wherein hypothetical elderly home care recipients are referred to as "chronically dependent persons" and "frail persons" (Monk \& Cox, 1991). Despite the book recognizing the varying levels of support and care a client may require, one of its concluding recommendations was that "all elderly clients living alone who are recipients of home care services should be required to use a personal emergency response system or lifeline" (Monk \& Cox, 1991). This blanket statement of "all elderly clients" ignores the potential varying capabilities and familial supports of clients. Surely a client who only needs some support with a couple housekeeping or domestic tasks (such as cooking meals) should not be considered to need the same level of medicalized intervention as a client with severe mobility or health issues. While these services provide supports to help elderly people remain in their own home, whether or not these services provide the same level of dignity and feelings of independence as social networks needs to be questioned. 
The ability to adapt to decreased physical abilities and a change to social circles with dignity directly connects to the concept of successful agers that was mentioned earlier in the exploration of gerontology literature. Those individuals with the ability to adapt to new challenges are more prepared and capable of leading independent lives. Additionally, these successful agers play an important role in counteracting ageism. Angus and Reeves explain that ageism often magnifies fears of aging amongst older populations by promoting negative stereotypes, such as the idea that elderly people can become unsociable and burdensome (2006). These negative perspectives serve to distance generations from one another, potentially isolating older people from much needed social and community engagement opportunities (Angus \& Reeves, 2006). Successful agers have the ability to adapt to the new challenges experienced through advanced aging, and the confidence to continue to grow and seek engaging opportunities for themselves (Angus \& Reeve, 2006., \& Morgan 1979). Their independence and higher self-esteem suppresses fears of aging while simultaneously challenging the negative stereotypes perpetuated by ageism.

In this section, the literature addresses potential decreases in physical capabilities and/or social networks that could negatively impact older men's quality of life if they find themselves unable to adapt to new challenges they may face. One potential challenge may be the need to learn to prepare their own meals, which could also be impacted by any physical changes they may experience. Designing to support cooking may help to improve older men's adaptability as they age. Additionally, cooking activities may serve to support a variety of physical and social activities, contributing to a higher quality of life. 


\subsection{Literature about Older Men Cooking}

As previously mentioned, one way we can support the independence of elderly populations may be by designing to support the development or maintenance of daily rituals, such as cooking. The few research studies that do look at cooking practices within elderly male populations help build an excellent foundation for my own research to stand on. Kullberg, Bjorklund, Sidenvall, and Aberg studied any food-related activities of older men (between the ages of 64-84) with somatic diseases participated in, including cooking, grocery shopping, and dinning habits (2011). Like Morgan mentioned in his gerontology research, Kullberg et al. also highlighted the importance of successful aging. Referred to in their article as "adaptation," Kullberg et al. define it as referring to "the means by which the [participants of their study] cope, for example, with altered life circumstances and activity limitations because of disease “ (2011). Through home interviews, it was found that participants could be categorized one of three ways: cooking as pleasure, cooking as need, and food is served (Kullberg, Bjorklund, Sidenvall, \& Aberg, 2011). Participants who cooked for pleasure found cooking as a source of joy and maintaining the ability to cook contributed to their overall well being (Kullberg et al., 2011). Meanwhile, inexperience and lack of cooking knowledge led men in the 'cooking as need' category to seek ways to minimize their time cooking (Kullberg et al., 2011). The final category, 'food is served' was reserved for men who cohabitated with a female partner who prepared all their meals for them (Kullberg et al., 2011). What was especially interesting about this category was the divided interests of the men. Men who were inexperienced cooks showed little to no interest in cooking, however, men who had spent time cooking prior to the limitations of their somatic disease missed the experience 
of cooking (Kullber et al., 2011). This finding might mean that a lack of experience create a lack of interest in cooking, and therefore a lack of positive cooking experiences to motivate new cooking habits. Regardless of cooking interests, all participants shared a common goal of maintaining independence in their daily lives through their food-related activities (Kullberg et al., 2011).

Another study also found that older men who have little to no experience in the kitchen tend to avoid cooking tasks as much as possible (Keller, Gibbs, Wong, Vanderkooy, \& Hedley, 2004). Keller et al.'s study developed and implemented a cooking class for men 65 years of age or older (2004). Through the program men developed new cooking skills and gained confidence in their newfound cooking abilities (Keller et al., 2004). In followup interviews participants reported cooking as an enjoyable activity, and most of the participants also valued the program for its engaging skill development and sociable qualities (Keller et al., 2004).

In an East Yorkshire study looking at the importance of maintaining and adapting food rituals in elderly people, the maintenance of feelings of autonomy were highlighted (Trees \& Dean, 2018). The study did not focus on one specific gender and two men's cooking experiences were discussed in the article. One man, who had never cooked a meal in his life, was recorded as reluctant to start cooking, but did so out of necessity in order to care for himself after the passing of his wife (Trees \& Dean, 2018). While the man tended to try his best to avoid cooking, he still invited his son and daughter-in-law over for a home cooked meal as opposed to a restaurant meal (Trees \& Dean, 2018). This information may imply that he saw a social value to cooking a meal to share with loved ones. Additionally, this social value may be seen as of greater importance than his own 
discomfort in the kitchen. The second man discussed in the study enthusiastically learned to cook as a way to care for not only himself, but his wife as well, who was no longer capable of doing the cooking herself (Trees \& Dean, 2018). In this instance, cooking was seen as a signifier for the care and love the man held for his wife (Trees \& Dean, 2018). Similar to the men in Keller et al.'s cooking group, the man also stated that he enjoyed the ability to learn a new skill (Trees \& Dean, 2018., \& Keller et al, 2004). The sociability and educational aspects cooking was found to have for men across the two studies showcase cooking as a method of which older men may be able to fulfill their needs for social engagement and mental stimulation (Angus \& Reeve, 2006.,Trees \& Dean, 2018., \& Keller et al, 2004).

In summary, the desire for independence may be a major cooking motivator for older men, regardless of their interest level. Motivation may also be tied to experience and skill levels. Lastly a higher skill level may result in an increase of enjoyment in cooking, as compared to those with lower skill levels who report cooking out of necessity.

\subsection{Gender Studies Literature}

Feelings of nurturing and caring for others through cooking are more traditionally seen as female experiences (Szabo, 2012., Short, 2006., Daniels, Glorieux, Minnen, van Tienoven, 2012., \& Sidenvall, Nydahl, Fjellström, 2000). Oftentimes women have been socialized to cooking due to cultural expectation (Sidenvall et al., 2000). As such, women are more likely to spend their free time on household tasks, such as cooking, as opposed to their male counterpart who would rather spend their free time focused on leisurely activities (Daniels et al., 2012). 
Michelle Szabo, who examined men's domestic cooking experiences, delved into the reasons that motivate men to cook (2014). Szabo explains that it has been suggested that men and women cook differently; that women cook in order to nurture and support their families, while men cook for leisure, as a display of artistry, and seduction (2014). Through Szabo's study it was found that while men do cook for all of the aforementioned reasons, $50 \%$ of the of the participants also saw cooking as a way to express care or connect with others (2014). It is important to acknowledge that none of the participants of the study were elderly (participant age ranged between 26-58), and it can be assumed that generational differences may impact the opinions of men towards cooking (Szabo, 2014). A study in Sweden, which had a broader range of participant age (participant age ranged between 22-88), asked participants what it meant to cook as well as follow up questions to gauge the cooking experiences of participants (Neuman, Gottzén, \& Fjellström, 2016). The greatest differentiator amongst participants was age; of the two elderly participants (both 79 years old) that were discussed in the article, one expressed little to no interest in cooking, while the other said he participated in a cooking course for older men (Neuman et al., 2016). There was little indication as to whether or not the participant engaged in the cooking class was enthusiastic about cooking (Neuman et al., 2016). It was found that cooking experiences were considered a more important part of the lives of younger men, implying that generational differences impact men's opinions of cooking (Neuman at al., 2016).

For the sake of this research in specific, which focuses on older men, it is important to understand how gender may impact kitchen tasks specifically in older demographics. Texts examining traditional household roles, which were and still are typically followed 
by today's older generations, found that women not only take on the responsibility of cooking, but of preparing "proper meals" as well (Charles \& Kerr, 1988). "Proper meals" within this context consist of meat and at least two forms of cooked vegetables, and a full Sunday roast was considered the ideal in which woman should strive towards (Charles \& Kerr, 1988). In contrast, in the absence of a female counterpart, men typically prepared "something to eat," which consisted of fast and easy to prepare foods (Sidenvall et al., 2000). In another Swedish study older woman (ages 63-87) still living at home were interviewed in regards to their cooking habits (Sidenvall et al., 2000). It was found that older women are motivated to cook as a method of caring for others, and that their interest in cooking tended to diminish if they were widowed and had no one to cook for (Sidenvall et al., 2000). The women who were not widowed tended to prepare daily meals that catered to their husband's tastes (Sidenvall et al., 2000). Additionally, the women took pride in preparing meals from scratch using fresh ingredients as opposed to pre-prepared or ready-made food or ingredients (Sidenvall et al., 2000).

In summary, generational experiences may play a major role in not only older men's attitudes towards cooking, but in their ability to cook as well. While cooking can be an expression of care regardless of gender, women in traditional household roles tend to take on the role of nurturer more often than men. Traditional household roles, which are practiced more regularly by older generations, may result in older men lacking cooking experiences due to their wives' skills in catering to their food tastes and requirements.

\subsection{Cooking Motivation Literature}

What factors impact someone's motivation to cook? In order to understand how to facilitate positive cooking experiences in older men, it is important to know what factors 
may impact motivation. The factors found predominantly in existing literature are: health, confidence, attitude, and social factors.

Eating home cooked meals is often considered a healthy behaviour. In a 10-year study of Taiwanese elderly people (65+ years), lower mortality rates were found among those who cooked frequently (Elrich, Yngve, \& Wahlqvist, 2012). The ability to cook provides an individual with a plethora of ways to provide healthy meal options to one's self (Short, 2006). For example, if an individual knows how to grill or steam food they can prepare a multitude of tasty meals that may otherwise be unobtainable healthy meal options (Short, 2006). If an individual cannot cook and they do not cohabitate with someone who can cook for them, then the individual's nutritional health and food choices may be at the mercy of people whose interest is purely financial (Short, 2006). A 2019 study exploring nutritional intervention for African American adults living with chronic diseases, such as type 2 diabetes mellitus, found that the implementation of nutrition education classes significantly improved confidence in cooking, reduced barriers to cooking, and improved healthful eating and healthy food preparation (Nara, Thompson, Johnson, Ntekim, Castor, \& Ngwa, 2019).

Confidence and positive attitude influence several different factors of cooking. Two studies conducted in the UK in the mid-1990s examined cooking ability and food knowledge (Short, 2006). The studies concluded that positive attitude and confidence play a key role in not only the frequency in which an individual chooses to cook, but also what an individual cooks (Short, 2006). As men typically prefer to spend time pursuing hobbies than fulfilling household tasks, cooking may need to be seen as a form of pleasurable pursuit or hobby in order to have an interest towards the activity (Daniels et 
al., 2012). Positive cooking experiences are important in this case, as confidence and attitude can easily be impacted when a home cooked meal does not turn out as intended. In these instances, the cook typically experience emotions such as disappointment, dissatisfaction, or frustration because there is no reward for the effort of cooking (Short, 2006).

Social factors are a major cooking motivator. Cooking can be seen as a method of showing care for others and cooking for guests or a social occasion tends to elicit higher levels of effort amongst cooks (Short, 2006., Daniels et al., 2012., \& Sidenvall et al., 2000). According to Short, the high value of social occasion in the cooking process can be highlighted by the questions a person may ask themself when preparing to cook a meal; questions such as "what is the occasion?", "who will be present?", and "what type of meal is befitting?" are often asked before "what food do I cook?" (2006). The high value of cooking as a social activity can also be seen when comparing solitary cooks to people who cook together. Solitary cooks tend to consider cooking as a necessity or a chore as opposed to people who cook together, who tend to consider it a pleasurable activity (Daniels et al., 2012). In addition to being pleasurable, people who attach social importance to their cooking habits, and who do not feel rushed in their day-to-day lives, are more likely to perceive cooking a leisure activity or hobby (Daniels et al., 2012). In summary, social factors and hobbies may be important cooking motivation factors to explore when designing for older men who are of retirement age and therefore more likely to have additional time for leisurely activity. Attitudes and confidence towards cooking activities as well as preexisting positive cooking experiences may also prove to contribute towards their motivation or willingness to cook. Additionally, the health 
benefits of home cooked meals could motivate older men to learn the cooking skills needed to support a healthy lifestyle overall.

\subsection{Design of Ritual or Routine in Literature}

There are multiple angles from which design perspectives can be applied to how design could support daily cooking experiences in elderly men. The first angle is to look at how design can impact everyday rituals, which are routine practices that are valued for their experience and take on a higher meaning beyond that of basic need fulfillment (Lévy, 2015., Lévy \& Hengeveld, 2016., \& Lévy, 2018). Routine practices, on the other hand, are regular experiences that serve to fulfill a need or want, typically with a degree of efficiency (Lévy, 2015). A very contextually appropriate example of ritual comes from Rozendaal's thesis work, which uses the example of cooking a meal from scratch versus cooking a TV dinner (2007). To cook from scratch is an enriching experience, one that can be appreciated for the process and can be considered a form of ritual (Rozendaal, 2007). The TV dinner, on the other hand, would more likely be considered a routine as it requires very little engagement and is more oriented toward achieving a goal (quickly providing a meal to satisfy hunger) rather than the experience overall (Rozendale, 2007). Understanding daily ritual can be an important factor in the design process, as a designed object has the potential to impact how a daily ritual is experienced or possibly how it is performed (Lévy \& Hengeveld, 2016., \& Lévy, 2018). If an object positively impacts the ritual it may become part of it (Lévy, 2018). To design a daily ritual, a designer must be able to examine how meaning \& value are assigned to sequences of events, thus forming or emerging into ritual (Lévy, 2015). 
The process of understanding what to design often depends on the observation, analysis, and synthesis of collected field data (Holtzblatt \&Beyer, 2016). Understanding what design will be most suitable, be it service, industrial, or experience design, is largely based on examining people's rituals or routines. Service design looks to either create a new service or improve upon a preexisting one in order to meet the needs of a user (Interaction Design Foundation, 2020). Industrial design refers to the facet of product design wherein contributory factors are merged into a three-dimensional form that is capable of being mechanically reproduced (Kirkham \& Blecksmith, 2003., \& Heskett, 1980). Both service and industrial design may fall under facets of experience design. Experience design, also known as user experience design, is a form of design that focuses on all aspects of the user experience and considers how the experience may unfold over time (i.e. the initiation, immersion, conclusion, and potentially the continuation of the experience) (Diller, Rhea, \& Shedroff, 2005., \& Interaction Design Foundation, N.D.). Don Norman, who coined the term 'user experience design,' describes the user experience as "[encompassing] all aspects of the end-user's interaction with the company, its services, and its products" (Norman \& Nielsen, N.D.). This study focuses on rituals -cooking rituals- which imply that the act of cooking is enjoyable and viewed as a valuable process, may support a higher quality of living for older men. In order to best design cooking rituals, it may be important to further understand the values of the intended demographic as well as what sort of designed objects can impact the experience of cooking. 


\subsection{Inclusive Design Literature}

Inclusive design, which is a field of design that takes a user centered approach to design in order to support wider ranges of abilities or disabilities, may be important to consider due to the changing abilities older people may experience (Gilbert, 2019). An inclusive design perspective would include an older age demographic, while also appealing to a range of different abilities from young to old (Wright, 2004., \& Shinohara, \& Wobbrock, 2011). This mode of working requires the designer to be cognizant of the accessibility qualities, human factors, and aesthetic features of a product (Wright, 2004). In Cagan and Vogel's book, Creating Breakthrough Products, they examine an often-cited example of inclusive design: the OXO GoodGrips vegetable peeler, which the inventor, Sam Farber, was inspired by his wife to create (2001). Farber's wife had arthritis in her hands and struggled to find an attractive peeler that was comfortable in her hands (Cagan \& Vogel, 2001). The solution, designed by the firm Smart Design, the OXO GoodGrips vegetable peeler, not only supported the needs of people with arthritis, but was also more comfortable in general and attractive enough that it quickly became popular with younger generations of cooks as well (Cagan \&Vogel, 2001).

By balancing between the accessibility and all the elements that make up product design (i.e. appearance or form, material selection, maintenance, usability, etc.), a product may have a positive impact on the users' everyday rituals or routines, as well as counteract any negative perceptions that may have formed due to the accessibility elements.

\subsection{Design \& Emotion in Literature}

Another design lens to consider is an emotional design perspective. A positive emotional response to a product can do a lot more than just attract continued use of the product. 
Experiencing positive emotions provides critical support in learning processes and facilitates creative thinking (Norman, 2004). Additionally, people are more capable of problem solving when they experience positive emotions (Norman, 2004). The ability to learn, think creatively, and solve problems are valuable skills to have when engaging in cooking experiences, which involve a multitude of choices as well as physical action and sensory stimulation.

Don Norman proposes that there are 3 levels of brain processing that contribute to humans' emotional reactions: visceral, behavioural, and reflective (2004). The visceral level engages the automatic, instinctive reactions; the behavioural engages controls everyday behaviour; and the reflective level engages the contemplative part of the brain that aims to consider the rationalization of a product or experience (Norman, 2004). The designed features that impact these levels are, respectively, aesthetic and sensory appearance (how the product looks and feels upon first look); product experience (functional and pleasurable to use); and long-term satisfaction in a product (Norman, 2004). It is important to note the Norman states that Cultural views have a large impact on two out of three of the levels of processing - the behavioural and reflective levels (2004). These two levels are impacted by experiences, training, and education, as well as cultural views (Norman, 2004). Ideally, a product is designed with all three levels of processing in mind as to support a complex and multifaceted positive emotional response that remains with the user, in the reflective part of their brain, long after the initial product use, encouraging repetitive use.

Beyond the 3 levels of processing, there are many different factors that must be understood and supported in order to achieve a design supporting the visceral, 
behavioural, and reflective levels. One emotional design researcher, Aaron Walters, suggests that empathy and a tie back to inclusive design is a key factor to emotional design (2020). Designing with inclusivity and empathy in mind can create positive experiences that resonate with a broader population (Walters, 2020). Inclusion can touch upon all 3 levels of process. A beautifully designed product (visceral) that meets the functional needs of someone with specific barriers or needs (behaviour) holds the potential to provide long-term satisfaction and extended use (reflective).

Positive Design, which is very similar to emotional design in the sense that it aims to support the wellbeing and happiness of people, may also be a lens of design that could support healthy daily ritual (Desmet \&Pohlmeyer, 2013). Positive design believes that through a balance of designing for pleasure, personal significance, and virtue, an intersection is found where people will flourish (Desmet \& Pohlmeyer, 2013). While these different lenses of designing for emotion all propose the need for a different variety of emotional considerations or factors, they all have one thing in common - they recognize the importance of positive emotions.

\subsection{Literature about Personas}

Personas, a method of communicating user information to designers through user profiles representing different groups of people, may be useful in supporting emotional design methods (Chen, R., Nivala., \& Chen, C-B., 2011., \& Adlin \& Pruitt, 2010). In the 1980's Alan Cooper, a software inventor, began using early iterations of personas internally in his work (Goodwin, 2009). Cooper further developed personas in the 1990s into a collection of characters as a tool for communicating user behaviours and needs to a client (Cooper, Reimann, Cronin, \& Noessel, 2014., \& Goodwin, 2009). Personas have evolved 
into a part of a narrative-based approach that serves to help anyone involved in the design process to understand the importance of certain design features based on user needs and facilitate design rationale (Cooper et al., 2014). The user profiles presented through a persona method act as a tool for constructing a clear understanding of who a designer is designing for and ensures this understanding is consistent across all designers examining the personas (Vincent, \& Blandford, 2014., \& Nielsen, 2019). As was previously discussed in 2.7, an emotional design lens requires designers to examine and understand the emotional levels or factors that may impact a product experience (Norman, 2004., Walters, 2020., \& Desmet \& Pohlmeyer, 2013). A persona can help a designer to empathetically design through it's ability to help the design to understand the user. An investigation by Chen, R., Nivala, and Chen, C-B.(2011) found that personas were capable of supporting both reflective and behavioural emotional design lenses and design ideas, which are 2 out of the 3 emotional design levels proposed by Don Norman (2004). Additionally, Nielsen stated that the success of personas can be measured by whether a designer can associate the persona with someone they know or when the persona evokes empathy (2019). Cooper et al., view personas as a tool for evoking empathy as well when designers, engineers, or other stakeholders begin to empathize with personas and begin to view personas as real people, they become more engaged with the design process as a method of supporting the persona (2014).

Despite beliefs that personas can support empathetic design thinking, some designers have been critical of the method (Vincent, \& Blandford, 2014., \& Nielsen, 2019). Of the critiques made of personas, some critics have viewed them ineffective to evoking empathy. Designers can find personas to be too abstract or impersonal, and therefore find 
difficulty empathizing with the persona (Nielsen, 2019). There is no set guideline for what is the best way to design personas and there is controversy in whether it is appropriate to include fictitious information in personas rather than information based solely off of users participating in research (Vincent, \& Blandford, 2014). The use of fictitious information could impact designers' buy in of the persona, therefore impacting their ability to empathize with it (Vincent, \& Blandford, 2014).

Many designers and/or researchers have outlined recommendations for persona building (Chen, R., Nivala., \& Chen, C-B., 2011., \& Adlin \& Pruitt, 2010., Vincent, \& Blandford, 2014., \& Nielsen, 2019., Cooper et al., 2014). Cooper et al. recommend that personas are developed using information gathered from interviews (2014). The decision of who should be interviewed should be determined through a persona hypothesis, which is built to consider the variables that will help to define and differentiate among various potential users (Cooper et al., 2014). Nielsen suggests that while developing personas, a focus should be placed not only on understanding the end user, but also on the specific tasks and processes involving the personas (Nielsen, 2019).

\subsection{Multisensory Design Literature}

There are so many physical and mental factors involved in the act of cooking, such as an individual's senses (smell, taste, sight, and hearing), mobility, and cognition. These factors can be especially unique to older people, as the experience of aging and potential decrease in physical capabilities can also result in a reduction of the senses used while cooking (Corso, 1981). It is important to explore a design field that acknowledges the importance of sensory experience and encourages the designer to understand how specific sensory experiences or challenges may impact experience. Developing an 
understanding of these sensory experiences can contribute to designing to support adaptability as well as increasing the potential enjoyment older men may have during the cooking process. Multisensory design explores how sensory stimulations (which include vision, hearing, touch, taste, and smell) are experienced, as well as how various changes to designed products may impact the layers of sensory experiences (Schifferstein \& Desmet, 2008). When multiple senses are engaged in an experience there is a higher level of neural activity, thus stimulating stronger experiences (Ranne, 2019). Therefore, designers who consider multisensory factors when intentionally designing a specific experience, such as a daily cooking ritual, are more likely to succeed as long as the designer understands how each sense is impacted by the experience (Schifferstein, 2011., \& Ranne, 2019).

\subsection{Conclusion}

There is plenty of research available, across many disciplines, demonstrating the benefits of supporting the independence and autonomy of elderly people, however, there is considerably less research exploring the significance of cooking habits amongst elderly populations (Angus \& Reeve, 2006., Keller et al., 2004., Kullberg et al., 2011., Morgan, 1979., \& Trees \& Dean, 2018). The amount of available research significantly reduces further when specifically exploring elderly men cooking, likely due to cultural belief structures reinforcing domestic cooking as feminine. While the research that is available on this niche topic shows that cooking skills amongst elderly men might have benefits socially, mentally, and physically, further research is needed to fully understand how the facilitation of these skills might be made possible. Additionally, further research is needed to answer the question: What might motivate older men to cook? This question is 
important in developing facilitation opportunities because preexisting research into cooking motivation is predominantly focused on the female experience.

While many facets of design were explored in this literature review there is still the question of how they will be applied to the facilitation of older men cooking - what factors might be identified as key to developing or supporting ritual? What specific needs may need to be met to elicit positive and long-lasting experiences?

Understanding the sociological influences on this research will be helpful in answering questions such as: how will traditional gender roles and cultural influences impact this research? Applying an interdisciplinary design approach to further research may not only help answer the questions outlined above, but may also produce design guidelines on how to support the facilitation of cooking skills in older men.

As a result of this literature, the research questions that are to be addressed by this study were developed. Listed below are the research questions:

1. How might design interventions support the facilitation of positive cooking experiences for older men?

2. How might insights into older men's daily cooking rituals or routines further support independence for this population?

3. How might the design of kitchenware further support independence of older men? 


\section{Chapter 3: Methods}

This study followed a qualitative research design utilizing three research methods, interviews, cultural probe kits, and focus groups, to examine the perspectives of older men and designers on the topic of older men and cooking rituals. Semi-structured interviews were selected as the first method of research due to the ability of interviews to collect broad expanses of information, both past and present, making it seem like an appropriate method for collecting data to build on the knowledgebase about the cooking experiences of older men. Cultural probe kits are a form of research method that originated in the field of design, and utilize a collection of research tools (in this instance a journal filled with prompts and a camera) to gather information about a person's daily life and experiences (Gaver, Dunne, \& Pacenti, 1999., \& Mattelmäki, 2006). For this study cultural probes were chosen as the second method to help collect more data about the participants on a much more specific and personal level. The probes made it easy to gather current data right in the homes of participants, directly relating to their present experiences (thus reducing the chance of unreliable memory skewing the data). Both interviews and cultural probe kits were used to collect data relating to older men's preexisting cooking comfort levels, experiences, and food habits; and served to provide information about how these demographic specific factors may impact the facilitation of positive cooking rituals. The final method, focus groups of designers, was used to help tie the data from the first two methods, which entirely focused on older men's cooking experiences, back to the topic of design. The focus group setting allowed for multiple collaborative activities to take place in order to explore multifaceted research questions. A group mind-mapping activity was chosen for the first part of the study for its ability to 
allow designers to explore the data about older men that had emerged from the first two methods of study. Within the mind-mapping activity personas were used due to their ability to communicate information about various users and the beliefs pertaining to their ability to evoke empathy (Chen, R., Nivala., \& Chen, C-B., 2011., Nielson, 2019). A discussion following the activity was chosen for its ability to further understand designers' thoughts on the data as well as the activity itself. It was important to understand whether the data from the prior methods would help support the design process, and if the data was communicated as either substantial or significant, or neither, the discussion could help shed light on whether it was the data itself that was the issue or if it was the method in which the data was presented to designers for the activity.

\subsection{Setting}

Due to the Covid-19 pandemic taking place at the time in which this research was conducted, all methods were planned and implemented in accordance with isolation measures and recommendations. As such, the physical setting of all three methods of research took place in each individual participant's home.

Interviews were conducted using either the phone or zoom conferencing services. Each participant was given the choice for the method of long-distance contact that was most comfortable to him. For the second research method, the cultural probe kits, a physical kit was developed, and therefore the method could not be conducted over a digital interface. Each participant was asked to provide their home address as a requirement of their participation in the second research method. The cultural probe kits were then delivered to each participant's doorstep either directly by the researcher or, for the participants residing outside of the city of Calgary, Alberta, by FedEx courier. The cultural probe kits 
were completed at each individual participant's home and a contactless doorstep pick-up was organized upon completion of the kit. The final research method, the focus groups, took place over zoom conferencing services and utilized Mural, an online digital interface.

\subsection{Participants}

There were two purposive samples of participants that were recruited for this study. The first group, which consisted of older men, participated in the interviews and cultural probe research methods. The second group, which consisted of designers, participated in the focus group research method.

\subsubsection{Older Men}

The older men recruited to participate in the study were required to be 65 years of age or older and living in their own home. All participants were required to be comfortable speaking English (as English is the primary language of the researcher). The majority of men were recruited through digital means (i.e. email invitations), however a select few were recruited through word-of-mouth (the researcher discussed the study with various people who had connections to older men in their communities). During the recruitment of participants a stated requirement was that participants' cooking experiences fit within a range of not cooking at all to participating only in very basic food preparation. There was intentionally no additional parameters added to better define this range, as each older men's own definition of their cooking abilities was considered potentially significant information to be collected as a part of the study.

There were eight men that were recruited to be a part of this participant group. All of the participating men were Canadian (as was the researcher). The age of the men ranged 
between 66 and 84 and all participants self-identified with the cooking experience range outlined during the recruitment process. The participants for this study were all local Canadian men: five from Alberta, one from B.C., one from Ontario, and one from Quebec. Of the eight men recruited, all eight men participated in the interview, but only seven men participated in the cultural probe, as one man (P8) was unable to be contacted for the follow up method.

For the sake of identifying each individual participant in the study, please refer to the table below.

\begin{tabular}{|c|c|l|}
\hline Participant Identifier & Age & Brief Description of Cooking Experiences \\
\hline P1 & 69 & $\begin{array}{l}\text { His wife is the primary cook. He voluntarily } \\
\text { works part-time at a golf course now that he is } \\
\text { retired. }\end{array}$ \\
\hline P2 & 71 & $\begin{array}{l}\text { His wife is the primary cook, but now that he } \\
\text { is retired, he tries to help out in the kitchen } \\
\text { more and will either buy dinner or cook a } \\
\text { simple meal once a week. }\end{array}$ \\
\hline P3 & 84 & $\begin{array}{l}\text { His wife is the primary cook. He is retired, but } \\
\text { has many hobbies, including sitting on a board } \\
\text { of directors for a curling club. }\end{array}$ \\
\hline P5 & $\begin{array}{l}\text { His wife was the primary cook up until her } \\
\text { passing, at which time P4 began preparing his } \\
\text { own food out of necessity. }\end{array}$ \\
\hline P6 & 69 & $\begin{array}{l}\text { His wife is the primary cook. He is retired and } \\
\text { enjoys spending his time restoring vintage } \\
\text { cars. }\end{array}$ \\
\hline P7 & $\begin{array}{l}\text { His wife is the primary cook. He is retired and } \\
\text { enjoys trying need food while on cruises with } \\
\text { his wife. }\end{array}$ \\
\hline P8 & 70 & $\begin{array}{l}\text { His wife is the primary cook, however, he acts } \\
\text { as "sous chef" in the kitchen and helps with } \\
\text { tasks such as peeling potatoes and chopping } \\
\text { vegetables when instructed by his wife. }\end{array}$ \\
\hline $\begin{array}{l}\text { He is divorced and has been responsible for } \\
\text { preparing his own food out of necessity for } \\
\text { many years. }\end{array}$ \\
\hline
\end{tabular}

TABLE 1 PARTICIPANT IDENTIFIERS 


\subsubsection{Designers}

The designers recruited to participate in the study were required to be experienced in a form of design that may be able to contribute to designing positive cooking experiences for older men. The areas of design that were relevant to this study were determined in advance of the recruitment for the focus group sessions. Designers with the relevant skills

and expertise were recruited through email. The areas of design that were identified were: product design, service design, accessibility design and/or healthcare design. It is important to note that designers were recruited after the interview and cultural probe research methods were completed, and the data collected and analyzed from the prior methods helped to inform the areas of design that held potential relevance to the topic. The designers that were recruited came from a variety of the previously outlined design disciplines. There were eight designers in total:

- Two service designers

- Four products designers, of which two had extensive experience in barbeque and kitchenware product design, and one had additional experience in accessibility design.

- Two designers working in the field of healthcare design Designers were assigned to a focus group based on their available time slots. Personas were then assigned to each of the focus groups for the purpose of a mind mapping activity. The largest focus group was assigned two personas, which all of the designers in the group reviewed prior to their session- however during the mind mapping portion of their session each designer only worked with one of the assigned personas. For 
the sake of identifying each focus group and each individual designer, as well as the persona(s) assigned to each of the groups, please refer to the tables below.

\begin{tabular}{|c|c|c|}
\hline Group Identifier & Assigned Personas & Number of Participants \\
\hline A & Carl & 2 \\
\hline B & Carl & 2 \\
\hline C & Liam \& George & 4 \\
\hline
\end{tabular}

TABLE 2 FOCUS GROUP IDENTIFIERS

\begin{tabular}{|c|c|c|l|}
\hline $\begin{array}{c}\text { Designer } \\
\text { Identifier }\end{array}$ & $\begin{array}{c}\text { Focus } \\
\text { Group }\end{array}$ & $\begin{array}{c}\text { Persona Examined } \\
\text { During Mural Activity }\end{array}$ & $\begin{array}{l}\text { Relevant Design } \\
\text { Experience/Expertise }\end{array}$ \\
\hline D1 & A & Carl & $\begin{array}{l}\text { Product designer with experience in } \\
\text { accessibility design }\end{array}$ \\
\hline D2 & A & Carl & Healthcare design \\
\hline D3 & B & Carl & Service Design \\
\hline D4 & B & Carl & Healthcare design \\
\hline D5 & C & Liam & $\begin{array}{l}\text { Product design with experience in } \\
\text { kitchenware \& barbecue design }\end{array}$ \\
\hline D6 & C & Liam & Product Design \\
\hline D7 & C & George & $\begin{array}{l}\text { Product design with experience in } \\
\text { kitchenware \& barbecue design }\end{array}$ \\
\hline D8 & C & George & Service Design \\
\hline
\end{tabular}

TABLE 3 DESIGNER IDENTIFIERS

\subsection{Measurement Instruments}

Each method of research required a different set of data collection tools. They were:

interviews, cultural probe kits, and focus groups. By using a variety of tools a more

holistic knowledgebase of older men's cooking experiences and the potential influence of design was developed.

\subsubsection{Interviews}

The first stage of data collection was semi-structured interviews, which were used to develop a foundational understanding of the lived experiences pertaining to food and cooking of older men with lower level cooking abilities. The interviews, which were typically 30-40 minutes in length, always opened by asking the questions: "Have you 
ever had any experiences cooking?" and "What is your comfort level cooking?" Participants were encouraged to comfortably converse, with interview questions asked only when it was seen as necessary to continue the conversation or to guide the conversation back on track to the topic of cooking and food. The interview questions typically used in these instances were prepared in advance and the same set were used for all of the interviews. The questions prepared in advance were approved by the Carleton University's Research Ethics Board (CUREB) as a part of CUREB-B Clearance \#114589.The prepared interview questions were as follows:

1. What sort of food do you eat on an average day?

2. How is the food you eat prepared?

3. What are your favorite foods? Is there any particular reason why is your favorite food?

4. What makes you uncomfortable about cooking?

5. Would you ever be interested in learning to cook?

6. Is there anyone you'd be inclined to learn to cook for?

7. Do you experience any physical challenges that you believe may impact your ability to cook?

8. Do you find the taste of food has changed for you as you get older?

9. Do you have any fond memories that come to mind when you think of a home cooked meal?

In addition to the questions prepared in advance, new questions were occasionally asked on the spot on the responses given by the interviewee. For example, a few of the participants mentioned their adult children using food subscription boxes during their 
interviews, in these instances questions such as "have you ever tried using a food subscription box yourself?" and "would you ever be interested in using a food subscription box?" were asked.

Once interviews were completed the data collected from the interviews was used to inform the next stage of the data gathering process.

\subsubsection{Cultural Probe Kits}

Ideally, this study would have used some form of ethnographic research method to gather more data on participants' personal experiences and daily lives, however, due to the Covid-19 Pandemic, a socially distanced alternative was required to be used. A cultural probe kit provided this alternative solution. The kit (see figure 1), which consisted of writing implements, a journal with writing prompts, and a disposable camera, was used to develop a further understanding of the older men's lived experiences, as was also the goal

of the interviews (See Appendix A. for the journal included in the cultural probe kit). Kits and packaging were designed to include some subtle playful elements to try and give participants a positive first interaction with the kit. As the kit primarily required a lot of writing, initial thoughts of the kit being 'homework' could have a negative effect on the results (i.e. participants potentially not completing the kit). The kit box was sealed with light-hearted egg stickers and upon opening the box participants were greeted by a bold "Hello!" on the cover of the journal, welcoming them into the activity. 


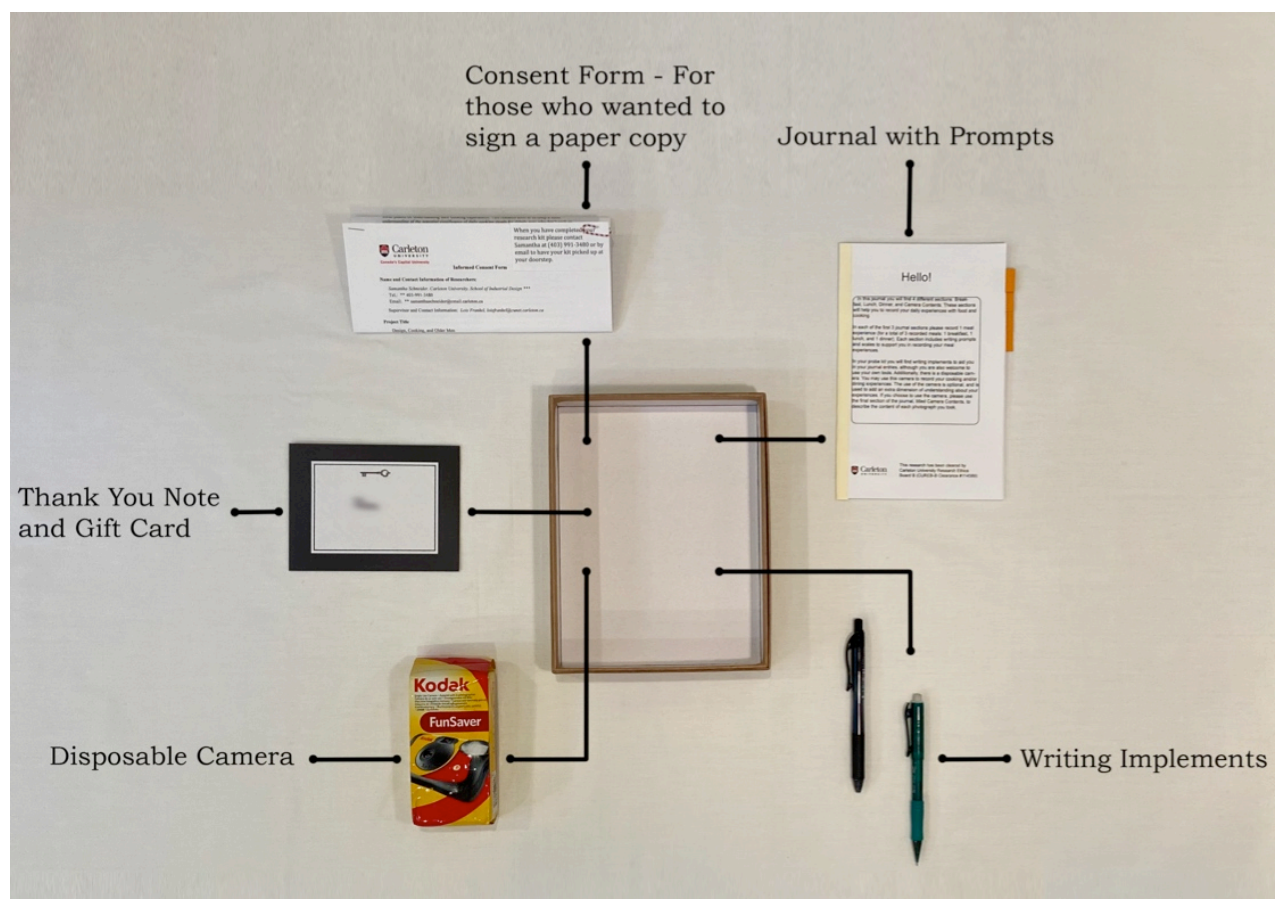

FIGURE 1 CONTENTS OF THE CULTURAL PROBE KIT

The journal with writing prompts was the primary tool of the kit and was broken into four sections: Breakfast, Lunch, Dinner, and Camera Contents. Participants were asked to record one daily meal experience in each of the three first sections (one breakfast, one lunch, and one dinner). The final journal section, Camera Contents, was to be used in coordination with the disposable camera provided in the kit and provided a space for participants to add written descriptions for any photos they took. The camera activity aimed to add an extra dimension of understanding about the experiences recorded by the men. As photographs can take on a very personal quality in a way that written descriptions typically do not, the use of the camera and its corresponding journal section were optional (which was clearly communicated on the front cover of the journal) in order to support the comfort of participants. 


\subsubsection{Designer Focus Group}

The designer focus groups were conducted online using Zoom video conferencing services and Mural, an online mind-mapping tool. There were three focus groups total, each spanning 1-hour in time. The majority of time for the focus groups was broken up into two primary activities, the mural activity and a group discussion.

Prior to the focus groups, personas informed by the first two methods were developed. There were three personas developed and each persona was a combination of deidentified data from two of the older male participants. Data was selected based on the information it provided on food and cooking experience, interest, and necessity, as well as daily meal experience. Personas, named Carl (Figure 2), George (Figure 3), and Liam (Figure 4), provided two pages of information each and followed a basic format of a few bullet points of general facts about the persona, a brief overview of his daily meals, a couple of quotes, and one or two photographs related to his cooking experience.

Additional sections based on the personalities that inspired the personas were included, such as a section outlining Liam's concerns about cooking, George's favorite tools, or the inclusion of a "dessert" section to Carl's daily meal overview. The personas were strategically designed to communicate specific features of the different "categories" of men that had emerged from the interviews and cultural probes. These categories were: living alone with very low cooking abilities; cohabitating with a spouse who cooks, but interested in learning to cook; and cohabitating with a spouse who cooks and interested in learning only basic skills to lend cooking support to their spouse. The persona for living alone with low cooking abilities, Carl, was the most drastically different from the other two personas, was examined by Focus Groups A and B. Due to Carl's need to cook out of 
necessity, interest in cooking was not mentioned as a factor. George and Liam, who respectively represented the cohabitating with desire to support spouse and cohabitating with cooking interest, were assigned to Focus Group C, wherein all 4 designers had read over both personas in advance of the session and then were paired off to work with one of the two personas during the session. Interest was seen as a necessary factor to discuss for the George and Liam personas due to their lack of need to cook. The model of divvying up the personas allowed for the researcher to examine how multiple groups approached Carl's situation as well as how multiple groups approached similarly situated personas (George and Liam) despite having a limited sample size of participants. 


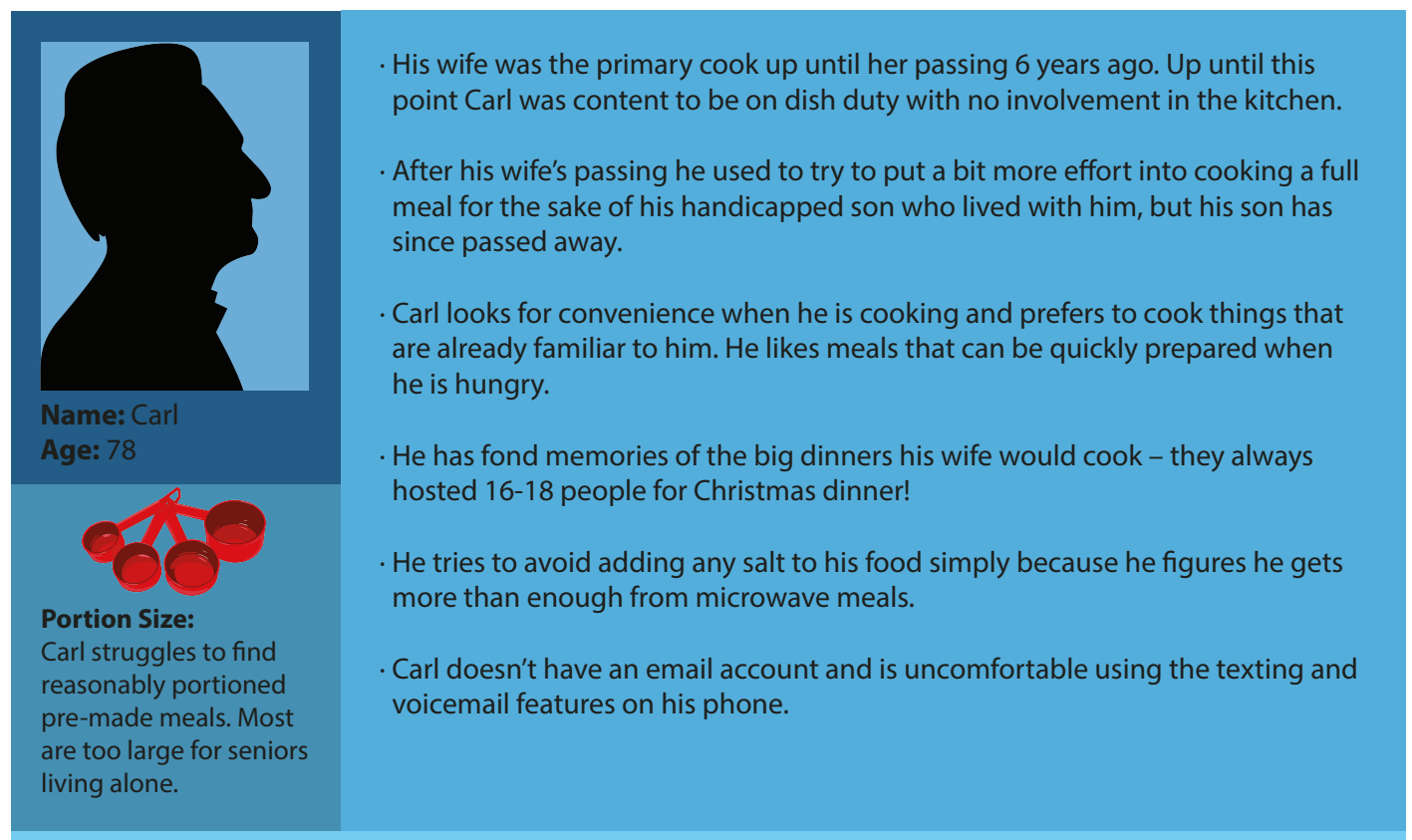

\section{Meals:}
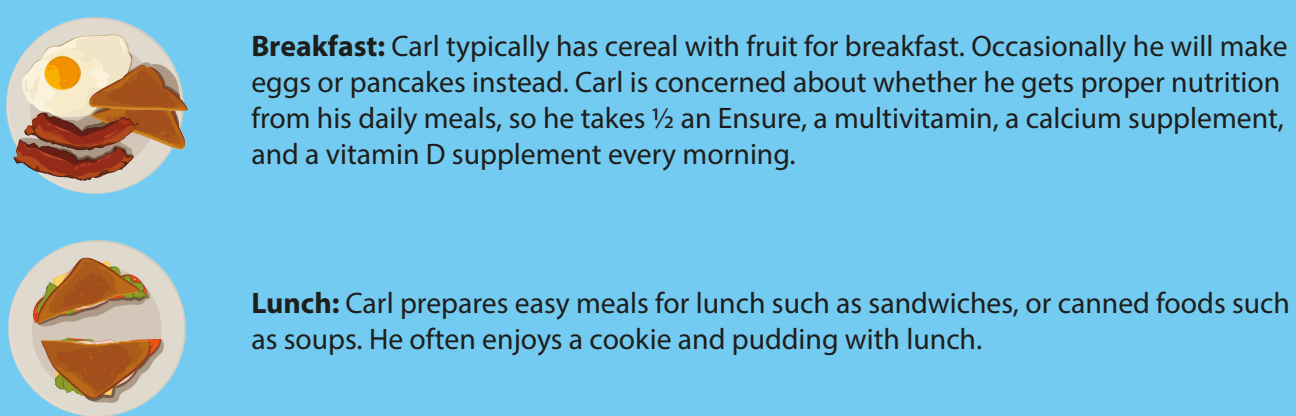

Lunch: Carl prepares easy meals for lunch such as sandwiches, or canned foods such as soups. He often enjoys a cookie and pudding with lunch.

Dinner: $80 \%-90 \%$ of Carl's dinners are frozen dinners. He keeps 10-20 on hand so he always has some variety to choose from and tries to only buy frozen meals containing less than 300 calories. He also tries to eat salad alongside his frozen dinner. Very occasionally he will make something like spaghetti. Pre-pandemic Carl went out for dinner 1-2 times a week.

Dessert: After dinner Carl has a glass of wine, tea, and some sort of goodie. 


\section{Carl's Quotes:}

"The problem with microwave meals is that you have to have a salad in addition to get some green. I don't all the time, but sometimes I get these pre-cut salads. I don't make a salad from scratch because when you get a head of lettuce, but only one person is eating, it's a lot of waste, so those salads that are already cut up in a little package, and you just have to add salad dressing and maybe some raisins, you know, they're good. But they have to be in smaller quantities, because a lot of seniors are singles living on their own, and the quantities you get are too big. And whatever you get, you end up throwing half of it out."

"I believe in a balanced diet - A cookie in each hand."

\section{Carl's Photographs:}
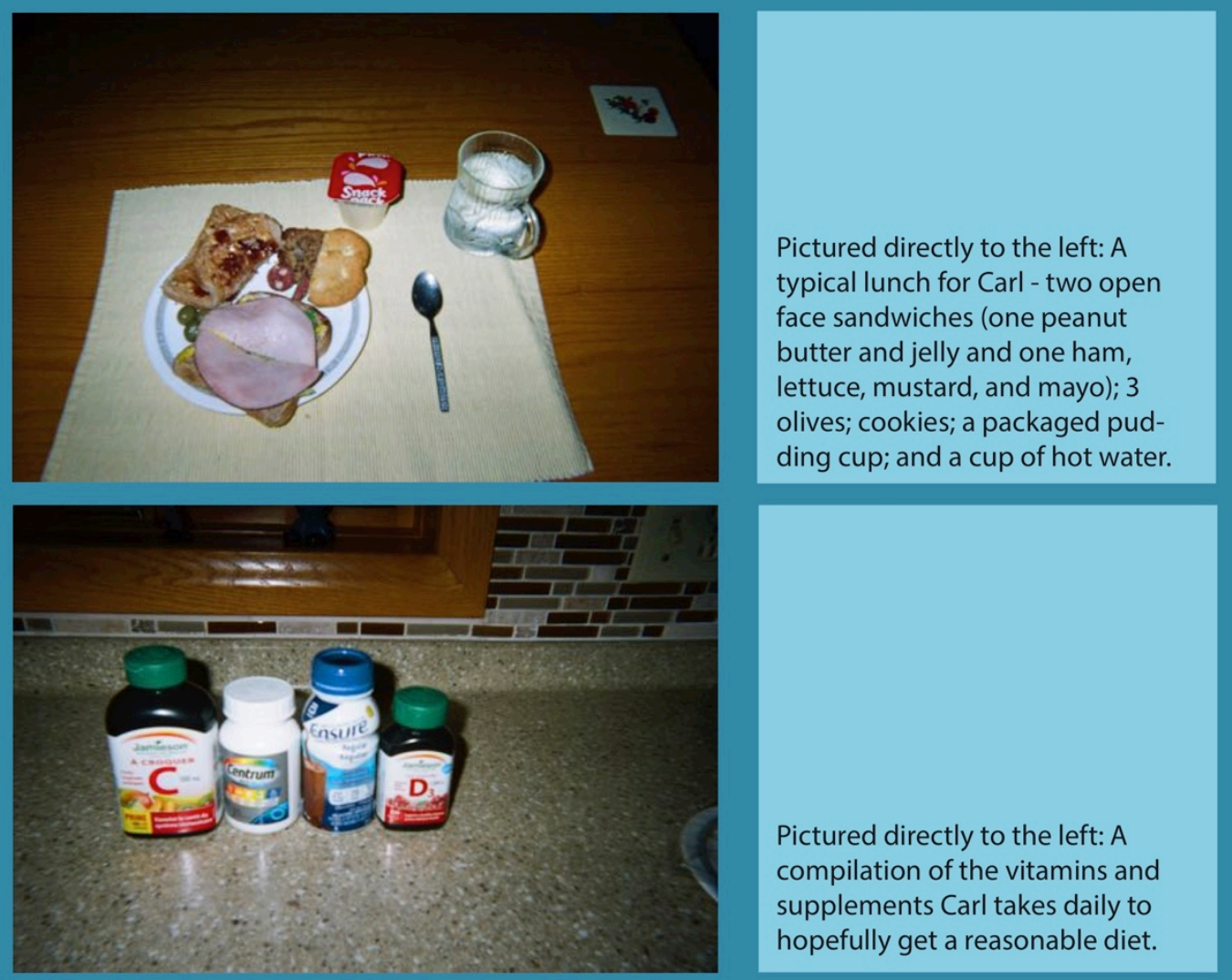

FIGURE 2 CARL PERSONA 


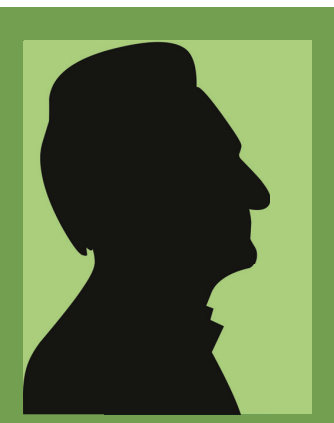

Name: George

Age: 70
- His wife is the primary cook.

- He would be interested in learning some basic cooking skills only in the context of helping out his wife, but is content with dish duty.

- He is concerned about time wasted if he learns to cook.

- Preparing more complicated meals takes a long time to prepare and cook (time better spent on hobbies).

- If the meal doesn't turn out he will have wasted his time for nothing.

- He enjoys eating out, but does not enjoy restaurants where he has to "build his own dish" as he doesn't know how to pair flavors (i.e. if he goes to subway he always orders a prebuilt sandwich).

\section{Favourite Tools:}

Keurig Coffee Maker, Toaster Oven, and Barbeque
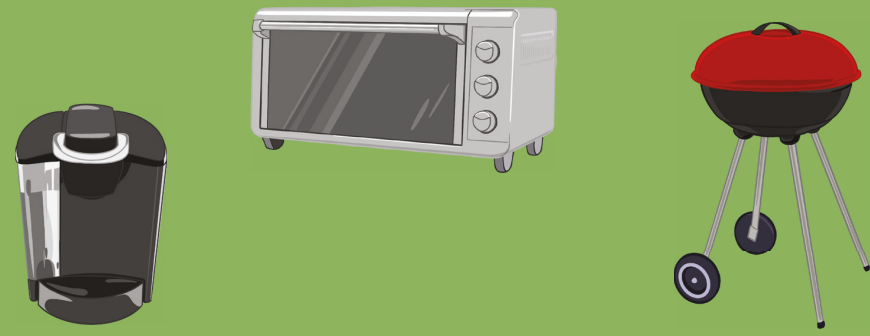

(1)

\section{Meals:}

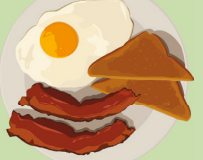

Breakfast: George cooks his own breakfast. Typically his breakfast features toast or a bagel with a spread on top (i.e. peanut butter, jam or jelly, etc.).

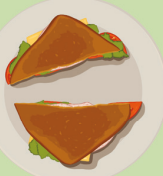

Lunch: George's Wife typically prepares them both lunch, unless Barbequing is involved. On the occasion that his wife does not prepare food he will often purchase his lunch. For the sake of the study, George prepared lunch for his wife and himself hotdogs on the BBQ with all the fixings. He noted that while the meal tasted okay "things always seem to taste better when someone else has prepared it."

Dinner: George's wife prepares dinner, which typically features more complex meals. George will assist with Barbequing meat if needed and cleaning up after dinner. 


\section{George's Quotes:}

"If I'm cooking, it's something that is as simple as taking something out of a box or the freezer and having to put it in the oven and heated or something I read the instructions for."

"I'Il look after the barbequing, but I don't really look at that as being any big deal. I mean it's not that complicated, you know, you go outside, put the meat on, flip it, stuff like that."

"When I think of sandwiches, like roast beef sandwiches, my wife makes a great roast beef sandwich - and when I was growing up my mom didn't make good sandwiches, so I didn't know how to make a good sandwich, so I guess to me - why would I try and make a roast beef sandwich when my wife does such a good job of it?"

\section{George's Photographs:}

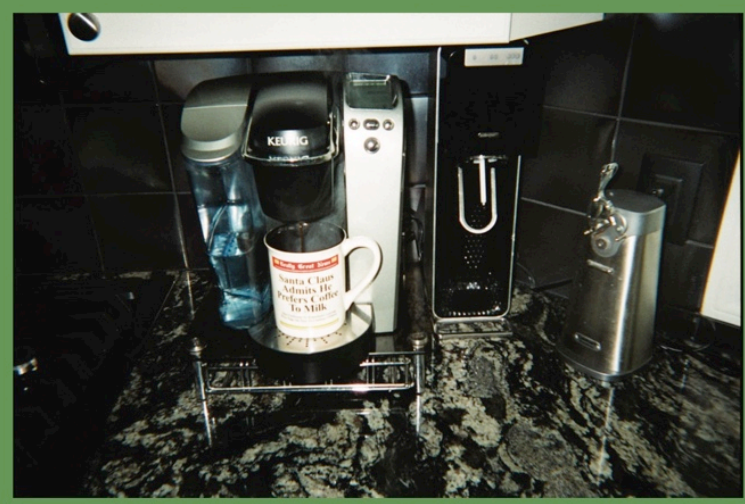

Pictured directly to the left: George uses his Keurig Coffee Maker every morning to make himself a cup of black coffee.

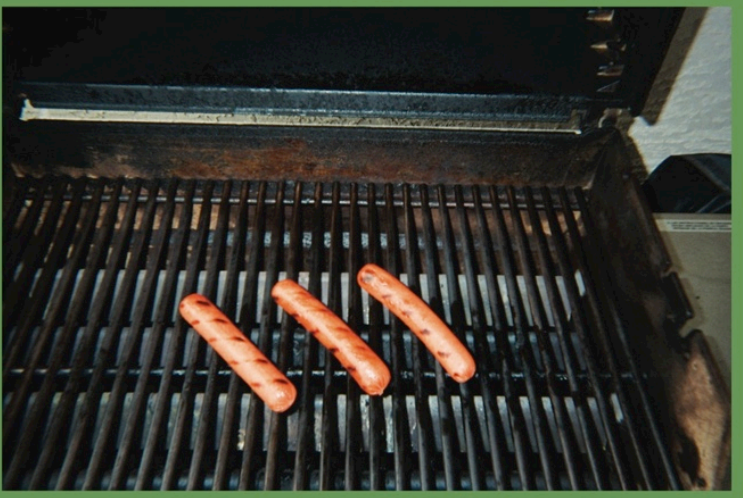

Pictured directly to the left: Grilling hotdogs on the barbeque for lunch.

FIGURE 3 GEORge PERSONA 


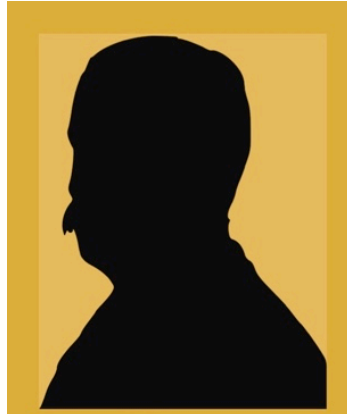

Name: Liam Age: 70
- Liam's wife has always been the primary cook in their household.

- Now that he is retired, Liam tries to help his wife in the kitchen by cutting up vegetables and meat when needed.

Occassionally he will make dinners and is comfortable cooking 3-4 familiar recipes with some assistance.

- Liam is interested in learning to cook more dishes, but wants a cookbook that provides clear, concise directions for every step, and practical, simple recipes that cater to his taste.

\section{Liam is nervous trying new recipes due to his lack of experience and tacit knowledge:}

· He struggles with timing while cooking (i.e. when is pasta finished cooking).

- He feels uncomfortable cooking any sort of layered dish (i.e. If he cooks lasagna some layers might be uncooked while others are overcooked).

- He worries about how unforgiving a new recipe could be.

- He sometimes needs to ask his wife to understand the ingredients for a recipe (i.e. what's the difference between tomato paste and sauce?).

\section{Meals:}

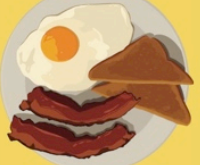

Breakfast: Liam often has simple breakfasts such as cereal, which he will prepare for himself. He occasionally enjoys bacon, eggs, and toast for breakfast, which either his wife or himself will prepare, but is trying to cut back on the amount of bacon and eggs he eats for health reasons.

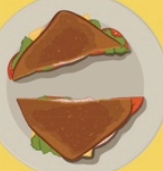

Lunch: Liam prepares his own lunches and typically keeps it simple (i.e. fruit, cheese and crackers, yogurt), however for the sake of the study decided to make himself a Denver Sandwich (ham, egg, dried onion, ketchup, and Cajun spice). He noted that he decided to cut the ham with a pizza cutter, and that he felt proud of himself for making that meal.

Dinner: Liam chose a new meatball recipe to prepare for dinner with the help of his wife. He felt proud of the meal, and noted it was one of the best he'd ever had. He also noted that he did not enjoy the gooey feeling of the ground meat while preparing the meatballs. 


\section{Liam's Quotes:}

"I diced 3 slices of deli ham with a pizza cutter (very clever I thought!)."

"90 percent of meals we (my wife, our son, and myself) have together are very social meals at night. The evening meal is still a very much-appreciated event. We light candles and we don't always sit at the formal dinning room table, sometimes we sit in the kitchen, but all together eating at the same time and chatting about the day."

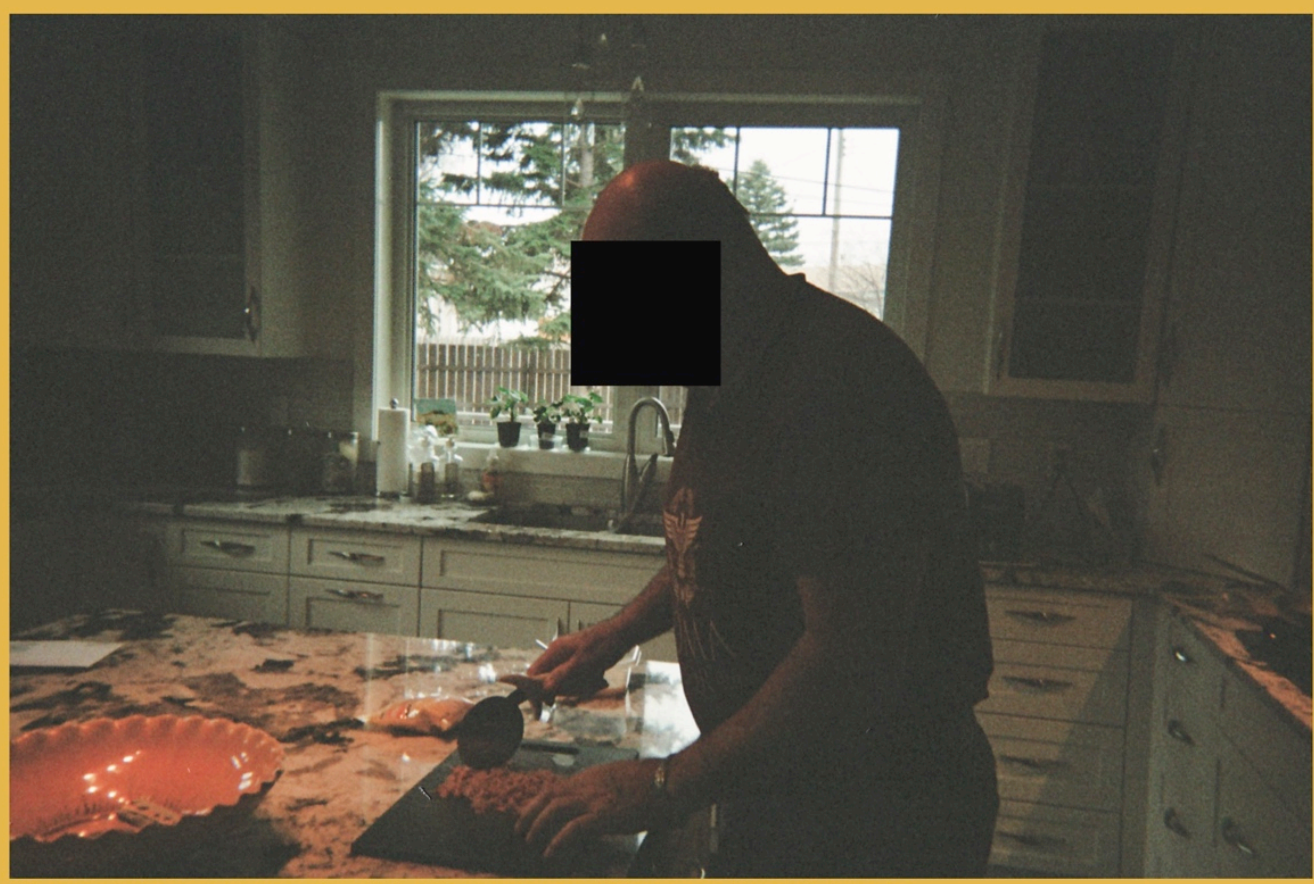

Pictured above: Liam using his pizza cutter while prepping his lunch.
Favourite Tools:

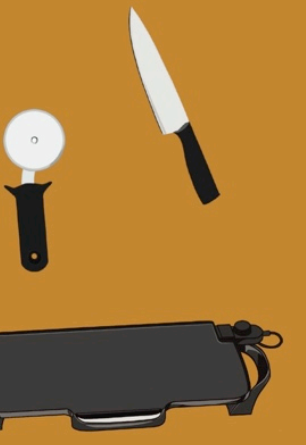

Pizza Cutter, Chef's Knife, and Electric Griddle

FIGURE 4 LIAM PERSONA

The personas were used as a part of the Mural mind-mapping activity. A single persona was used per Mural mind-mapping activity. Personas were sent to participants one week 
in advance with the request that they were to be read in advance of the focus group. Focus Group C participants were not informed in advance about which of the two personas they would be working with during the mind-mapping activity, so all of the designers had read through both personas in advance. Digital templates (See Figure 5 and Appendix B) for the mind-mapping activity were created in advance and included questions and prompts as a way to provide guidance for the activity as well as a copy of the persona for participants to reference back to. Participants were able to create digital "sticky" notes to write and maneuver across the template to communicate different ideas. During the activity, participants were asked to work in pairs using their assigned persona to answer the following questions:

1. "Given the current situation, how can design support [Persona]'s cooking activities right now?"

2. "What could the future look like for [Persona]'s cooking activities with design support?”

3. "What changes need to take place to achieve the future vision of design supporting [Persona]'s cooking activities?"

For each of the three questions listed above, participants were prompted to consider product solutions, service solutions, and other/miscellaneous solutions.

The pairs were encouraged to work on the activity without the intervention of the researcher, however, were allowed to ask clarifying questions of the researcher if need be. 


\begin{tabular}{c|l|l|l|} 
& $\begin{array}{l}\text { Given the current } \\
\text { situation, how can } \\
\text { design support } \\
\text { [Persona's] cooking } \\
\text { activities right now? }\end{array}$ & $\begin{array}{l}\text { What could the future } \\
\text { look like for } \\
\text { [Persona's] cooking } \\
\text { activities with design } \\
\text { support? }\end{array}$ & $\begin{array}{l}\text { What changes need to } \\
\text { take place to achieve } \\
\text { the future vision of } \\
\text { design supporting } \\
\text { [Persona's] cooking } \\
\text { activities? }\end{array}$ \\
\hline Product? & & & \\
\hline Service? & & & \\
\hline Other? & & & \\
\hline
\end{tabular}

FIGURE 5 LAyout FOR the Digital Mural template. SEe APPENDix B FOR FUlly TEMPLATED VERSION

A group discussion followed the mind-mapping activity and was used to examine how the materials given helped either support or hinder the design process. Additionally, for the one larger focus group, Focus Group C, wherein the paired activity resulted in multiple mind-maps being created, this discussion time also served as further brainstorming time, as participants were eager to discuss how the different maps could impact their different personas. The following three questions were asked in all of the focus group discussions:

1. "What stood out most to you when reviewing the materials provided?"

2. "As a designer, how did the materials you received inspire any ideas for design solutions to support older men's cooking activities?"

3. "Is there anything you found too ambiguous, or anything you feel would be beneficial to receive additional clarification for? 
As previously mentioned in the opening section of methods, section 3 , it was important that the discussion would be able to include designers' thoughts on the data as well as the activity itself. By asking set questions about the materials used in the session, as well as on the spot questions relating back to conversation or Mural board content from the activity, the researcher was able to use the discussion segment of the session to better understand the solutions proposed during the activity. Additionally, the discussion helped the researcher to understand whether the persona and mind-mapping methods supported design thinking responding directly to the persona's specific needs and the activity prompts. While all three questions were consistently asked in all the group discussions, they were always used as a tool to guide the conversation. As such, variation in the direction each discussion took depended on the responses provided to each question.

In total, there were two focus groups consisting of two participants (Focus Groups A and B) and one focus group consisting of four participants (Focus Group C). While all focus groups followed a similar structure, and each session included the two primary activities outlined above, the structure slightly differed between the groups of two and the group of four for the sake of efficiency and organization. The structure for the groups of two sessions (Focus Group A \& B) were as follows:

- 10 Minutes - Session Opening

- The sessions opened with introductions of each participant, a quick review of the consent form each designer had signed prior to the session, a discussion of the session schedule and a quick introduction to Mural with 
a brief explanation on how to use the tools for any participants who needed it.

- 30 Minutes - Mural Mapping Activity

- 15 Minutes - Discussion

- 5 Minutes - Session wrap-up

○ At the 5-minute remaining mark participants were told that there were 5 minutes of the session remaining and asked if they had any questions before the end of the session. In some instances questions were asked and in other instances participants chose to use this time to continue their discussion.

The structure for the group of 4 (Focus Group C) was as follows:

- 10 Minutes - Session Opening

- 20 Minutes - Paired Mural Mapping Activity

In the instance of the group of four, all participants received two personas in advance of the session. During the session participants were paired off and each pair was assigned one persona to work with during the mindmapping activity. Pairs were then sent into Zoom "breakout rooms," which is a method of splitting the video conference so members of a call are only able to interact with other assigned members of the call rather than the entire group. Once in their assigned breakout rooms, participants began working with their assigned persona on the mind-mapping activity.

- 10 Minutes - Group Presentations 
- After the completion of the mind-mapping exercise each group was given 5 minutes to present the ideas they generated in their assigned pairs. These presentations assured that all participants, as well as the researcher, were on the same page moving into the group discussion.

- 15 Minutes - Group Discussion

- As was previously mentioned, the group discussion for the group of 4 answered the three questions outlined, but also allowed for participants to further discuss the results of the mind mapping activity. This discussion provided opportunity for the researcher to further understand how ideas generated during the mind-mapping activity may be applicable to different personas and therefore applicable to different older men in real-life settings.

- 5 Minutes - Session wrap-up

- Like the sessions with groups of two, the structure of the group of four's wrap-up was guided by how the participants' wished to use the time. In this instance, the wrap-up was used to further the discussion segment of the session.

\subsection{Data Analysis}

Interviews and focus groups were recorded, and transcribed using NVivo software for the purpose of the data analysis. Transcription of the cultural probes was unnecessary as the journal method were already a written record of the activity. Disposable cameras that were used during the probing activity were developed individually and the resulting photographs were grouped with the corresponding journal. 
Once the transcription of data was completed, chunks of data were assigned descriptive codes based on the information communicated within each chunk of data (Saldaña, 2009). There were three 'passes' in the coding process. The first pass was used to place each data chunk into a very general category, the second pass was then used to shortly summarize each data chunk and the third pass applied the final code. For example, a raw data chunk from an interview participant stated "I use to love spicy food and I have less tolerance for it now as I got older, but other than that I think the taste is the same." In the first pass, this statement was placed in the category "Food Factor", in the second pass it was summarized to "low spice tolerance" and in the third pass the statement was shortened once again and assigned a final descriptive code, which in this instance was "taste considerations."

Once coded, data sets were compared to other data sets from the same method (i.e. coded interview data sets were compared to other coded interview data sets). During the comparison stage of analysis, similar coded data was grouped together. After all the coded data was grouped together the codes in each grouping were further analyzed in order to identify how each piece of coded data within a group related to one another. Similarities in data as well as differences were noted as potentially important at this stage, and codes were further categorized based on their similarities.

Finally, once all data had been organized into categories based off the third pass, the categories were interpreted in order to draw out any potential themes in the data. For example, the codes "Sunday Roast" and "Christmas Dinner" were both categorized as "Special Meals" during the third pass, which fell into the theme of cultural experience. How a theme may or may not relate to all three sets of categorized data (one set for each 
method) was considered and patterns for themes that emerged between all three data sets were noted as significant. During the process of creating themes, each theme was carefully considered for how it may relate back to the research questions. See the tables $(4,5$, and 6$)$ below for more details on the data coding for each of the methods.

\begin{tabular}{|c|c|c|c|}
\hline \multicolumn{4}{|c|}{ Coding for Interviews } \\
\hline First Code & Second Code & $\begin{array}{l}\text { Third Code (Category } \\
\text { Code) }\end{array}$ & Common Theme \\
\hline \multirow[t]{8}{*}{ Wife } & Wife cooks & \multirow[t]{5}{*}{ Gender Dynamics } & \multirow[t]{5}{*}{ Gender Dynamics } \\
\hline & Wife is faster & & \\
\hline & Wife makes it better / better cook & & \\
\hline & Wife's cooking skills & & \\
\hline & Wife is a great cook & & \\
\hline & Ate meal with wife & Social activity & Cultural Experience \\
\hline & Helps wife in the kitchen & \multirow{2}{*}{$\begin{array}{l}\text { Cooking interest \& } \\
\text { experience }\end{array}$} & \multirow{2}{*}{$\begin{array}{l}\text { Cooking Interest \& } \\
\text { Experience }\end{array}$} \\
\hline & Supporting wife as interest & & \\
\hline \multirow[t]{13}{*}{ Food Factors } & Food Preferences & \multirow[t]{4}{*}{ Taste Considerations } & \multirow{5}{*}{$\begin{array}{l}\text { Available } \\
\text { Alternatives }\end{array}$} \\
\hline & Low spice tolerance & & \\
\hline & Nostalgic favorite food & & \\
\hline & Food tastes richer & & \\
\hline & Portioned & $\begin{array}{l}\text { Alternative meal } \\
\text { considerations }\end{array}$ & \\
\hline & Eat to feel full & $\begin{array}{l}\text { Cooking interest \& } \\
\text { experience }\end{array}$ & $\begin{array}{l}\text { Cooking Interest \& } \\
\text { Experience }\end{array}$ \\
\hline & Reduce red meat & \multirow[t]{7}{*}{ Nutrition } & \multirow[t]{7}{*}{ Nutrition \& Food } \\
\hline & Struggles to eat healthy & & \\
\hline & Salt & & \\
\hline & Healthy foods & & \\
\hline & Healthy diet & & \\
\hline & Goodies & & \\
\hline & Supplements & & \\
\hline \multirow[t]{8}{*}{ Interest } & Interest levels & \multirow[t]{4}{*}{ Interest } & \multirow{4}{*}{$\begin{array}{l}\text { Cooking Interest \& } \\
\text { Experience }\end{array}$} \\
\hline & Prefers cleaning over cooking & & \\
\hline & Boring to cook daily & & \\
\hline & Tasty food is not a cooking motivator & & \\
\hline & Being cooked for is enjoyable & $\begin{array}{l}\text { Interest \& Social } \\
\text { Experience }\end{array}$ & $\begin{array}{l}\text { Cooking Interest \& } \\
\text { Experience / Cultural } \\
\text { Experience }\end{array}$ \\
\hline & Watching others cook is inspiring & Social connection & Cultural Experience \\
\hline & Time Waste/Time Constraints & \multirow[t]{2}{*}{ Resource Allocation } & \multirow[t]{2}{*}{ Resource Allocation } \\
\hline & Food Waste & & \\
\hline
\end{tabular}




\begin{tabular}{|c|c|c|c|}
\hline & Cooking lacks technology & Technology & Technology \\
\hline \multirow[t]{5}{*}{ Experience } & Experience levels & \multirow[t]{4}{*}{ Experience } & \multirow{4}{*}{$\begin{array}{l}\text { Cooking Interest \& } \\
\text { Experience }\end{array}$} \\
\hline & Past experiences & & \\
\hline & Present experiences & & \\
\hline & Cooking questions & & \\
\hline & Traditional household roles & Gender Dynamics & Gender Dynamics \\
\hline \multirow[t]{2}{*}{ Confidence } & $\begin{array}{l}\text { Low skill level/lack of tacit } \\
\text { knowledge }\end{array}$ & \multirow[t]{2}{*}{ Confidence } & \multirow[t]{9}{*}{ Feeling Factors } \\
\hline & Lack of recipe range & & \\
\hline Intimidation & $\begin{array}{l}\text { Intimidation due to high skill level of } \\
\text { spouse }\end{array}$ & Intimidation & \\
\hline \multirow[t]{7}{*}{ Discomfort } & Not knowing cook times & \multirow[t]{6}{*}{ Discomfort } & \\
\hline & Cooking food with layers & & \\
\hline & Not knowing how to pair flavors & & \\
\hline & Lack of variety in cooking abilities & & \\
\hline & $\begin{array}{l}\text { Worried about serving poor quality } \\
\text { meals }\end{array}$ & & \\
\hline & Lack of experience & & \\
\hline & Using technology & Tech literacy & Technology \\
\hline \multirow{3}{*}{$\begin{array}{l}\text { Social } \\
\text { Experiences }\end{array}$} & Friends and family gathering & \multirow[t]{3}{*}{ Social experiences } & \multirow[t]{3}{*}{ Cultural Experience } \\
\hline & Cooking for others & & \\
\hline & Eating out at restaurants & & \\
\hline \multirow[t]{3}{*}{ Hobbies } & $\begin{array}{l}\text { Has lots of hobbies (car collecting, } \\
\text { sports, travelling) }\end{array}$ & \multirow[t]{3}{*}{ Hobbies } & \multirow[t]{5}{*}{ Cultural Experience } \\
\hline & Eating in front of TV & & \\
\hline & Tries new foods on vacations & & \\
\hline \multirow[t]{2}{*}{ Special Meals } & Christmas Dinner & \multirow[t]{2}{*}{ Special meals } & \\
\hline & Sunday Roast & & \\
\hline \multirow[t]{10}{*}{ Pre-prepared } & Frozen Pizza & \multirow[t]{10}{*}{ Pre-Prepared } & \multirow{10}{*}{$\begin{array}{l}\text { Available } \\
\text { Alternatives }\end{array}$} \\
\hline & Canned foods and soup & & \\
\hline & Ordering food & & \\
\hline & Microwave meals & & \\
\hline & Pre-prepared meals & & \\
\hline & Salad kits & & \\
\hline & Boxed frozen foods & & \\
\hline & Store-bought goodies & & \\
\hline & Pre-marinated meats & & \\
\hline & Food subscription boxes & & \\
\hline
\end{tabular}




\begin{tabular}{|c|c|c|c|}
\hline \multicolumn{4}{|c|}{ Coding for Cultural Probes } \\
\hline First Code & Activity & Second Code & Common Theme \\
\hline \multirow[t]{2}{*}{ Wife } & Helping wife cook & $\begin{array}{l}\text { Experience/ Social } \\
\text { Experience }\end{array}$ & $\begin{array}{l}\text { Cooking Interest \& } \\
\text { Experience / Cultural } \\
\text { Experience }\end{array}$ \\
\hline & Wife cooks meal & Gender Dynamic & Gender Dynamic \\
\hline \multirow[t]{5}{*}{ Food Factors } & Found in fridge & Planning & Resource Allocation \\
\hline & Dessert & \multirow[t]{4}{*}{ Nutrition } & \multirow[t]{4}{*}{ Nutrition \& Food } \\
\hline & Baked good & & \\
\hline & Goodie & & \\
\hline & Supplements & & \\
\hline Experience & Participant cooks & Experience & $\begin{array}{l}\text { Cooking Interest \& } \\
\text { Experience }\end{array}$ \\
\hline \multirow[t]{3}{*}{ Familiarity } & Familiar & \multirow[t]{3}{*}{ Familiar } & \multirow[t]{3}{*}{ Feeling Factors } \\
\hline & Habit & & \\
\hline & Routine & & \\
\hline \multirow[t]{4}{*}{ Time } & Easy prep & \multirow[t]{4}{*}{ Resource Allocation } & \multirow[t]{4}{*}{ Resource Allocation } \\
\hline & Stockpile & & \\
\hline & Quick prep & & \\
\hline & No planning & & \\
\hline \multirow[t]{3}{*}{ Social Experiences } & Shared meal & \multirow[t]{3}{*}{ Social activity } & \multirow[t]{6}{*}{ Cultural Experience } \\
\hline & Shared kitchen cleanup & & \\
\hline & Restaurants & & \\
\hline \multirow{3}{*}{$\begin{array}{l}\text { Enjoyable } \\
\text { Experiences }\end{array}$} & Watched TV while eating & \multirow{3}{*}{$\begin{array}{l}\text { Enjoyable } \\
\text { experiences }\end{array}$} & \\
\hline & Read newspaper while eating & & \\
\hline & Explored new kitchen gadgets & & \\
\hline \multirow[t]{4}{*}{ Pre-prepared } & Frozen microwave meals & \multirow[t]{4}{*}{ Pre-prepared } & \multirow{4}{*}{$\begin{array}{l}\text { Available } \\
\text { Alternatives }\end{array}$} \\
\hline & Salad kit & & \\
\hline & Subway & & \\
\hline & Hotdog stand & & \\
\hline
\end{tabular}

\section{TABLE 5 Cultural Probe Coding}

\begin{tabular}{|c|c|c|c|}
\hline \multicolumn{4}{|c|}{ Coding for Focus Groups } \\
\hline First Code & Activity & Second Code & Common Theme \\
\hline \multirow[t]{4}{*}{ Interest } & Discussing engagement levels & \multirow[t]{3}{*}{ Interest } & \multirow{3}{*}{$\begin{array}{l}\text { Cooking Interest \& } \\
\text { Experience }\end{array}$} \\
\hline & Supporting cooking interest & & \\
\hline & Supporting avoidance & & \\
\hline & Desire for Independence & $\begin{array}{l}\text { Life experience/ } \\
\text { motivation }\end{array}$ & Cultural Experience \\
\hline \multirow[t]{2}{*}{ Interest Building } & Embedding hobbies & \multirow[t]{2}{*}{ Resource Allocation } & \multirow[t]{2}{*}{ Resource Allocation } \\
\hline & Embedding social activities & & \\
\hline Gendered Roles & Discussing traditional gender roles & Gendered role & Gender Dynamic \\
\hline
\end{tabular}




\begin{tabular}{|c|c|c|c|}
\hline \multirow{5}{*}{ Social Activities } & Discussing the wife impact & & \multirow{6}{*}{ Cultural Experience } \\
\hline & $\begin{array}{l}\text { Discussing loss of variety due to } \\
\text { loss of wife }\end{array}$ & $\begin{array}{l}\text { Gendered role/ } \\
\text { independence }\end{array}$ & \\
\hline & Cooking activities with wife & \multirow[t]{3}{*}{ Social activity } & \\
\hline & Social solutions & & \\
\hline & Community building activities & & \\
\hline Hobbies & Embedded activities & Hobbies & \\
\hline \multirow[t]{3}{*}{ Empathy } & $\begin{array}{l}\text { Call for more information on daily } \\
\text { living experiences }\end{array}$ & \multirow[t]{3}{*}{ Empathy } & \multirow{3}{*}{$\begin{array}{l}\text { Interest as a Support } \\
\text { for Designer } \\
\text { Empathy/ } \\
\text { Feeling Factors }\end{array}$} \\
\hline & Discussing empathy in design & & \\
\hline & Discussing empathy in personas & & \\
\hline \multirow[t]{5}{*}{ Technology } & Tech literacy & \multirow[t]{5}{*}{ Technology } & \multirow[t]{5}{*}{ Technology } \\
\hline & Tech design barrier & & \\
\hline & Analog solutions & & \\
\hline & Tech learning solutions & & \\
\hline & Tech stereotypes & & \\
\hline Confidence & Discussing confidence & \multirow[t]{3}{*}{ Confidence } & \multirow[t]{3}{*}{ Feeling Factors } \\
\hline \multirow{2}{*}{$\begin{array}{l}\text { Confidence } \\
\text { Building }\end{array}$} & Skill building solutions & & \\
\hline & Confidence building solutions & & \\
\hline \multirow[t]{7}{*}{ Alternatives } & New cooking alternatives & \multirow[t]{7}{*}{ Alternatives } & \multirow{7}{*}{$\begin{array}{l}\text { Available } \\
\text { Alternatives }\end{array}$} \\
\hline & Domestic care services & & \\
\hline & Medicalized solutions & & \\
\hline & Catering & & \\
\hline & Food box subscription & & \\
\hline & Pre-portioned meals & & \\
\hline & Grocery services & & \\
\hline Nutrition & Dietary challenges & Nutrition & Nutrition \& Food \\
\hline
\end{tabular}

TABLE 6 DESIGNER Focus GROUP CODING

\subsection{Ethical Considerations}

This research has been cleared by Carleton University Research Ethics Board B

Clearance \# (CUREB-B Clearance \#114589). Please refer to Appendix C to view the Certification of Institutional Ethics Clearance.

The ethical concerns for this research were very low. While the research did involve older age brackets of adult, who are considered a vulnerable population, the subject of the research (cooking) is generally not seen as a sensitive topic. However, the research was aware that discussions of cooking could bring up possible emotions related to loneliness, 
or potential loss of spouse. As such, methods such as interviews were designed in a semistructure to allow participants to direct the conversation in a way that was comfortable for them.

All research was conducted remotely to reduce any foreseeable risk caused by Covid- 19 . Participants were provided with several communication channels for contacting the researcher remotely to ensure they had ample ability to ask questions or voice any potential concerns they may have had. 


\section{Chapter 4: Results and Findings}

Upon analyzing the data from the three different methods (interviews, cultural probe kits, and focus groups), eight overarching themes were formed. Each of the three methods were analyzed separately and then, once all data was categorized and themes were being formed, the emerging themes from each of the three methods were compared to understand how similarities or differences between the three methods melded together to create the final overarching themes. The overarching themes identified are as follows: Cooking Interest \& Experience; Cultural Experiences; Technology; Gender Dynamics; Feeling Factors; Resource Allocation; Available Alternatives; and Nutrition and Food.

\subsection{Cooking Interest \& Experience}

The first overarching theme, and perhaps the most significant in its impact on how the resulting recommendations of this research were approached, is Cooking Interest \& Experience. Interest not only majorly impacts whether cooking experiences may be facilitated (positive or negative), but also impacts what experiences might be defined as cooking. Experience and interest have been included within the same theme as they both refer to the preexisting state of being and opinion of the older men involved in this study. Additionally, in some instances experience may influence interest.

While Interest has been identified as its own individual overarching theme it is important to note that interest factors intersect with all of the other overarching themes in some capacity or another.

\subsubsection{Cooking Interest \& Experience in Interviews}

As a part of the interviews, all eight participants were all asked some variation of the question "would you ever be interested in learning to cook?" As such, data was collected 
from all eight of the interviews that specifically addressed each participant's interest levels in cooking and the descriptive code of 'interest' was assigned within all eight data sets. There was some variation amongst the data assigned the 'interest' descriptive code based on the variation in responses given during the interviews.

Seven out of the eight men interviewed described themselves as having historically limited or basic experiences with cooking. Four of the men mentioned barbequing as a method of cooking when discussing their limited cooking experiences.

Five of the men had no interest in learning to cook. Of the men who cited a lack of interest, three cohabitated with a wife who is the primary cook, one man lived alone due to the death of his wife (who was, prior to her passing, the sole cook), and one man lived alone due to divorce. Both of the men living alone were responsible for preparing their own meals. Of the three remaining participants, one had some interest in learning to cook and two stated that they were interested in learning to cook. Only one participant said his primary motivation to learn to cook was purely out of his own interest.

\begin{tabular}{|l|l|l|}
\hline Men Reporting Their Cooking Experiences & Participants \\
\hline Men reporting limited or basic cooking experiences & 7 & $\begin{array}{l}\text { P1, P2, P3, P4, P5, P6, } \\
\text { P7 }\end{array}$ \\
\hline $\begin{array}{l}\text { Men reporting the barbecue as a cooking tool they } \\
\text { use }\end{array}$ & 4 & P2, P5, P6, P7 \\
\hline Men reporting helping their wife in the kitchen & 4 & P1, P2, P5, P7 \\
\hline $\begin{array}{l}\text { Men preparing all of their own meals out of } \\
\text { necessity }\end{array}$ & 2 & P4, P8 \\
\hline
\end{tabular}

TABLE 7 MEN REPORTING THEIR COOKING EXPERIENCES (PARTICIPANTS SPECIFIED)

\begin{tabular}{|l|l|l|}
\hline Men Reporting Their Cooking Interests & Participants \\
\hline No interest in learning to cook & 5 & P3, P4, P5, P6, P8 \\
\hline Some interest in learning to cook & 1 & P1 \\
\hline Interested in learning to cook & 2 & P2, P7 \\
\hline Interest as the primary motivator for learning to cook & 1 & P7 \\
\hline
\end{tabular}

TABLE 8 MEN REPORTING THEIR COOKING INTEREST (PARTICIPANTS SPECIFIED) 
Past experience is another influencing factor. The data collected during interviews shows that both negative and positive past experiences influence the present day lifestyles and attitudes of the older interviewees. Negative experiences can influence an individual's present desire to cook. P1 explained that his last cooking experience was early on in university, when, tired of his limited cooking skills, P1's roommates delegated him to dish duty for the rest of the year - a delegated duty he continues to take on to this day as his contribution to cooking process in his household. P4's mother was hospitalized when he was in middle school and cooking duties suddenly fell upon him to be completed, which has impacted his attitude to cooking in present day - "I know I can [cook], but I haven't done it since and I don't intend to.” P2 reported his ongoing aversion to brussels sprouts to be the result of a specific event from his childhood wherein he and his sister cut into some boiled brussels sprouts only to discover maggots inside.

Similarly, positive experiences reported also impacted the attitudes of participants. When asked about fond memories of home cooked meals, P8 fondly reported that he began making canned soups for himself as a teenager when he got home from school, and that he continues to make himself canned foods all the time. P6, who was quoted earlier in this section for his love of Sunday roasts, explained that he has enjoyed so many roasts in his life (from both his mother and his wife making them) that he knows all the steps and feels that, if he had to, he would be able to make a roast beef dinner by himself. In fact, roast beef dinner was among the list of four things he felt he could make (omelet, sandwiches, barbecued meat, and roast beef).

\begin{tabular}{|l|l|l|}
\hline $\begin{array}{l}\text { Past Experiences Reported as Influencing Factors in Cooking } \\
\text { Attitudes and Experiences }\end{array}$ & Participants \\
\hline Negative cooking or food related experiences & 5 & P1, P2, P3, P4, P5 \\
\hline Positive cooking or food related experiences & 3 & P2, P6, P8 \\
\hline
\end{tabular}


TABLE 9 PAST EXPERIENCES AS INFLUENCING FACTORS IN COOKING ATTITUDES AND EXPERIENCES (PARTICIPANTS SPECIFIED)

\subsubsection{Cooking Interest \& Experience in Cultural Probes}

The men were prompted to record everyone who was involved in the preparation of each of their meals in their journal. Answers varied between the participant being the only cook, participant and a spouse cooking together, and a spouse cooking the entirety of the meal. The descriptive codes 'cooking experience,' 'partial cooking experience,' and 'no cooking experience' were assigned accordingly. There were no 'interest' descriptive codes assigned directly to cultural probe data, however, the 'interest' codes from the interview data were compared to cultural probe date assigned the 'cooking experience,' 'partial cooking experience,' and 'no cooking experience' codes in order to search for patterns across all the data.

The cultural probe kits captured a snapshot of the present experiences of older men. Of the seven men to participate in this method, six participated in preparing dinner at least to some capacity. Two men prepared dinner entirely on their own; one man cooked dinner by scratch entirely by himself for the sake of the study, and ate it with his wife and son; the other man, who lived alone due to the passing of his wife, prepared a microwave meal as an alternative method to cooking a meal from scratch. The remaining four men participating in the preparation of cooking did so alongside their wives; three out four of these men participated by using the barbeque; the remaining one man cooked a meal from scratch with his wife. P3 (who was not involved in the dinner preparation process) had his dinner prepared by his wife.

\begin{tabular}{|l|l|l|l|}
\hline \multicolumn{2}{|l|}{ Dinner Preparation Experiences } & Participants \\
\hline Participant as the sole cook & Cooked meal from scratch & 1 & P2 \\
\hline
\end{tabular}




\begin{tabular}{|l|l|l|l|}
\hline & Prepared a microwave meal & 1 & P4 \\
\hline \multirow{2}{*}{$\begin{array}{l}\text { Participant cooked alongside } \\
\text { wife }\end{array}$} & Using barbeque & 3 & P1, P5, P6 \\
\cline { 2 - 4 } Participant had no involvement & Cooked from scratch together & 1 & P7 \\
\hline
\end{tabular}

TABLE 10 DINNER PREPARATION EXPERIENCES (PARTICIPANTS SPECIFIED)

Both men involved in cooking a meal from scratch did so for the sake of the study, and both were men who had stated an interest in learning to cook during the interviews. P1, who stated some interest in learning to cook during the interviews, was one of the men who participated in the cooking process via the use of barbeque.

\begin{tabular}{|l|l|l|}
\hline $\begin{array}{l}\text { Dinner Preparation Connected to Men Interested in Learning to } \\
\text { Cook, as Identified in Interviews (3) }\end{array}$ & \multirow{2}{*}{ Participants } \\
\hline Cooked meal from scratch on his own & 1 & P2 \\
\hline Cooked meal from scratch with his wife & 1 & P7 \\
\hline Barbequed meat while his wife cooked the rest of dinner & 1 & P1 \\
\hline
\end{tabular}

TABLE 11 DINNER PREPARATION CONNECTED TO MEN INTERESTED IN LEARNING TO COOK, AS IDENTIFIED DURING THE INTERVIEWS (PARTICIPANTS SPECIFIED)

\subsubsection{Cooking Interest \& Experience in Designer Focus Groups}

There was some variation in what was assigned the descriptive code 'interest' in the data sets produced by the focus groups. Data from the discussion segment of the sessions that outright discussed how interest might impact older men's engagement levels with certain proposed design solutions was assigned the 'interest' descriptive code. Additionally, proposed solutions that catered to supporting cooking experiences received the descriptive code 'supports cooking interest' while proposed solutions that catered to a potential disinterest in cooking received the descriptive code 'supports avoidance.'

Despite the fact that designers from all the focus groups were asked during the mural activity to propose design solutions to support cooking activity, Focus Groups A and B, who explored the Carl persona, proposed solutions that catered to the support of cooking activities as well as solutions that avoided the need to cook entirely. Designers from 
Focus Group C, who examined the George and Liam personas, exclusively proposed solutions supported cooking activities at least to some degree.

\begin{tabular}{|l|l|l|}
\hline Solutions Proposed for Facilitating Cooking Experiences & Groups \\
\hline Design solutions supporting cooking experiences & 3 & A, B, C \\
\hline Design solutions catering to cooking avoidance & 2 & A, B \\
\hline
\end{tabular}

TABLE 12 SOLUTIONS PROPOSED FOR FACILITATING COOKING EXPERIENCES (GROUPS SPECIFIED)

Interest in cooking was only outright discussed as an important design factor by Group C, and all four designers acknowledged its importance.

\subsection{Gender Dynamics}

Data examining the dynamic between husband and wife, the history behind gender and cooking, and the potential impacts gender had on older men's cooking experiences has been all sorted into the theme of gender dynamics.

\subsubsection{Gender Dynamics in Interviews}

Descriptive codes that were assigned to the interview data in the gender dynamics theme included: 'wife cooks,' 'better cook,' 'wife's cooking skills,' and 'supporting wife as interest.' All of these codes referred in some way back to the relationship between a participant and his wife (which inherently has a gender dynamic).

Data on gender dynamics in the interviews mostly consisted of the participants' accounts of their relationships with their wives and the household roles each of them held. Six out of eight of the men interviewed cohabitated with their spouse, and all six men identified their wives to be the primary cooks in their household. The remaining two men lived alone, however, of these two; P4 described his late wife to have been the primary cook prior to her passing. 
Wives' cooking skills were often held in high regard and were often described as superior or a reason why men did not do the cooking. P2 explained that, despite his interest in learning how to cook, his wife's superior cooking skills often results in her taking on more of the cooking. He used the example of a specific pasta recipe he used to cook - "I used to cook [a particular pasta dish], but [my wife] was just simply better than me. So, now she cooks sort of the pancetta pasta dish and I don't, simply because she's quicker and better at it." Other participants less interested in learning to cook often cited their wives strong abilities to cook as a reason why they did not need to learn to cook. "My wife is very competent. She will cook without sort of suggesting I cook first, in fact, she would rarely do that, and so we fall into this method of operation where, you know, [my wife] will cook and I just accept that," explained P3 while describing his own lack of cooking experience and motivation. P1 said "why would I try and make a roast beef sandwich when [my wife] does such a good job of it?" While this data shows that men may prefer their wives to cook - the gender dynamic of this preference may not have anything to do with gender, and may instead be simply related to the preference of not having to do the cooking. P2 expressed that "If I did a stir fry, [my wife] would enjoy that more than I would because sometimes if you're cooking it, you don't always enjoy it as much as somebody cooking it for you." While P1 and P2 both reported at least some interest in learning to cook, they also reported a preference for their wife to do the cooking.

\begin{tabular}{|l|l|l|}
\hline $\begin{array}{l}\text { Gendered Dynamics Influencing Older Men's Cooking } \\
\text { Experiences and Desires }\end{array}$ & Participants \\
\hline $\begin{array}{l}\text { Wives reported as the primary cook (presently and in } \\
\text { the past) }\end{array}$ & 7 & $\begin{array}{l}\text { P1, P2, P3, P4, P5, } \\
\text { P6, P7 }\end{array}$ \\
\hline $\begin{array}{l}\text { Men who reported their wife as the better cook } \\
\text { (presently and in the past) }\end{array}$ & 5 & P1, P2, P3, P4, P7 \\
\hline
\end{tabular}




\begin{tabular}{|l|l|l|}
\hline $\begin{array}{l}\text { Men who identified as unmotivated due to wives' } \\
\text { cooking skill (presently and in the past) }\end{array}$ & 4 & $\mathrm{P} 1, \mathrm{P} 2, \mathrm{P} 3, \mathrm{P} 4$ \\
\hline
\end{tabular}

TABLE 13 NuMBERS RELATED TO GENDERED DYNAMICS (PARTICIPANTS SPECIFIED)

Of the three men in this study who stated an interest in learning to cook, P1 and P2 reported their reason for wanting to learn being to support their wife (although P1 also cited practicality of the skill as a secondary reason behind wanting to learn as well).

\subsubsection{Gender Dynamics in Cultural Probes}

Cultural probe data that was sorted into the gender dynamics theme was the data assigned the descriptive codes 'participant cooks' and 'participant's wife cooks.' The descriptive code 'participant cooks' was included in this theme after comparing the data sets to the interview data sets, which showed a contrast between 'wife cooks' codes in the interview data and 'participant cooks' codes in the cultural probe data.

Despite the fact that all six men who cohabitated with a spouse reported their wife to be the primary cook in the household, all of the men involved in the cultural probe method reported some involvement in the kitchen. All seven men prepared their own breakfasts and six men prepared their own lunches. P1, who did not prepare his own lunch, had his lunch prepared for him by his wife. As mentioned in 4.1.2, six men were also involved in the preparation of dinner to varying degrees (see table 10 for details).

\begin{tabular}{|l|l|l|}
\hline Breakfast and Lunch Preparation Experiences & Participants \\
\hline Participant prepared their own breakfast & 7 & P1, P2, P3, P4, P5, P6, P7 \\
\hline Participant prepared their own lunch & 6 & P2, P3, P4, P5, P6, P7 \\
\hline Participant's wife prepared their lunch & 1 & P1 \\
\hline
\end{tabular}

TABLE 14 BREAKFAST AND LUNCH PREPARATION EXPERIENCES (PARTICIPANT SPECIFIED)

P5 expressed that food was more enjoyable when prepared by someone else, a similar sentiment to the one expressed by $\mathrm{P} 2$ in the interviews. This participant, P5, reported his wife typically prepares both of their lunches during the interview, but prepared lunch for 
himself and his wife (likely for the sake of the study) using his barbeque. When asked to rate the meal, he selected a 3, which was defined as “this meal was okay, I wouldn't mind eating it occasionally." In the proceeding comments section he explained "things always seem to taste better when someone else has prepared it, in my opinion."

\subsubsection{Gender Dynamics in Designer Focus Groups}

Descriptive codes that were eventually assigned to the gender dynamic theme emerged from both the discussion segment and the Mural activity segment of the sessions. During the Mural activity, proposed solutions that blatantly stated a gender factor were assigned the descriptive code 'gender dynamic.' This code was also assigned to any discussion looping back to the gender-related design solutions. Gender was also discussed within the context of history and tradition as well as in potential scenarios for older men involving their wife - these chunks of data were assigned the descriptive codes 'traditional gender roles' and 'wife impact' respectively.

Designers from Focus Groups B and C discussed gender dynamics and traditional household roles during the group discussion segment of the focus group. Focus Group C also considered the influence wives might have on older men's cooking activities during the Mural activity. It should be noted that the personas used by Focus Group C, Liam and George, mentioned their wives' involvement in their lives; while the persona used by Focus Group A and B, Carl, was described as widowed. This difference in personas made gender dynamics between spouses an irrelevant design consideration for Focus Group A and B when completing the Mural activity.

Six designers recognized that gender roles impacted the skillsets carried by men and women of the older generation. Furthermore, three designers recognized the impact a 
wife passing away could have on the independence of older men. D3 noted that older men might typically be accustomed to a variety of food catering to their tastes and preferences when their wife cooks their meals. As such, D3 expressed that older men's choice may become much more limited upon the passing of a wife - which may result in feelings of independence eroding away. D5 noted the impact that gendered design may have on potential customers - "I think that's one thing to be really careful of - is this dynamic. The differences between those two [genders of customers], even down to the colour of the kitchen tools."

Focus Group C, wherein all designers examined gender dynamics during their Mural activities, suggested that gender might play a major factor in designing motivating solutions for older men to learn to cook. One design solution that was suggested, which was popular amongst all four of the designers, was the idea of a cooking group for older men. The suggested solution proposed that because gender may play an important role in cooking experiences for older men, creating a space that is not only interesting and comfortable for older men to learn to cook in, but also separates cooking from traditional notions of feminine activity. D6 drew upon his own personal experiences with older family and friends to point out that older men tended to gravitate towards activities that were considered "manly" such as sports night or beer drinking - activities that the group collectively recognized could be integrated into a men's cooking group to build upon an "old timey old men's club" vibe as a method of attracting participants.

\begin{tabular}{|l|l|l|}
\hline Gender as an Acknowledged Consideration by Designers & Participants \\
\hline $\begin{array}{l}\text { Designers who recognized traditional gender roles may } \\
\text { impact older men's skillsets }\end{array}$ & 6 & $\begin{array}{l}\text { D3, D4, D5, D6, } \\
\text { D7, D8 }\end{array}$ \\
\hline $\begin{array}{l}\text { Designers who recognized the impact a wife passing might } \\
\text { have on a older man's food experiences }\end{array}$ & 3 & D3, D5, D6 \\
\hline Designers who examined gender dynamics during the & 4 & D5, D6, D7, D8 \\
\hline
\end{tabular}




\section{Mural activity}

TABLE 15 GENDER AS AN ACKNOWLEDGED CONSIDERATION BY DESIGNERS

(DESIGNERS SPECIFIED)

\subsection{Cultural Experiences}

The third overarching theme of this research is cultural experiences. Cultural experiences as a theme encompasses any data centering around social factors, events, and other enjoyable influences that may contribute to the way daily life is experienced and how these daily life influences may impact ability to form cooking experiences. The factors that encompass cultural experiences in this section are: social experiences, networks, enjoyable activities and special meals. Please note that while hobbies can serve as a cultural experience, the hobby factor is primarily discussed within the theme titled 'Resource Allocation.'

\subsubsection{Cultural Experience in Interviews}

Any chunk of data discussing an experience that is social was assigned a descriptive code relevant to the specific experience. These codes included: 'social activity,' 'social connection,' 'Christmas dinner,' and 'Sunday Roast.' Eventually 'Christmas dinner' and 'Sunday roast' codes consolidated themselves under one descriptive code: 'special meals,' which were understood to be meals where more added effort was placed into the food and the special meal was used as a marker for gathering with others. This understanding was developed based on the context of the data that was assigned the descriptive codes 'Christmas dinner' and 'Sunday Roast.'

Social experiences were discussed in at least some capacity in all eight interviews. Food was seen as a factor for gathering, especially with spouses or other family. Sometimes the social aspects of meals were the subjects of participants' responses, and sometimes the 
social aspects were mentioned organically as a part of a response to a different topic. While describing his own food preferences and tolerance to spice, P5 mentioned his grandson, who he often shares meals with, having a much higher spice tolerance than him. When asked specifically about the social aspects of his meals, another participant, P2, said "90 percent of the meals [my wife, my son, and I] have together are very social meals at night. The evening meal is still a very much-appreciated event. We light candles and we don't always sit at the formal dining room table, sometimes we sit in the kitchen, but all together eating at the same time and chatting about the day." P3 noted that the pandemic had shifted the way him and his wife chose to share their evening meals -

This is somewhat embarrassing, but I'll divulge it to you, is that since the pandemic began, being locked in, we do spend our meals watching TV. [...] our meals before, were never in front of the TV. Maybe once, you know, once every two months, now it's 99 percent of them are in front of the television. [...] For us, what started it was when the pandemic first broke, it was depressing, right? It was awful to see what was happening. And even though case counts were so tiny compared to now, our fear level was up, you know, we were inundated with all these different new terrifying information. So we needed an outlet and we needed some comedy. So we started watching Friends.

Reinforcing the data of meals being valued as social events was data discussing special meals. Sunday roasts were brought up in four interviews and Christmas dinner was also brought up in four interviews. When asked why a Sunday roast was his favorite food, P6 responded, "I think it was the whole thing. The food, just the smell while it's cooking is nice in the house, and then usually it meant there was family around or family and friends, which is always nice." 
Some men also recognized the social aspects in the act of cooking itself. Two out of the three men who showed interest in learning to cook also recognized cooking with their wives as a social activity. Both P2 and P7 described themselves as acting as "sous chef" when discussing their current defined role in the kitchen. P1 also recognized certain social aspects in the process of cooking. For P1, he described fond memories of watching his wife, mother-in-law, and father-in-law all cook and experiment in the kitchen.

\begin{tabular}{|l|l|l|}
\hline Social Experiences Reported During Interviews & Participants \\
\hline Sharing meals with others & 3 & P2, P3, P5 \\
\hline Sunday roast & 4 & P2, P5, P6, P8 \\
\hline Christmas dinner & 4 & P2, P3, P4, P7 \\
\hline Cooking as a shared activity (acting as 'sous chef') & 2 & P2, P7 \\
\hline Observing others cooking as an enjoyable activity & 1 & P1 \\
\hline
\end{tabular}

TABLE 16 SOCIAL EXPERIENCES REPORTED DURING INTERVIEWS (PARTICIPANTS SPECIFIED)

\subsubsection{Cultural Experiences in Cultural Probes}

The descriptive codes 'social activity' as well as 'enjoyable activity' were assigned to the cultural probe data that was sorted into the theme of cultural experiences.

The cultural probes helped to highlight not only the social ways daily meals are consumed, and in some instances prepared, but also the enjoyable activities that are embedded within food related processes as well. All seven of the men reported social activity in some manner or another related to food activities. Six out of seven men shared meals with a spouse or family member; another four prepared a meal alongside their wife; three men shared clean up duties after meals with family members; one man shared a grocery shopping trip with his wife; and one man expressed how much he looked forward to eating out at restaurants again after the pandemic.

In some instances enjoyable activities that were not necessarily related to food were embedded within food related activities, with the food related activity acting as a catalyst 
for the enjoyable activity to take place. Three men noted that they enjoyed watching a television show while eating their meals and P6 also reported reading the newspaper at his sunny dining room table as a factor in how much he enjoyed his meal (which he rated a 2 - "this meal was good, I would enjoy eating it again") (See Figure 6). P7, who made his own lunch, noted that he typically ate simple foods for lunch, like yogurt or ham sandwiches, but decided to engage in "cooking" his lunch for the sake of the study. $\mathrm{He}$ found the experience of cooking his lunch an opportunity to explore kitchen gadgets he wouldn't typically use - "[I] diced 3 slices of deli ham with a pizza cutter (very clever I thought!)." His enjoyment of trying out the pizza cutter was further highlighted when he had someone take a picture of him using it and selected it as his favorite tool when prompted as well (see Figure 7).

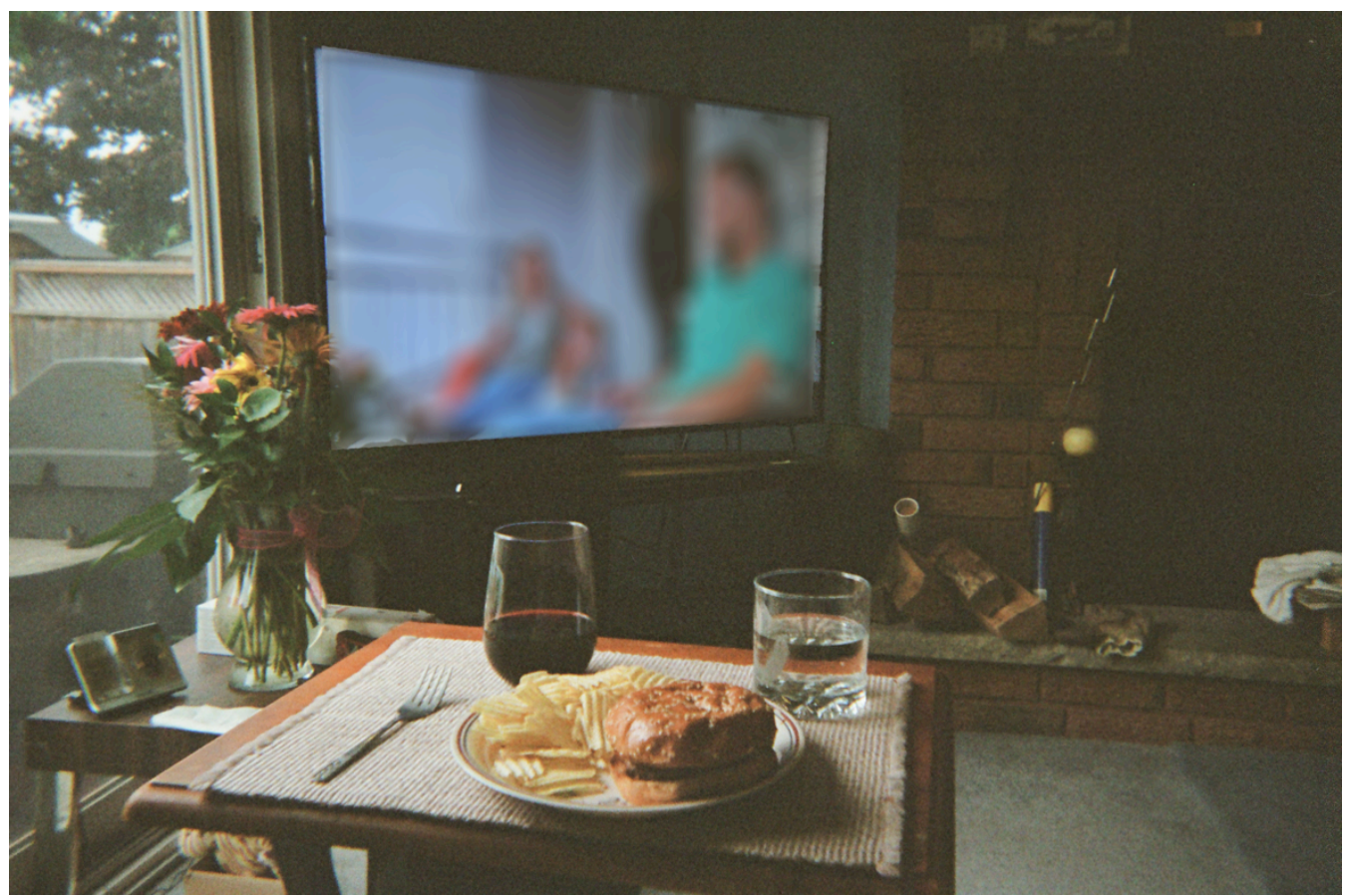

FIGURE 6

PhotograPh FROM P6's CULTURAL PROBE KIT TITLED “TV TABLE IN FAMILY RM" 


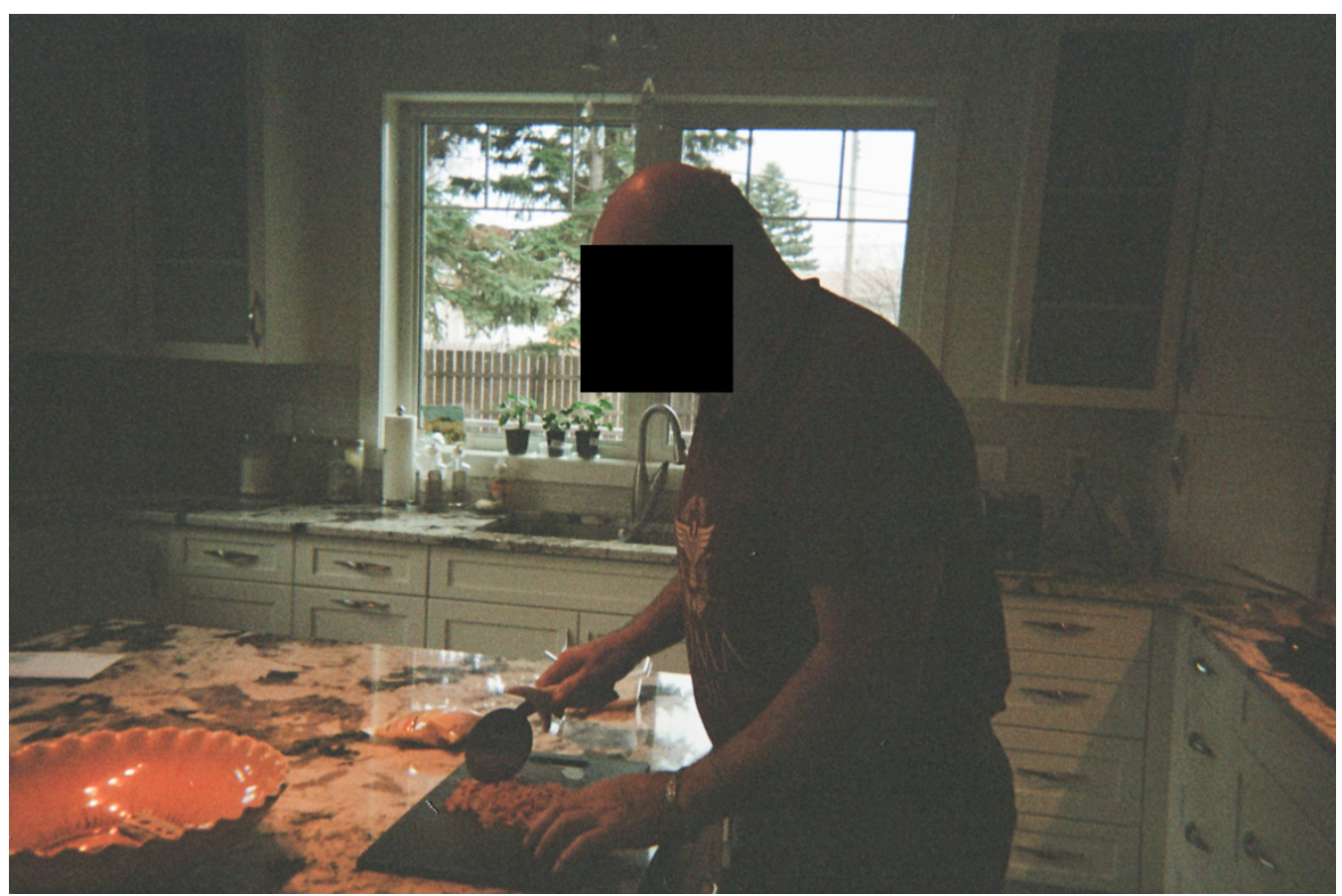

FIGURE 7 PHOTOGRAPH FROM P7'S CULTURAL PROBE KIT TITLED "PREPARING HAM"

\begin{tabular}{|l|l|l|}
\hline \multicolumn{2}{|l|}{ Social Factors Related to Food Experienced by Older Men } & Participants \\
\hline $\begin{array}{l}\text { Shared at least } 1 \text { meal with a spouse or other family } \\
\text { member }\end{array}$ & 6 & $\mathrm{P} 1, \mathrm{P} 2, \mathrm{P} 3, \mathrm{P} 5, \mathrm{P} 6, \mathrm{P} 7$ \\
\hline Prepared a meal alongside a spouse & 4 & $\mathrm{P} 1, \mathrm{P} 5, \mathrm{P} 6, \mathrm{P} 7$ \\
\hline $\begin{array}{l}\text { Shared kitchen cleanup duties with a spouse or other } \\
\text { family member }\end{array}$ & 3 & $\mathrm{P} 2, \mathrm{P} 5, \mathrm{P} 7$ \\
\hline $\begin{array}{l}\text { Expressed looking forward to eating out at restaurants } \\
\text { again after the pandemic }\end{array}$ & 1 & $\mathrm{P} 4$ \\
\hline
\end{tabular}

TABLE 17 SOCIAL FACTORS RELATED TO FOOD EXPERIENCED BY OLDER MEN (PARTICIPANTS SPECIFIED)

\begin{tabular}{|l|l|l|}
\hline $\begin{array}{l}\text { Enjoyable Activities Related to or Embedded within Food } \\
\text { Activities }\end{array}$ & Participants \\
\hline Watched television while eating & 3 & P3, P4, P6 \\
\hline Read the newspaper while eating & 1 & P6 \\
\hline Explored new kitchen gadgets & 1 & P7 \\
\hline
\end{tabular}

TABLE 18 ENJOYABLE ACTIVITIES RELATED TO OR EMBEDDED WITHIN FOOD ACTIVITIES (PARTICIPANTS SPECIFIED)

\subsubsection{Cultural Experiences in Designer Focus Groups}

The most prominent descriptive code from the designer focus groups to appear under the cultural experiences theme was the descriptive code 'social solution.' This code was 
assigned to any data that was a proposed design solution that had some form of social experience or activity embedded within the solution. The descriptive code 'embedded activity' also appears for data relating to potentially enjoyable activities that could be embedded within a cooking activity.

In addition to the men's cooking group mentioned in 4.2.3, which involved both social activity and embedded enjoyable activities, all three of the focus groups recognized the social aspects of food and cooking and explored social solutions. Various types of cooking classes, intergenerational cooking opportunities (grandfather and grandchild prepare a meal together), caregivers, chef-for-hire services, catering for larger events, and restaurant discount programs were all solutions that were proposed that have social aspects to them.

\begin{tabular}{|c|c|c|}
\hline \multicolumn{2}{|c|}{$\begin{array}{l}\text { Proposed Design Solutions Involving Social Factors or Enjoyable } \\
\text { Activities }\end{array}$} & \multirow{2}{*}{$\begin{array}{l}\text { Groups } \\
\mathrm{A}, \mathrm{B} \\
\end{array}$} \\
\hline Domestic care & Professional caregivers & \\
\hline services & Meals on Wheels & $\mathrm{A}$ \\
\hline \multirow{3}{*}{$\begin{array}{l}\text { At-home cooking } \\
\text { services }\end{array}$} & Community-based in-house cooking visits & $\mathrm{B}$ \\
\hline & Catering Services for group meals & $\mathrm{A}, \mathrm{B}$ \\
\hline & Hiring a home chef (chef-for-hire) & A \\
\hline \multirow{6}{*}{$\begin{array}{l}\text { Class-based } \\
\text { learning }\end{array}$} & Online/digital cooking classes & $\mathrm{A}, \mathrm{B}$ \\
\hline & At-home cooking classes & A \\
\hline & Community center cooking classes & $\mathrm{B}$ \\
\hline & Grocery store cooking classes & A \\
\hline & Cooking classes tailored to older adults & $\mathrm{B}$ \\
\hline & Cooking class for older men & $\mathrm{C}$ \\
\hline \multirow{3}{*}{$\begin{array}{l}\text { Family \& friend } \\
\text { support }\end{array}$} & Connecting to cooking services via family or friends & $\mathrm{B}$ \\
\hline & Cooking activities with wife & $\mathrm{C}$ \\
\hline & Intergenerational family cooking activities & $\mathrm{C}$ \\
\hline \multirow{2}{*}{ Enjoyable activities } & $\begin{array}{l}\text { Hydroponic gardening activities to provide fresh } \\
\text { produce }\end{array}$ & $\mathrm{A}$ \\
\hline & $\begin{array}{l}\text { Encouraging new cooking activities using } \\
\text { familiar/favorite cooking tools (the barbecue) }\end{array}$ & $\mathrm{C}$ \\
\hline \multirow{2}{*}{$\begin{array}{l}\text { Miscellaneous } \\
\text { social solutions }\end{array}$} & $\begin{array}{l}\text { Restaurant discount programs for regular, guaranteed } \\
\text { patronage }\end{array}$ & A \\
\hline & Shared assistant amongst retirement community & $\mathrm{B}$ \\
\hline
\end{tabular}


TABLE 19 PROPOSED DESIGN SOLUTIONS INVOLVING SOCIAL FACTORS OR ENJOYABLE/HOBBY ACTIVITIES (GROUPS SPECIFIED)

\subsection{Technology}

The theme of technology examines data pertaining to the use of technology in daily life as well as data pertaining to the potential design barriers surrounding technology and technological literacy.

\subsubsection{Technology in Interviews}

The descriptive codes found in this section include 'technology' and 'tech literacy.' These codes only appeared in two of the data sets as very little conversation about the topic of data appeared. How technology was used to recruit and contact participants was also considered for this section.

On top of past experiences, current day experiences and abilities relating to technology also impact the lifestyles of older men and may contribute in various ways towards cooking attitudes and abilities. While not an outright topic discussed in all of the interviews, seven out of eight men appeared to be relatively comfortable with technology to at least some degree. The seven men comfortable with technology all utilized email as a communication tool at some point during the study. Additionally, two participants sent text message communications and one participant opted into using Zoom instead of the phone for his interview.

Due to the semi-structured nature of the interviews, the topic of technology came up naturally in two interviews. P3 outright mentioned his interest in technology as a hobby of his, "I'm an I.T. guy, so I have the technical skill set that I like to tinker with things. I like to learn new computer languages or whatever. [...] We all use technology, except cooks, there's not a lot of technology there, but, you know, we use technology in our 
lives a lot." While seven out of eight participants were comfortable with technology to at least some degree, P8 was not comfortable with it at all. Signed up for the study by a family member, the recruitment process and signing of consent forms was all completed with the support of his daughter, as P8 himself did not have an email. His interview was conducted over the phone, at which time he also communicated his discomfort using texting and voicemail phone features.

\begin{tabular}{|l|l|l|}
\hline \multicolumn{2}{|l|}{ Comfort with Technology } & Participants \\
\hline Utilized email during the study & 7 & P1, P2, P3, P4, P5, P6, P7 \\
\hline Utilized text during the study & 2 & P3, P7 \\
\hline Utilized Zoom during the study & 1 & P4 \\
\hline $\begin{array}{l}\text { Did not utilize email during the study (did not } \\
\text { have an email account) }\end{array}$ & 1 & P8 \\
\hline $\begin{array}{l}\text { Reported interest and enjoyment from using } \\
\text { technology during the interview }\end{array}$ & 1 & $\mathrm{P} 3$ \\
\hline $\begin{array}{l}\text { Reported discomfort using technology (texting } \\
\text { and voicemail) during the interview }\end{array}$ & 1 & $\mathrm{P} 8$ \\
\hline
\end{tabular}

TABLE 20 COMFORT WITH TECHNOLOGY (PARTICIPANTS SPECIFIED)

\subsubsection{Technology in Cultural Probes}

Experiences in technology were not highlighted using the cultural probe method, however, the impact technology may have on access to experiences was showcased in a unique way. P8, who reported being uncomfortable with many forms of communication technology in the interviews, was unable to be reached for the second method. Due to his discomfort with voicemail, texting, and email there were communication barriers present with this participant that were not present with any of the others. Ultimately, because these barriers resulted in an inability to reach the participant, the participant did not take part in the cultural probe segment of research. 


\subsubsection{Technology in Designer Focus Groups}

'Tech literacy' and 'tech design barrier' were the two descriptive codes that appeared from the designer focus group data that was eventually sorted into the technology theme. 'Tech literacy' codes related back to data that directly discussed the low technological literacy or potentially low technological literacy pertaining to designing for older men. 'Tech design barrier' codes related back to any data that discussed how difficult it was to design for low-level technological literacy.

Technological literacy was also discussed in all three focus groups. While Focus Groups A and B, who worked with Carl, received prompting information about technological literacy within the persona ("Carl doesn't have an email account and is uncomfortable using the text and voicemail features on his phone"), Focus Group C, who worked with the Liam and George personas, did not receive any prompting information regarding technology. Due to common stereotypes that older people struggle with technology, Focus Group C designers were concerned they were missing a key piece of information. D3, from Focus Group B, had a similar concern regarding accessibility issues.

All of the groups expressed the need for digital technology-free design solutions, referred to by some designers as analog solutions, to be difficult, and reported low technological literacy to be a barrier in what design solutions could be proposed. Focus Group A also expressed that low technological literacy creates barriers for advertising any design solutions that were produced. Focus Groups A and B suggested that some sort of training to improve technological literacy and reduce fears pertaining to technology would be a good course of action. D4 pointed out that the natural order of things as civilization progresses is that there's always going to be a generation that is behind. In today's world, 
D4 explained, being behind refers to digital technology, but that too will continue to change, so it was important to consider how design solutions could evolve to cater to changing environments and the generations left behind.

\begin{tabular}{|l|l|l|}
\hline \multicolumn{2}{|l|}{ Technology as a Barrier to Design Solutions } & Groups \\
\hline $\begin{array}{l}\text { Designers who recognized technology as a } \\
\text { barrier or potential barriers to designing } \\
\text { solutions }\end{array}$ & 8 & A, B, C \\
\hline $\begin{array}{l}\text { Designers who recognized technology as a } \\
\text { barrier to advertising design solutions }\end{array}$ & 2 & A \\
\hline
\end{tabular}

TABLE 21 TECHNOLOGY AS A BARRIER TO DESIGN SOLUTIONS (GROUPS SPECIFIED)

\subsection{Resource Allocation}

Resource allocation examines data revolving around the resources, such as food or time, which may impact attitudes towards cooking. Some data regarding hobbies can also be found under this theme.

\subsubsection{Resource Allocation in Interviews}

'Time constraints', 'time waste', and 'food waste' descriptive codes within interviews that were identified to be a part of the resource allocation theme. 'Time waste' and 'food waste' were both present day factors that impacted the attitudes the men had towards learning to cook. 'Time constraints' were past and present day factors that had influenced the men's exposure to cooking and their experiences.

Experiences revolving around time constraints fell into two categories - men whose time constraints resulted in them rushing through meal preparation (either in the past or in the present), and men whose past time constraints resulted in forming of traditional household roles. The men whose time constraints resulted in rushing, were all men with past or present experiences of living alone, where they had to feed themselves. P8, who is divorced and lives alone, recalled that prior to his retirement he would be tired coming 
home from work and so he would rush through cooking as quickly as he could - a habit he carried forward into his retired life. P7, who lived alone for some time before meeting his wife also cited work impacting his cooking habits - "I was on the farm all the time $[\ldots]$ for years and years it was always come in and it was a rush to eat. [...] We were working long hours and late hours and didn't have the opportunity to cook much." P4 reported that time constraints existed simply due to his own disinterest in planning ahead, which resulted in a strong desire for convenient meals. P3, whose wife cooks his meals, expressed a similar hypothetical concern - "The thought of a meal taking an hour to prepare is daunting for me, like wow, I'm going to die of starvation before it's even ready - even though that's irrational, right? That's not a rational thought for sure." On the traditional role side of things, $\mathrm{P} 2$ explained that he had been the higher wager earner and worked longer hours than his wife when they were younger, so it made sense to them to have very traditional household roles. As such, his wife took on the task of doing all the cooking. "It was always just a practical partnership for us. Who had the more time available? Who had the more skills?"

Time wasted was a factor that contributed towards the attitudes of whether men wanted to allocate time towards cooking. Due to a lack of skill, two of the men expressed in their interviews that there was a concern for time wasted if they made a poor quality meal. "I'm a fairly pragmatic person, so it would be discouraging for me to go through an hour's worth of preparation and have it turn out badly and have to order pizza," expressed P1. In addition, hobbies were also an influencing factor that fueled concerns of time waste. P3 explained “even though I'm retired, I look at [cooking] as something that takes 
up time that could be spent doing something more fruitful and beneficial." P3 is involved in a sport hobby amongst many other interests that take up his time.

Food waste was the final resource of concern. Some men expressed concern with allocating food to learning to cook and potentially wasting the food. P1 explained, "One thing that I'm afraid of, well not afraid of - that's too strong of a word, but the pains that [my wife and I would] go through until I gather some confidence and ability. I mean, how many meals would we have to throw out?" Similar sentiments regarding wasting food and producing poor quality food were expressed by P3 when asked if he would be interested in learning how to cook for someone else.

\begin{tabular}{|l|l|l|}
\hline Cooking Concerns Regarding Resource Allocation & Participants \\
\hline Past or present time constraints resulting in rushed meals & 3 & $\mathrm{P} 4, \mathrm{P} 7, \mathrm{P} 8$ \\
\hline $\begin{array}{l}\text { Past time constraints resulted in the formation of } \\
\text { traditional household roles }\end{array}$ & 2 & $\mathrm{P} 1, \mathrm{P} 2$ \\
\hline $\begin{array}{l}\text { Concerned about time wasted on producing poor quality } \\
\text { food }\end{array}$ & 2 & $\mathrm{P} 1, \mathrm{P} 3$ \\
\hline $\begin{array}{l}\text { Concerned about food waste caused by cooking poor } \\
\text { quality meals }\end{array}$ & 2 & $\mathrm{P} 3, \mathrm{P} 5$ \\
\hline Feel that time is better spent on doing other things & 2 & $\mathrm{P} 1, \mathrm{P} 3$ \\
\hline
\end{tabular}

TABLE 22 RESOURCE ALLOCATION CONCERNS IN INTERVIEWS (PARTICIPANTS SPECIFIED)

\subsubsection{Resource Allocation in Cultural Probes}

'Easy prep,' 'quick prep,' 'stockpile' and 'found in fridge,' were the descriptive codes from cultural probes included in the resource allocation theme. 'Easy prep' and 'quick prep' both referred to data that highlight either easy or fast (or both) meal preparation to be a positive factor that influenced the participant's attitude towards their meal.

'Stockpile' and 'found in fridge' codes were assigned to data relating to low amounts of meal planning or an avoidance of meal planning. 
In terms of resource allocation the cultural probe kits only produced data regarding time as a resource. Five out of seven of the men reported easy, or quickly prepared meals to be an influencing factor in their enjoyment of meals they prepared by themselves. One such participant, P1, rated his meal a 2 (" this meal was good, I would enjoy eating it again") and cited "convenience" as the only influencing factor to the rating, however, also reported that he was also still hungry after his meal (4 - "I am still a little hungry") despite the positive rating.

In addition to the convenience ratings, planning avoidance was also revealed. Six men reported either finding ingredients the day of already in the fridge or their wives doing the grocery shopping for at least one meal when prompted to discuss their planning process. This number dropped to four men when only examining dinnertime meals. P4 lived alone and did his own grocery shopping, and therefore provided more details to his shopping processes when faced with the same prompt. Despite his more in-depth answers, $\mathrm{P} 4$ arguably could still be placed within the same planning echelon as the others. In his response he explained his process of stockpiling in order to have things ready without the need for planning - "I buy a variety of frozen dinners and keep 10 to 20 on hand."

\begin{tabular}{|l|l|l|}
\hline $\begin{array}{l}\text { Resource Allocation Influencing Daily Meal or Food } \\
\text { Experiences }\end{array}$ & Participants \\
\hline $\begin{array}{l}\text { Easy or quickly prepared meals reported as a } \\
\text { positive factor }\end{array}$ & 5 & P1, P2, P3, P4, P6 \\
\hline $\begin{array}{l}\text { Low or no planning (ingredients found in the } \\
\text { fridge) reported for at least 1 meal }\end{array}$ & 6 & P1, P2, P3, P5, P6, P7 \\
\hline $\begin{array}{l}\text { Low or no planning reported for dinnertime } \\
\text { meal }\end{array}$ & 4 & P1, P3, P6, P7 \\
\hline $\begin{array}{l}\text { Meal stockpiling as a method of alleviating the } \\
\text { need for meal planning }\end{array}$ & 1 & P4 \\
\hline
\end{tabular}

TABLE 23 RESOURCE ALLOCATION INFLUENCING DAILY MEAL OR FOOD EXPERIENCES (PARTICIPANTS SPECIFIED) 


\subsubsection{Resource Allocation in Designer Focus Groups}

Due to the fact that focus groups were exploring solutions to help support older men cooking, the descriptive codes in this section pertain to proposed solutions as well, rather than resource allocation outright. 'Embedded hobby' and 'social activity' were descriptive codes that were assigned to data discussing design solutions that serve to entice older men to allocate time towards cooking.

Time allocation was discussed in two out of three focus group sessions within the context of hobbies. D7 and D8, who worked with the George persona, which mentions using the barbecue, explained that the barbecue serves the potential to be the catalyst for George to learn to cook. If he enjoys using the barbecue, then he will be more willing to allocate time in his day to use it. By introducing a wider variety of barbeque tools to George, he could expand the variety of foods he can cook on the barbecue while building skill and confidence in cooking. Similarly, designers from Focus Group A expressed that if Carl is a person who enjoys social activities then working to develop social activities that also build cooking skills may be more appealing and therefore more worthwhile of Carl's time.

\begin{tabular}{|l|l|l|}
\hline Allocation of Time-Based Resources as a Design Factor & Participants \\
\hline $\begin{array}{l}\text { Designers who proposed solutions that } \\
\text { embedded hobbies within cooking activities }\end{array}$ & 6 & D2, D5, D6, D7, D8 \\
\hline $\begin{array}{l}\text { Designers who proposed solutions that } \\
\text { embedded sociality with cooking activities }\end{array}$ & 2 & D1, D2 \\
\hline
\end{tabular}

TABLE 24 ALLOCATION OF TIME-BASED RESOURCES AS A DESIGN FACTOR (DESIGN PARTICIPANTS SPECIFIED) 


\subsection{Feeling Factors}

Feelings play an important role in the attitudes and willingness of older men to participate in unfamiliar tasks where new skills need to be built, such as cooking. Feelings of confidence and discomfort appeared the most in the data.

\subsubsection{Feeling Factors in Interviews}

When assigning the descriptive codes to the data that ended up organized into this theme, it was found that feeling, such as confidence, were typically discussed within the context of experience. As such, data where experience, or lack thereof, was cited as the catalyst for feeling a certain way were assigned a feeling related code such as 'confidence,' 'intimidation,' or 'discomfort.'

Four out of eight men reported that feelings of wavering confidence or intimidation during or even just at the thought of cooking activities. Lack of experience or tacit knowledge (which is developed through experience and skill building) was commonly cited as the reason for low levels of confidence or feelings of intimidation. While discussing his experience and comfort level in cooking P2 said

I don't have the background cooking skills - I mean, I used to make my own food now and again as a kid, but I never went to cooking school. So I think in the case of someone like me, I think you're at a disadvantage where you lack the confidence. So it's not that I wouldn't try something. It's just my odds of success are not [high].

P3 expressed feeling intimidated by the thought of moving away from familiar recipes that he did have experience with - 
I'll do a frozen pizza. It comes out of the freezer. I feel more comfortable on meals that I've prepared, that I've done before. So I would not take on a brand new meal from a recipe out of a book [...] I just would be kind of be somewhat intimidated by that and just kind of out of my element, trying to know where all the different ingredients are and how to... Like I can run a measuring cup, but, you know, what's a pinch of salt? That kind of thing.

Another reason for lower confidence levels was discouraging past experiences resulting in less experience over time and a historical lack of recipe variation. P1 explained, that lack of experience had impacted his confidence in his cooking abilities - "I have no confidence in it, in my ability to cook. So, I guess that's what prevents me from jumping in more - because I'm only good for making one dish, which is why my roommates in university said 'no, enough of that.' I had no variety, or no, I guess, thoughts of making different things." P7 reported a similar concern for lack of recipe variation. P1 and P2 reported that they felt slightly intimidated to learn to cook due to their spouses, who were already very good cooks.

Six out of eight men also experienced feelings of discomfort towards the topic of cooking. These feelings were largely based on specific concerns they had about cooking abilities. Two men reported feelings of discomfort over not knowing the cook times of specific foods and one of those men, P2, was also concerned about cooking any food with layers. One example he used to explain this concern was lasagna - if he makes lasagna he doesn't have the tacit knowledge to know how thick or thin certain layers might need to be resulting in some layers being overcooked while others are undercooked. P5 reported that he felt uncomfortable with pairing flavors, as he did not have the tacit knowledge to know what tastes go well together. "I'd rather someone else, you know, put [my meal] 
together that knows what flavors go with other flavors and spices, rather than trying to figure that out myself."

\begin{tabular}{|l|l|l|l|}
\hline Feeling Factors Impacting Cooking Attitudes & Participants \\
\hline \multirow{3}{*}{$\begin{array}{l}\text { Feelings of wavering } \\
\text { confidence or } \\
\text { intimidation }\end{array}$} & Low skill level/lack of tacit knowledge & 3 & $\mathrm{P} 1, \mathrm{P} 2, \mathrm{P} 3$ \\
\cline { 2 - 4 } & Lack of recipe range & 2 & $\mathrm{P} 1, \mathrm{P} 7$ \\
\cline { 2 - 4 } & $\begin{array}{l}\text { Intimidation due to high skill level of } \\
\text { spouse }\end{array}$ & 2 & $\mathrm{P} 1, \mathrm{P} 2$ \\
\hline \multirow{4}{*}{$\begin{array}{l}\text { Feelings of discomfort } \\
\text { towards cooking }\end{array}$} & Not knowing cook times & 2 & $\mathrm{P} 2, \mathrm{P} 6$ \\
\cline { 2 - 4 } & Cooking food with layers & 1 & $\mathrm{P} 2$ \\
\cline { 2 - 4 } & Not knowing how to pair flavors & 1 & $\mathrm{P} 5$ \\
\cline { 2 - 4 } & Lack of variety in cooking abilities & 1 & $\mathrm{P} 1$ \\
\cline { 2 - 4 } & $\begin{array}{l}\text { Worried about serving poor quality } \\
\text { meals }\end{array}$ & 1 & $\mathrm{P} 3$ \\
\cline { 2 - 4 } & Lack of experience & 1 & $\mathrm{P} 7$ \\
\hline
\end{tabular}

TABLE 25 FEELING FACTORS IMPACTING COOKING ATTITUDES (PARTICIPANTS SPECIFIED)

\subsubsection{Feeling Factors in Cultural Probes}

Due to the fact that the cultural probes already included emotion scale prompts, there was no descriptive coding to each individual emotion scale, and the rating provided from the scales were used to compare to other data that was assigned a descriptive code. The only descriptive code assigned that appeared in this section was the 'familiar' code.

Five participants reported familiarity, habit, or routine to be positive influencing factors for meals they prepared themselves. While happy, relaxed, and neutral feelings were reported by all of the participants, feelings of anxiety or frustration were reported on varying levels at least once by five of the participants. P5 reported a small amount of anxiety or stress for photographing his barbecue during the cooking process. P7 reported feeling anxious and a small bit frustrated while making spaghetti with his wife - he cited the cause to be the gooey feeling of the meatball mixture, which he did not like. P3 noted in his lunch log that meal prep does not typically set his mood because his mood is often already set by what he was doing beforehand. 
P2, who was the only participant to prepare breakfast, lunch, and dinner all on his own (and with breakfast and dinner being prepared from scratch) reported the widest range of emotion in his meal journal. For the sake of recognizing any deviations away from daily routine, it should be noted that his wife is typically the primary cook in the household and that P2 took over cooking responsibilities for the sake of the study. P2 prepared pancakes from scratch (a first time experience) alongside eggs, bacon, and coffee and noted that he required advice from his wife for selecting a recipe and again while mixing the pancake batter. High levels of anxiety (rated a 4 on a scale of 1-5 where 1= I am not experiencing this emotion at all and 5=I am mostly experiencing this emotion) and some frustration (rated a 2) were reported during the cooking process of the meal. It was noted that he felt anxious about having all of the items hot and ready to eat at the same time. In contrast to the negative emotions experienced during the breakfast cooking process, $\mathrm{P} 2$ feeling only positive or neutral emotions during lunch (happy, relaxed, and neutral). For lunch he prepared himself a meal that was easy to prepare and familiar to him.

Finally, P2 prepared a stir-fry for dinner. During his interview, P2 had mentioned that he had previously cooked stir-fries and they were one of the few things he felt comfortable cooking due to how forgiving they were to cook. He explained that if the sauce is too thick he could just add a little more liquid and if the sauce is too thin he just needed to cook it for a little longer. As such, he only reported small levels of anxiety (rated a 2) alongside much higher levels of positive or neutral emotions (happy was rated a 5, relaxed was rated a 4, neutral was rated a 3). Additionally he reported enjoying the cooking process despite being tired afterwards and rated the meal itself a 1 (meaning "this meal was one of the best meals I've ever had"). In the additional comments section 
P2 noted that he would cook the recipe again because everyone (his wife, his son, and himself) really enjoyed the dinner.

\begin{tabular}{|l|l|l|l|}
\hline \multicolumn{2}{|l|}{ Feelings Impacting Daily Cooking Experiences } & Participants \\
\hline \multirow{2}{*}{ Familiarity } & $\begin{array}{l}\text { Feelings of familiarity (sometimes described } \\
\text { as routine or habit) }\end{array}$ & 5 & $\begin{array}{l}\text { P2, P3, P4, P5, } \\
\text { P6 }\end{array}$ \\
\hline \multirow{4}{*}{ Frustration } & Poor product experience & 1 & P2 \\
\hline \multirow{4}{*}{$\begin{array}{l}\text { Frustration } \\
\text { Anxiety }\end{array}$} & Having multiple hot foods ready at once & 1 & P2 \\
\cline { 2 - 4 } & Cracking eggs & 1 & P3 \\
\cline { 2 - 4 } & Taking pictures while barbecuing & 1 & P5 \\
\cline { 2 - 4 } & Unexplained & 2 & P2, P6 \\
\cline { 2 - 4 } & $\begin{array}{l}\text { Poor tactile cooking experience (did not like } \\
\text { the gooey feeling of making meatballs }\end{array}$ & 1 & P7 \\
\hline
\end{tabular}

TABLE 26 FEELINGS IMPACTING DAILY COOKING EXPERIENCES (PARTICIPANTS SPECIFIED)

\subsubsection{Feeling Factors in Designer Focus Groups}

When examining data from the focus groups, it was found that there were several chunks of data that discussed emotional connection and its significance to the design process.

These chunks of data were designed were assigned the descriptive code 'empathy' which was eventually sorted into the overarching theme of feeling factors.

As was previously mentioned in 4.3.3, Cultural Experiences in Designer Focus Groups, Designers from all of the groups called for more details regarding the personas' lives outside of food related habits. D2, from Focus Group A, suggested that having more information on lifestyle and daily experience could encourage more empathetic design, which may challenge designers to approach problems differently than they typically would. He explained that in his professional work personas typically provide very targeted information for very targeted demographics with very specific design problems. In contrast, the Carl persona he worked with during this exercise described more of an ecosystem in which Carl lived, rather than just targeted information about Carl or the 
older male population. By embracing the idea of an ecosystem and building out the personas to provide more information about the daily environment of Carl and his routines within this environment there was more potential for designers to emphasize. D6 and D8, from Focus Group C, also noted the importance of the quotes included in the personas, which humanized the personas, therefore helping them empathize with the personas better.

Focus Group C explored a more specific feeling factor, and proposed solutions that build feelings of confidence. It was proposed that by easing older men into cooking with recipes that are easy to prepare and fast, feelings of confidence might be built up as cooking successes are experienced. Similar confidence building may also be possible by introducing new cooking experiences to tools that older men are already familiar and comfortable with, such as the barbecue.

\begin{tabular}{|l|l|l|}
\hline Emotions as a Part of the Design Process & Participants \\
\hline $\begin{array}{l}\text { Call for broader information on lifestyle and daily } \\
\text { experience as a method of encouraging empathy }\end{array}$ & 1 & $\mathrm{D} 2$ \\
\hline $\begin{array}{l}\text { Designers who found real quotes served as a humanizing } \\
\text { factor, contributing to better empathy for the persona }\end{array}$ & 2 & $\mathrm{D} 6, \mathrm{D} 8$ \\
\hline $\begin{array}{l}\text { Designers who recognized the importance of feeling } \\
\text { confident and proposing confidence building solutions }\end{array}$ & 4 & $\mathrm{D} 5, \mathrm{D} 6, \mathrm{D} 7, \mathrm{D} 8$ \\
\hline
\end{tabular}

TABLE 27 EMOTIONS AS A PART OF THE DESIGN PROCESS (DESIGN PARTICIPANTS SPECIFIED)

\subsection{Available Alternatives}

One consideration that was not taken into account when this research began was the available alternatives that may impact the motivation of older men to develop their cooking skills. This theme discusses any data that mentioned a potential alternative to traditional cooking processes. For example, microwave meals are still 'cooked' in the microwave, but do not engage in any handling of ingredients, mixing, or cooking of raw 
ingredients, and therefore would be considered an available alternative. While meal kits, such as Good Food, do require a user to engage in some cooking processes (such as mixing and cooking of raw ingredients), the process is streamlined and designed for convenience, and therefore were also categorized as an available alternative.

\subsubsection{Available Alternatives in Interviews}

The descriptive codes included for the chunks of date in this section include: 'frozen food,' 'pre-prepared food,' 'restaurant food,' 'canned food,' 'store-bought,' 'portioned,' and 'salad kit,' as well as 'food box' All of these descriptive codes were assigned to chunks of data that refer to an available alternative to traditional cooking. During interview seven out of eight participants mentioned some form of available alternative to traditional means of cooking or food preparation.

If I can't order in pizza then I think I'm quite okay with a frozen pizza and, you know, cooking, I don't really count that as cooking, you just put something in the oven; but doing that rather than trying to even make one on my own, I mean, a person probably could, but to me it would be a lot of bother to do it. I mean, really, you know, I'd just rather someone else put everything into it and then leave it up to me to put it in the oven or in Skip the Dishes kind of thing

Explained P5. Four men total discussed frozen foods during their interviews, with P4 and P8 who lived alone being regular users of frozen food products, such as microwave meals. "I've gone to these frozen dinners, the ones you [microwave], they're pretty good. You get a variety of that, and, you know, you buy the odd pie and cookies," said P4. He also expressed that some of the frozen dinners were too large, and therefore created food waste if he accidently bought a brand that made too large of a portion size for him to eat. 
In addition to frozen foods men also discussed salad kits, canned food, and pre-marinated or pre-prepared meats from the butcher.

Meal subscription boxes, such as Good Food, were discussed in three of the interviews.

In all three instances the men showed disinterest towards the product or indicated that the idea of a meal subscription simply wasn't for them. P8 explained that his daughter was a fan of the boxes and would use them, however, he found the meals were too spicy and had too much salt. Additionally, he noted, “I don't have any desire to make anything more complicated," when discussing meal subscription boxes. P3 reported that while he and his wife had tried one of the boxes out, his wife felt she could make better meals on her own and P3 simply had zero interest in the box.

\begin{tabular}{|l|l|l|}
\hline $\begin{array}{l}|l| \\
\text { Available Alternatives to Traditional Cooking Discussed by Older }\end{array}$ & Participants \\
\hline Men who discussed at least 1 available alternative & 7 & $\begin{array}{l}\text { P1, P2, P3, P4, } \\
\text { P5, P6, P8 }\end{array}$ \\
\hline Ordering meals out/ ordering pizza & 3 & P1, P2, P5 \\
\hline Frozen pizza & 3 & P3, P5, P8 \\
\hline Frozen microwave meals & 2 & P4, P8 \\
\hline Pre-prepared meals (Costco, M\&M Meats) & 2 & P2, P5 \\
\hline Dried Chinese food packets & 1 & P2 \\
\hline Salad kits & 1 & P4 \\
\hline Canned soups \& canned foods & 2 & P5, P8 \\
\hline Boxed frozen foods & 1 & P5 \\
\hline Store-bought cookies \& pie & 1 & P4 \\
\hline $\begin{array}{l}\text { Butcher counter pre-marinated/ pre-prepared meats for } \\
\text { the barbecue }\end{array}$ & 1 & P6 \\
\hline
\end{tabular}

TABLE 28 AVAILABLE ALTERNATIVES TO TRADITIONAL COOKING DISCUSSED BY OLDER MEN (PARTICIPANTS SPECIFIED)

\subsubsection{Available Alternatives in Cultural Probe}

The descriptive codes assigned to this section includes 'frozen food,' 'portion,' 'salad kit,' and 'restaurant food.' Similar to the interviews, the descriptive codes relate back to chunks of data discussing available alternatives to cooking to a varying level of detail. 
Six out of seven men lived with a spouse who cooks for them on a daily basis and therefore the men did not have a need for regular use of the alternative products. P4, who did live alone, further emphasized his use of meal alternatives in his cultural probe kit. For dinner P4 ate a microwave meal as well as a salad (made using pre-prepared romaine lettuce). In addition to recording his three meal experiences, $\mathrm{P} 4$ noted that he was looking forward to eating out at restaurants again after the pandemic is over.

The only other mention of an alternative meal option in the cultural probe kits came from P1 who opted-out of using the camera in his kit. As an alternative, P1 decided to record his meals for a week in the section of his journal that was earmarked for recording camera content. Over the course of a week P1 ate lunch out three times (two subway sandwiches and one hotdog from a stand).

\begin{tabular}{|c|c|c|}
\hline \multicolumn{2}{|c|}{$\begin{array}{l}\text { Reported Use of Available Alternatives to Traditional Cooking in } \\
\text { Daily Life }\end{array}$} & \multirow{2}{*}{$\begin{array}{l}\text { Participants } \\
\text { P1, P4 }\end{array}$} \\
\hline Men who used at least 1 available alternative & 2 & \\
\hline Frozen microwave meal & 1 & $\mathrm{P} 4$ \\
\hline Salad kit & 1 & P4 \\
\hline Ordered meals out (Subway, hotdog stand) & 1 & P1 \\
\hline
\end{tabular}

\subsubsection{Available Alternatives in Designer Focus Group}

The descriptive codes in this section include codes for new or reimagined design solutions as well as preexisting solutions. As such, newly proposed or reimagined cooking alternatives received the descriptive code of 'new cooking alternative,' while codes for preexisting solutions included 'medicalized solution,' 'catering,' and 'food box.'

Designers from all of the focus groups proposed a wide variety of potential alternatives to traditional cooking methods, some of which were preexisting solutions and some of 
which were new ideas. Some of the new or reimagined design solutions that were proposed were a chef-for-hire using an app, resized food offerings, redesigned product packaging to accommodate for leftovers, fresh microwave meal options, interactive cooking videos, and restaurant discount programs. Preexisting options that were discussed during sessions included caregiver, catered meals, Meals on Wheels, and meal subscription boxes.

Meal subscription boxes were a particularly popular solution and was the only alternative meal method discussed in all three focus groups. Designers recognized that the meal subscription model could be well suited to supporting older men learning to cook. Meal subscription boxes provide all the necessary ingredients already portioned out and a clear recipe. It was noted by designers in all three groups that subscription boxes would be challenging for anyone with a resistance to technology, but only Focus Group C proposed an analog system of signing up and ordering weekly meals. D7 also pointed out that the boxes might be better adapted for beginner cooks if the ingredients delivered are always pre-prepared on top of pre-portioned and only very basic recipes were provided.

\begin{tabular}{|l|l|l|}
\hline New or Reimagined Design Solutions & Participants \\
\hline Chef-for-hire using an app & 2 & D1, D2 \\
\hline Resized food offerings & 2 & D1, D2 \\
\hline Redesigned product packaging to accommodate leftovers & 1 & D1 \\
\hline Fresh microwave meal options & 1 & D2 \\
\hline Interactive cooking videos & 4 & D1, D2, D3, D4 \\
\hline Restaurant discount programs & 1 & D2 \\
\hline $\begin{array}{l}\text { Meal subscription boxes with technology-free features and } \\
\text { more basic cooking options }\end{array}$ & 4 & D5, D6, D7, D8 \\
\hline
\end{tabular}

TABLE 30 NEW OR REIMAGINED DESIGN SOLUTIONS

\begin{tabular}{|l|l|l|}
\hline Preexisting Options Recommended Supporting Food Activities & Participants \\
\hline Meals on Wheels & 2 & D1, D2 \\
\hline Caregivers who can cook meals & 4 & D1, D2, D3, D4 \\
\hline Catered meals for large group dinners & 4 & D1, D2, D3, D4 \\
\hline Meal subscription boxes & 4 & D1, D2, D3, D4 \\
\hline
\end{tabular}

TABLE 31 PREEXISTING OPTIONS RECOMMENDED SUPPORTING FOOD ACTIVITIES 


\subsection{Nutrition and Food}

Nutrition and food as a theme encompasses any data pertaining to nutritional concerns, choices, attitudes, or opinions.

\subsubsection{Nutrition and Food in Interviews}

The descriptive codes used for this section include 'nutritional concern,' 'healthy diet,' 'supplements,' 'salt,' 'healthy foods,' and 'goodies.' The data within each of these code discussed the topic discussed health in some way in every instance except for the in the 'goodie' code. All the data assigned the 'goodie' code discussed sugary treats, baked goods, or dessert in some way. Only some of the 'goodie' data discussed goodie consumption in relation to health.

Four men in the interviews mentioned nutritional concerns or the importance of nutrition. While P4 was content using microwave meals, he was also concerned about having the right amount of nutrition in his diet as well, and didn't feel he received proper nutrition from his meals alone. As a result he would take vitamins and half a bottle of Ensure each day to help supplement his diet. Additionally, P4 reported that he makes sure not to add any salt to his food due to the high amounts of salt in the microwave meals he eats. A similar concern for higher amounts of salt was mentioned by P8, who explained that one of the reasons he was uninterested in trying meal subscription boxes was because they had too much salt. P3 discussed a reduction of red meat in him and his wife's diet, which, while partially fueled by concern for the environment, was also fueled by the understanding that consuming smaller amounts of red meat is healthier for you. P2 reported that him and his wife are trying to eat a healthier diet as they get older. 
P5, on the other hand, reported that he did not like health foods. When delving into what he considered a healthy food he used the example of preferring pancakes made with white flour to those with brown flour. Additionally, while P5 did report that his daily diet includes vegetables, he does not care for them as much as he would a baked good. "Well [my wife], you know, I give her credit for [my balanced diet] because she makes an attempt to make it kind of a balanced thing, whereas I probably wouldn't," said P5. Six men total mentioned baked goods during their interview. Despite being concerned about his nutrition, P4 also explained that he enjoys goodies - "I believe in a balanced diet, a cookie in each hand." P2 mentioned that while he greatly enjoys dessert and chocolate, he had developed a muscle condition wherein he is stiff and sore if he consumes too much sugar. This condition has helped motivate $\mathrm{P} 2$ to reduce the amount of sugar in his diet; however, he also credited his wife, who makes sure he maintains a balanced diet.

\begin{tabular}{|l|l|l|}
\hline Older Men's Diets in Relation to Nutrition & Participants \\
\hline $\begin{array}{l}\text { Men concerned about the nutritional value of their } \\
\text { meals }\end{array}$ & 4 & P2, P3, P4, P8 \\
\hline Men taking nutritional supplements & 1 & P4 \\
\hline $\begin{array}{l}\text { Men who reported their spouse as helping to supply } \\
\text { their balanced diet }\end{array}$ & 2 & P2, P5 \\
\hline Men who reported a dislike for health foods & 1 & P5 \\
\hline Men who discussed goodies/baked goods & 6 & $\begin{array}{l}\text { P2, P3, P4, P5, P7, } \\
\text { P8 }\end{array}$ \\
\hline
\end{tabular}

TABLE 32 OLDER MEN'S DIETS IN RELATION TO NUTRITION (PARTICIPANTS SPECIFIED)

\subsubsection{Nutrition and Food in Cultural Probes}

Similar to the interview data, the cultural probe data for this section received codes of 'nutritional concern' as well as 'goodie.' In this instance 'goodie' simply referred to any data mentioning a sugary treat, baked good, or dessert, but none of the data behind 'goodie' codes referred to health. 
In his cultural probe kit, $\mathrm{P} 4$ further voiced his concerns regarding receiving proper nutrition that were brought up during the interview. Alongside his breakfast he recorded that he took 1 multivitamin, 1 vitamin C, 1 vitamin D, and $1 / 2$ a bottle of Ensure, a detail that he chose to further emphasize by photographing his collection of supplements (see Figure 8). For dinner P4 ate a microwave meal as well as a salad (made using preprepared romaine lettuce). The salad was added to his meal due to the fact that microwave meals typically do not include anything green.

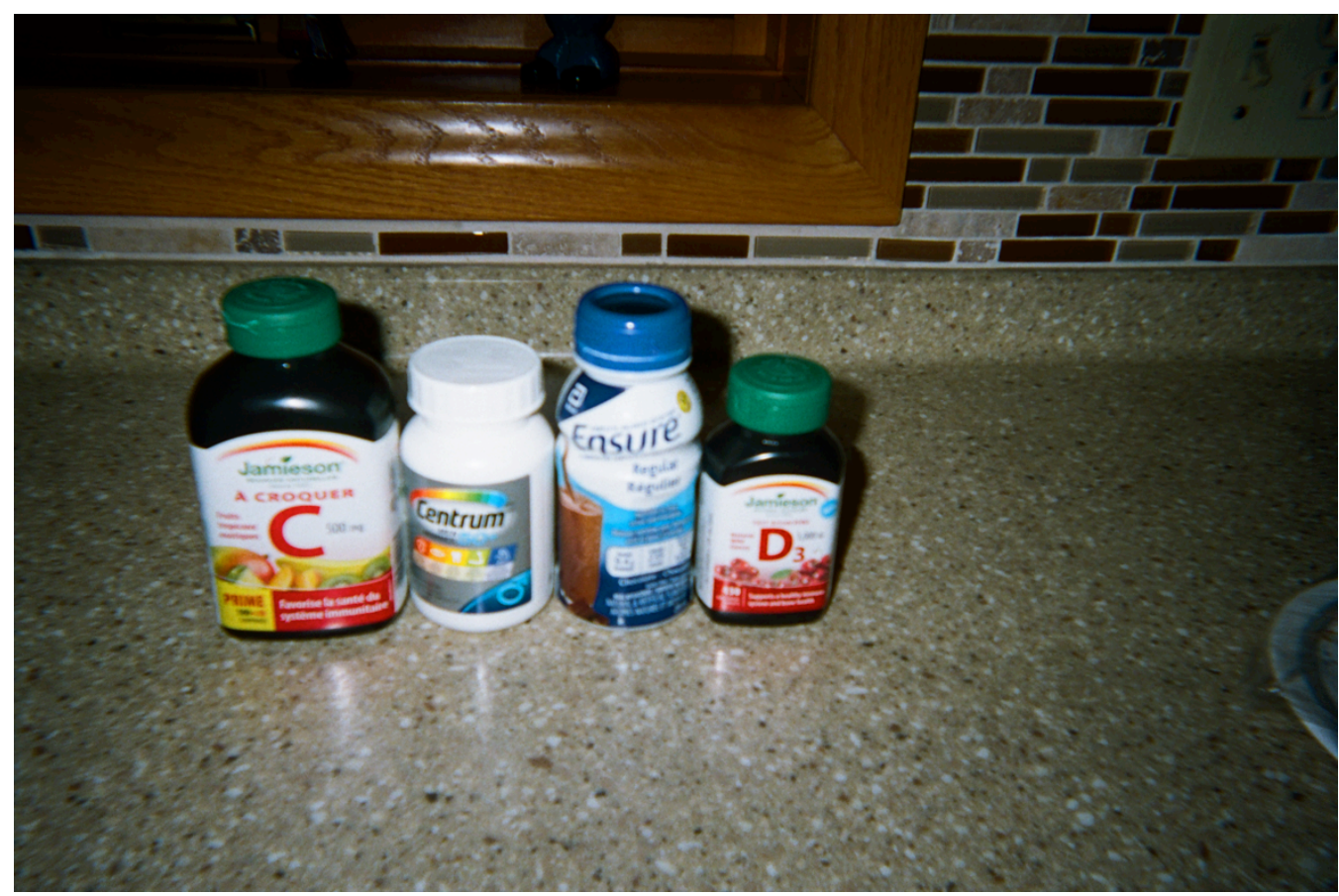

FIGURE 8 PHOTOGRAPH FROM P4's CULTURAL PROBE KIT TITLED "THESE ARE THE VITAMIN SUPPLEMENTS I TAKE TO HOPEFULLY GET A REASONABLE DIET.”

Six men reported having at least one goodie or dessert with either lunch or dinner. Of those six men, three had desserts containing more than one goodie (for example, two of these men ate both a pudding cup and a cookie in one sitting). Two men had desserts at both lunch and dinner.

\begin{tabular}{|l|l|l|}
\hline \multicolumn{2}{|l|}{ Dessert or Goodies in Older Men's Diets } & Participants \\
\hline Men who reported eating at least 1 goodie or dessert & 6 & P1, P3, P4, P5, P6, \\
\hline
\end{tabular}




\begin{tabular}{|l|l|l|}
\hline with either lunch or dinner & & P7 \\
\hline Men who ate 2 goodies in 1 sitting & 3 & P1, P4, P6 \\
\hline Men who ate a dessert with both lunch and dinner & 2 & P4, P7 \\
\hline
\end{tabular}

TABLE 33 DESSERT OR GOODIES IN OLDER MEN'S DIETS (PARTICIPANTS SPECIFIED)

\subsubsection{Nutrition and Food in Designer Focus Groups}

While nutrition wasn't a major focus in any of the groups, it was briefly discussed within

Focus Group A. During the discussion segment of Focus Group A, D2 theorized that one

reason the persona, Carl, might show a concern for his nutritional health, but still eat

plenty of desserts may be a result of finding comfort in food. The Carl persona is a

widower who lives alone. Due to the context of this theory, nutritional health and

struggling to balance diet, this discussion point received the descriptive code of 'dietary

challenges,' which falls within the theme of nutrition and food. 


\section{Chapter 5: Discussion}

Largely due to traditional household structures, which older generations of people living today have subscribed to throughout their lives, older men are often detached from cooking processes. Older men with little to no cooking abilities may struggle to adapt in scenarios where their spouse or partner are no longer able to prepare household meals and the task of preparing their own meals falls to them. The purpose of this qualitative preliminary study was to better understand how design could support older men with little to no cooking skills in adapting to potential scenarios where they may need to be responsible for their own meal preparation in order to remain independent.

\subsection{Cooking Interest \& Experience}

The first theme in this research helped to organize the data that set the tone for the study; what sort of experiences with cooking activities did study participants have; were participants interested in learning to cook; what were the daily food experiences of the participants; and how did daily food experiences relate back to interest levels? Based on the literature review that was conducted when first approaching this research, it was understood that older men were a largely ignored demographic when it came to topics of cooking due to the influences of traditional gender roles, which historically have determined cooking to be a feminine household role (Sidenvall et al., 2000. \& Charles \& Kerr, 1988). As such, the researcher approached this study under the assumption that one of the greatest design challenges that would need to be addressed in this research would be a lack of experience and a resulting need for skill building support. During the interview stage of research it was revealed that while lack of experience does present a challenge (seven out of eight men reportedly described themselves to only have limited 
or basic experience), interest (which had not been a previously considered factor) revealed itself to also be a prominent factor as well.

Five of the men, or over half of the participants, in the study were simply not interested in learning how to cook in any capacity. This information was a catalyst for reconsidering how the research questions would be approached and how the data collection methods following the interviews were designed. Rather than developing a cultural probe that encouraged older men to partake in a cooking activity, an idea that was originally toyed with, the probe prompts were instead written with the intent of exploring the older men's current daily activities pertaining to food and meals. For the design focus groups, personas were designed to reflect the varying levels of interest or options that older men had towards cooking (i.e. while the Liam and George personas reflected on interest outright, the Carl persona, who lived alone, did not have a choice but to find a way to feed himself if he wanted to remain independent, regardless of interest). In designing interventions to support the facilitation of positive cooking experiences for older men, considering a broad understanding of what is a cooking experience and acknowledging the potential disinterest men have towards cooking may help to avoid alienating men who are disinterested or uncomfortable with cooking. The recommendation for this consideration intends to support the six men in the study who reported feelings of discomfort cooking, but who all still reported participating in daily cooking experiences to at least some degree. Additionally, this consideration aims to support men like P4 and P8, who both reported a disinterest in learning to cook, but who were also required to look after their own daily sustenance. Design solutions might aim to explore ways to gain the interest of men, but might also aim to develop alternative 
cooking methods to support disinterest - both of these approaches have validity as long as potential lack of interest is not ignored. These interest traits may be connected to the reflective level of processing introduced by Norman (2004) - after all, interest may be connected to experience and cultural views. As a result, a reflective design lens, which considers how design solutions could be contemplated or scrutinized based on past experience and interest, might help to produce design solutions more readily accepted by older men (Norman, 2004). P4 and P8, who had no choice but to prepare their own meals, still avoided traditional cooking methods when they could. Kullberg et al. found a similar attitude amongst men who were inexperienced cooks (2011). The men who were inexperienced cooks, but needed to cook out of necessity, would do so while seeking ways to minimize their time spent cooking (Kullberg et al., 2011). This data combined with the information from Kullberg et al. may serve to highlight that if someone is not interested in doing something, in this instance cooking, they will try their best to find a work around.

Additionally, while the design of kitchenware might further support older men's independence, there are also many possible solutions that better suit potential disinterest in cooking that do not involve the design of a physical product. The lack of interest in cooking became apparent by the time the first research method was completed, and as a result the fields of design that were initially considered relevant to this research (which at the time were product design and design involving healthcare) were reconsidered. Keller et al.'s study (2004), which successfully interested and engaged older men in a cooking class, helped to indicate that service design was an important field of design to consider. Service designers were not only added to the list of relevant design experts for the focus 
groups, but also impacted the makeup of the sessions as well. For the mind-mapping activity Mural templates were created, including three prompts to urge designers to consider the range of design that might produce possible solutions - the prompts simply read: Products? Services? Other? The inclusion of service design when approaching the focus groups marked a shift in understanding about what kind of design outcomes might support independence in aging male populations. However, there is no tangible proof that the service designers who participated in the focus groups produced work that was notably different than the rest of their design peers. This lack of difference may be the result of the service prompt - which produced many proposed solutions by all of the designers. One of the most well-rounded design solutions, which were produced by Focus Group $\mathrm{C}$ and a major discussion point during the discussion segment of the session, was a service design - a cooking class for older men. Considerations into whether the solution would not only support older men learning to cook, but also be capable of motivating participation and engaging men in a way that interested them were factors that impacted how well-rounded the solution was considered. The cooking class solution also considered intimidation factors such as time, meal complexity, and spouses who are more experienced cooks. Similar to Keller et al.'s (2004) cooking class for older men, Focus Group C also proposed a cooking class for older men. In the name of interest and making their proposed class appealing to older men, Focus Group C ideation exercise included embedding hobbies or other enjoyable activities (such as watching a sports game and drinking beer in order to create a more social, leisurely environment) into their cooking class concept. 
Low interest from older men may serve as a major barrier for designers approaching the design problem of supporting older men learning to cook. Designers should consider factors such as what preexisting cooking experiences do older men have when gauging what solutions may be appropriate. Due to the older men's low interest, designers may also want to consider what factors could motivate older men to engage with their solution. With so many cooking alternatives on the market designers may want to consider how these alternatives exist within the realm of cooking experiences in order to compete with the preexisting alternatives.

\subsection{Gender Dynamics}

Gender dynamics, or traditional gender roles, demonstrated an impact on the opinions and experiences of older men cooking, as well as the approaches designers took when designing supporting recommendations. Gender Dynamics as a theme includes data regarding specific gender dynamics, such as the dynamic between individual older participants and their respective wives, and data speaking to more generalized dynamics, such as the history of gender dynamics as a whole.

A pattern that emerged from the gender dynamics data in the interviews and cultural probes related to how present-day traditional household roles impact daily rituals. When aiming to support the development of new skills, a designer may want to first consider how preexisting daily rituals might help or hinder this process. This consideration falls in line with Lévy, who explains that rituals are significant experiences in people's lives that are considered of high value to the ritual practitioner (Lévy, 2015., \& Lévy, 2018). Why do those daily rituals exist? Are the daily rituals positive and for what reason would the practitioners of the ritual want to change their preexisting rituals? Further reflecting on 
the meaning and value assigned to current cooking practices, as is recommended by Lévy and Hengeveld (2016) when examining daily ritual design and design support, helped to highlight the important role rituals already play in the older men's lives, and helped to understand what design solutions may or may not be successful. For the six married men who participated in the study, food rituals were already in place wherein their spouses would cook a meal and the men would lend support in other ways, such as cleaning up the kitchen or setting the table. P3 noted that he was happy and grateful to clean the dinner dishes as he had received a great meal via his wife as a result of the dirtied dishes. While building new cooking skills and abilities might support married men to be more independent, aiming to support independence makes little sense because they don't live independently, they live jointly and their daily rituals reflect this joint living.

Furthermore, for men who are not interested in learning to cook, preexisting daily rituals in which their wife provides their meals is a much loved daily ritual as highlighted by the five men who talked about their wife's superior cooking abilities in the interviews.

The history of gender roles may also have an impact on the personal kitchen dynamics of older men and their wives (Charles \& Kerr, 1988., \& Sidenvall et al., 2000). Educational opportunities, such as home economics class, have historically been viewed as feminine; as a result, historically many men likely did not receive the same educational foundation in skills such as cooking. The impact of past gendered educational opportunities were touched on by P2 who explained, "I know [my wife] learned how to cook bread at school and learned how to do basic meals. I never had that experience." During the focus group sessions, designers recognized that traditional gender roles resulting in lower skillsets might negatively impact the independence of men whose wives pass away before them. 
Regardless, preparing for the hypothetical death of a spouse is an unlikely motivator for learning to cook for most (unless perhaps the death is not so hypothetical and a long illness is involved). While the independence factor makes much more sense for older men who are living alone, it does not change the fact that often times there have been historical gender dynamics that have impacted their skills and attitudes towards cooking. Additionally, based at least in part on these histories, there are often still rituals in place that must not be ignored, such as $\mathrm{P} 4$, who described his late wife as much faster and efficient in the kitchen, who now sought quick-to-prepare meal solutions himself. Despite traditional gender dynamics, wives may also act as a motivator for some men to want to learn how to cook. While the data presenting women as a barrier for older men to learn to cook, especially in the instances where they were presently cohabitating with their wives, it must be noted that this data did not present the perspective of the women involved in these cooking rituals. Due to the word-of-mouth nature of the recruitment for this study, the researcher had contact with some of the wives. Two wives volunteered their husbands for the study - one of these participants even mentioned it in his initial email to the researcher - "Hi Samantha, [my wife] has apparently volunteered me for this study. Please use this email to reach me."

In the process of organizing pick-ups of completed cultural probe kits, the researcher spoke to two wives (one was a wife who had also voluntold her husband to join the study) who were very excited to tell me that they had told their husbands that the kit intended for the men participating to be involved in the cooking process. Sidenvall et al. described the older women in their study as motivated to cook as a method of caring for others, with motivation diminishing when only cooking for themselves (2000). While this 
study did not have ethics approval to collect data from the wives of participants and therefore the wives were not focused on enough to confirm or deny these findings, wives' actions may imply that while women do participate in traditional household roles and care fore their husbands, they might be eager for additional support or relief from their own daily cooking rituals, which might fuel men to become more involved.

By acknowledging and understanding preexisting daily rituals and the potential impact of gendered roles, designers may be able to develop cooking skill-building solutions that older men are motivated to use. For example, when designing solutions that acknowledge a preexisting ritual wherein a wife is the primary cook it would likely not be suitable to seek to encourage men to take over cooking responsibilities entirely. In contrast, what may be suitable, are solutions that encourage men to lend support with the cooking process - thus building skill while also acknowledging the ritual dynamic of the wife as primary cook.

Another consideration in relation to gendered dynamics is how those dynamics may influence how cooking is defined by men. For example, all of the men prepared their own breakfast, but all of the married men identified their wives as the primary household cooks. Similarly, Charles and Kerr explained that the meals women more commonly prepare, such as dinner, are typically considered the "proper meals" in contrast to the meals that men prepare (1988). In order to encourage men to learn new cooking skills, how they define their preexisting cooking skills, no matter how basic these skills are, should be understood and acknowledged. Developing methods that acknowledge preexisting skills and utilize these preexisting skills to expand upon the definition of what 
is considered "proper cooking" might serve to encourage and build confidence in learning a new skill.

The final consideration to be noted in regards to gender dynamic would be the design of physical products. As D5 pointed out, the look of a product may be important for both its aesthetic as well as helping to separate cooking from the idea of feminine task. Similar to how the comfortable and good-looking appearance of the Oxo Good Grips Vegetable peeler has engaged a broad audience of people, attractive kitchenware that is not outwardly feminine may be more attractive for older men and a broader audience of users, aiding in the goal of separating cooking from the idea of being a feminine task (and therefore encouraging men to become more engaged with cooking tasks) (Cagan \& Vogel, 2001).

Traditional household roles, which assign cooking as a feminine task, may be factored in to the design process in multiple ways (Charles \& Kerr, 1988., \& Sidenvall et al., 2000). First, traditional household roles impact daily rituals. Married men typically participate in joint daily rituals wherein both themselves and their wives play a role in the ritual. In regards to food, wives typically play a pivotal role in these rituals, which may be important to consider when designing for older men cooking. In addition to the ritual factor, traditional roles impact older men's cooking skills, attitudes, and opinions. Redefining what is considered to be a cooking experience may also help older me to build confidence in their preexisting skill level. Considering the aesthetic appearance of physical designed products may also impact attitudes. Kitchenware with an aesthetic appearance ranging from gender-neutral to more masculine may be more inclusive to a broader population of cooks, including older men. 


\subsection{Cultural Experiences}

Cultural experiences encompasses any data relating to how social factors or other enjoyable activities impact the way daily life is experienced, such as social experiences, networks, and special meals.

Social experiences outside of cooking experiences seem valuable to consider in order to understand how positive cooking experiences may be facilitated for older men.

Additionally, how enjoyable experiences unrelated to cooking often embed themselves within food-related activity should be considered. For example, social experiences may serve as a major motivating factor when integrated into cooking experiences. Humans are naturally social creatures, which is evident within the data by the fact that all the men highlighted social food experiences as positive or important food experiences in some way or another. These social experiences, such as a family gathering in the evening to talk about their day, or two spouses enjoying a comedy show to distract from heaviness of the global pandemic could still happen without food, but they don't - food is the central factor, it is the thing that gathers the participants and their wives together. Playing into the social aspects of cooking may build off on past positive experiences, which were seen to elicit positive attitudes and willingness to try new but related experiences (such as the man who had watched a Sunday roast being made so many times he felt willing and confident to try to make one on his own). Smith and Ryan (2016), as well as Svanborg (1984), acknowledged that the innate sociality of human beings is an important factor to aging positively.

The designer participants also predominantly gravitated towards social solutions; although most said they required more information to understand their persona's interest 
or engagement in social situations. There were 18 types of social solutions proposed and some of the types of solutions were suggested by multiple groups, making for a total of 21 proposed social solutions across the three focus groups (see table 19 in chapter 4.3.3 for more details). The example of P2, who cooked dinner by scratch all by himself, might additionally showcase the importance that social influences have on attitudes towards cooking. In his journal records he rated the meal a 1 (with 1 being described as "this meal was one of the best meals I've ever had) and noted that he would cook the meal again because everyone (he ate the meal with his wife and son) really enjoyed the meal. This rating and comment may imply that a social factor - his wife and son eating the meal with him and complementing it - was a contributor to his satisfaction. This example may also help support Daniels et al.'s (2012) finding that people who attach social significance to their cooking habits (and who are not rushed in their daily lives), are more likely to perceive cooking as an enjoyable leisurely activity. These social experiences or enjoyable activities may also fall into the realm of the reflective level of processing, as well as the behavioural level (Norman, 2004). Like interest levels, social activities and enjoyable activities are experiences that may impact how something is reflected on and considered (Norman, 2004). These activities may also be connected to pleasure, which relates back to the behavioural level that Norman proposes and is impacted by calculating qualities at the reflective level (2004).

Enjoyable experiences outside of the realm of cooking, such as social experiences, may embed themselves into the cooking process or food experiences. In fact, social experiences within this context already exist, with men from this study showcasing embedded experience as well received and warmly regarded. As such, these experiences 
may, as was recommended by designers in the focus group sessions, act as a major motivator for positive cooking experiences for older men.

\subsection{Technology}

How current abilities and skills, such as technological literacy, impact the lives of older men also act as contributing factors to the results of this study. However, designers must be careful when approaching this topic to take the time to research and come to understanding what the actual needs of older men might be versus what the stereotypical vision of an older person's needs might be. Designers must be careful not to perpetuate socially constructed stereotypes, such as the idea of elderly people as helpless, dependent, or frail, as was forewarned by Pelham and Clark, and Fisk $(1986,1986)$. Only one of the men involved in the study, P8, was uncomfortable with technology and, as such, only one of the personas designed for the focus groups made mention of low technological literacy. P3, on the other hand, who expressed a high interest towards technology, showed that there is a range of technological abilities and skills amongst older men. In the absence of this information Focus Group C expressed concern about tech literacy being a missing detail, and ideated with the idea that all personas may have unaddressed issues with technology. Since all the men in the study reported having no physical barriers, no persona was developed mentioning a physical barrier - in the absence of this information one designer expressed concern about what accessibility needs might need to be addressed, likely because society has created an image of all older people as having accessibility needs. While developing inclusive supports is always a positive addition to any product, placing too much focus on needs that are not present may instead create an aversion to that product, where men feel it is simply not for them based on their physical 
capabilities. Understanding needs that emerge from research findings may confirm certain stereotypes, however most of the men involved in this research were relatively fine with using digital technology and only one, P8, was not. In this instance, if resistance to technology is not considered when designing supports, P8 likely may not be attracted or engaged with the designed support.

Designers should be conscious of socially constructed stereotypes and be careful not to perpetuate these stereotypes. Instead, designers may want to consider the potentially wide range of abilities found amongst older men and look to design solutions that are inclusive to a range of skills.

Personal Note from the Researcher... Throughout my work on this thesis, I couldn't help to think of a personal experience I had while working at my local Apple store several years ago. It was the year that the Apple Watch came out with fall detection and there was an influx of older people and their families coming into the stores to look at the device. One customer, an elderly woman, explained to me that the Apple Watch appealed to her because it now did the same thing as life alert, but wouldn't make her feel old the way life alert would. The same might apply to available alternatives to cooking - after all, when being old is viewed as a negative (as it often is in North America), then who would want to be viewed as old (Angus \& Reeve, 2006)?

\subsection{Resource Allocation}

Resource allocation, while very closely tied to cultural experiences due to its focus on hobbies, was separated into its own theme due to the important role it seemed to play in the men's preexisting motivation or lack of motivation to learn to cook. The data related 
to this theme highlighted time and food as resources and illustrated how the allocation of those resources directly tied back to food and cooking.

Daniel et al.'s claim that men show time preferences towards hobbies more so than household tasks proved to be true in the case of many of the men participating in this study (2012). P1 and P3 reported feeling that the time they would need to spend on cooking a meal is better spent on doing other things. Additionally, P4 reported time constraints existed in his cooking regime simply because he does not want to spend the time planning a meal and cooking it. While a little different to the other three men, P7 and $\mathrm{P} 8$ both recalled prior to their retirements making rushed meals after work because they were tired.

As mentioned in the cultural experiences theme, understanding what enjoyable activities are for older men outside of cooking may be important to the design process. More specifically to resource allocation, understanding the hobbies and activities deemed worthy of time allocation by older men might help designers understand how these activities could be integrated or acknowledged in order to earn cooking activities their own time allocation as well. For example, in relation to the men's cooking group proposed by designers and discussed in 4.2 .3 , social community as well as other interest factors such as beer or a sports game might serve as interest for men to join the group and may motivate men to continue to allocate time every week to joining the group. As result, men would not only allocate time towards activities they already enjoy doing, but also towards building cooking skills. As mentioned in section 5.1, the potential success of this idea could be supported by looking at Keller et al.'s cooking class for older men, in which participants of the class reported enjoying the sociable qualities of the classes, as 
well as associating cooking with enjoyable activities after the completion of the classes (2004). This idea of embedding hobbies within skill building opportunities was also mentioned by one of the designers in this study's focus groups; D8 described working on a project to encourage young girls to learn computer science programing where similar hobby embedding was explored as a method of attracting girls to programming while not forcing them to choose between building a skill and the activities they enjoyed. Perhaps once cooking skills are more developed there might be less concern for food waste, as was the concern for P3 and P5. Understanding and focusing on tools that are already deemed worthy of time allocation by older men, such as the barbecue, might also be beneficial for kitchenware design. As was recommended by D7 and D8, who examined the George persona, men who are already confident in using their barbecue, might be open to learning new ways they could use it. This idea might be supported by Kullberg et al.'s findings that men who were experienced in cooking associated it as an enjoyable activity (2011). As a result, considering how preexisting tools are already used might encourage designers to consider how these tools might be built upon in order to expand on variety of cooking experiences using time that is already allocated towards cooking. For example, D7 and D8 suggested that for men who already allocate time towards barbecuing, introducing barbecue tools that help roast vegetables or even bake bread might encourage men to expand on their cooking experiences.

Time and food as limited or precious resources may be a factor that impacts men's openness to developing new cooking skills. Developing an understanding of the hobbies and activities that are perceived as worthy of time allocation may help designers to 
develop solutions that are appealing to older men, and therefore more likely to be successful.

\subsection{Feeling Factors}

The data from the interviews that explored feeling factors revealed that feelings of low confidence in their cooking abilities and discomfort towards new cooking tasks impacted older men's ready willingness to build their cooking skills and become more involved in daily cooking routines. Some of the reasons these feelings developed in relation to cooking are due to a lack of experience, intimidation, and/or negative history. P4 and P8, who prepared their own meals on a regular basis, were the only two participants who did not report any of the feelings of intimidation, lack of confidence, and/or discomfort. This contrast in feelings with those of the men who prepare their own meals on a regular basis may be the result of a discomfort in the unknown or a lack of familiarity for those with less experience. Kullberg et al. (2011) found a similar result wherein men who were inexperienced cooks tried to avoid cooking and showed little to no interest in it. During the cultural probes method there was less data regarding discomfort or confidence, likely due to the fact that most men who cooked did so in a manner that was already familiar and comfortable to them (i.e. microwave meals or using the barbecue). Working with empathy, as D2 pointed out, is important in considering how human factors, such as emotion, play into not only what forms of designed support while cooking may be needed, but also whether older men may feel interested, motivated, and/or empowered to use those supports. While design methods such as positive design or emotional design may contribute towards developing products or services that elicit positive responses and long-last use for people already shopping for a specific product or 
service, these design methods don't really touch on how preexisting negative experiences and opinions of oneself might impact whether an individual would even consider using a product or service (Norman, 2004, Desmet \& Pohlmeyer, 2013). For example, when considering the balance of pleasure, personal significance, and virtue in the design of a cooking product for older men - whether the older men will consider the product pleasurable to use, aligning with personal goals, or enabling of virtuous behaviour is all dependent on whether the men first feel confident and capable to pick it up, turn it on, or use it in the first place (Desmet \& Pohlmeyer, 2013).

Interacting with personas may have also had an impact on the emotional and empathetic lens that designers approached the Mural activity with. Designers from all three focus groups called for more information on hobbies, social experiences, and/or social networks outside of the realm of cooking experiences. This call contrasted to Nielsen (2019), who stated that the focus of personas should be on both understanding end users and understanding the specific tasks or processes that involve the personas and the design problem at hand. Designers made this call because they saw value in understanding how daily experiences and enjoyable aspects of older men's lives may impact or even serve as motivators to cooking. D2 described the addition of broader information to the personas as building an ecosystem. D2 believed that understanding the full ecosystem of the persona would allow for a fuller understanding of the persona's life, allowing for designers to make deeper connections and more suitable recommendations. Despite the call for more information by all of the focus groups, only Focus Groups A and C appeared to make an empathetic connection to the personas (Focus Group C to a higher degree than Focus Group A) that Nielsen (2019) describes as a necessary factor to a 
successful persona. In both instances personal comparisons were used in discussion, however Focus Group $\mathrm{C}$ was the only group to make these connections throughout the discussion, while Focus Group A only did so on two occasions. The call for more information in of itself may, however, imply a certain level of empathy as it might mean that designers are thinking beyond the persona and making connections to a bigger picture.

For older men, inexperience in cooking may result in lower levels of confidence and higher levels of discomfort. Taking an empathetic approach to designing for older men cooking may help to acknowledge these negative feeling factors as well as open up the designer to considerations such as interest, motivation, and empowerment. While preexisting emotional design frameworks may help to guide future design, alone these frameworks don't necessarily provide guidance into examining how past experiences and feelings may impact outcome. The use of personas can support these emotional frameworks in the context of not only evoking empathy, but also prompting designers to consider the past and present influences that may either create barriers or provide support towards the success of a designed solution.

\subsection{Available Alternatives}

A long list of available alternatives to cooking already exist within the world, and were discussed in interviews, such as the microwave meals used by P4 and P8, who both live alone. Available alternatives were not discussed with the same frequency in the cultural probe data as they were in interviews due to the fact that the cultural probes recorded daily meal experiences in contrast to interviews where the alternatives were discussed within a much broader context (i.e. foods men might feel confident preparing 
already was a context in which frozen foods were discussed in some interviews). P4, who had no choice but to cook during his daily life, communicated through the cultural probe just how much he depended on microwave meals as an available alternative. P1 was the only man participating in the cultural probe who did not prepare his own lunch and stated in the interviews that he typically relied on his wife to do so for him. In the cultural probe kit he recorded purchasing his lunch on some days as an alternative to his wife preparing it. The lack of mention of available alternatives by the majority of participants in the cultural probe kits may imply that the best available alternative to cooking is simply having a spouse who is willing to do the cooking - an alternative that is not only very gender skewed, but also might prove problematic to some in the future. As defined at the beginning of chapter 2.5 , everyday rituals are valued on an experiential level and take on a higher meaning (Lévy, 2015., Lévy \& Hengeveld, 2016., \& Lévy, 2018). While positive cooking experiences may be able to facilitate rituals, routines are also important to consider when designing to support cooking practices. Routines are regular experiences that serve to fulfill a need or a want, typically with a degree of efficiency (Lévy, 2015). Due to the data related to lack of interest and motivation, available alternatives that may cater more towards supporting routine rather than ritual might need to be considered for those unwilling to cook. Access to a variety of healthy meals that support independent living and high quality of life can be a goal for both cooking experiences and alternatives to cooking experiences.

In order for an alternative method to be successful, it must consider traits such as taste, lifestyle or cultural experience, and product reputation. While designers across all groups agreed that meal subscription boxes might be a healthy way of providing older men with 
a more streamlined and easy way to prepare a meal with fresh foods, the men who discussed subscription boxes in their interviews were not interested. Examining the potential experience of an older man with low cooking experience using a meal subscription might give insight into why there was the contrast between the designers recognizing subscription boxes as a valuable solution and older men's negative perceptions. Multisensory experiences might play a factor into this disinterest. While meal subscription boxes aim to streamline the process, they might not do so in a way that is ideal for the beginner cook. Is the first visual of opening the meal subscription box overwhelming? Meal subscription boxes come in a large box with many different pieces, and the recipes can be one-two pages long with lots of text. How will the process of cooking engage multiple senses and cognition? Balancing the timing of different foods cooking as well as their associated sounds may also be a part of this process. What does bring to a boil or reduce to simmer sound like? Can simmering be heard away from the stove while chopping other ingredients, or does the pot need to be watched? If one dish requires 20 minutes to cook and another requires 10 minutes, is it overwhelming to keep track and have all the foods ready at the right times? Taste might also be a large factorwhile only P8 voiced concerns about subscription food being too spicy and salty, P1 and P6 mentioned a lower tolerance for spice and P2 found food much richer, all because of aging, as well as a preference for simple, basic foods ("I'm a simple person - meat and potatoes" explained P6). In contrast, subscription boxes, which often introduce new spins on recipes and occasionally unique ingredients, might appear overly complex and may not appeal to the tastes of older men. Developing an understanding of how all these sensory factors may play into cooking alternatives, such as meal subscription boxes, may 
help designers to develop cooking alternatives that support adaptability and increase potential enjoyment older men may have while using the designed product (Schifferstein, 2011., \& Ranne, 2019).

Compared to the meal subscription boxes, microwave meals come in a large variety and often offer blander 'classic' meals that would be considered familiar to older men (such as chicken, gravy, and mashed potatoes). The microwave meals provide the guaranteed simplicity older men feel comfortable with, but do not necessarily offer the nutritional value P4, a regular user, sought. Similar to what was discussed by Short (2006), Microwave meals leave the meal-taker at the mercy of people fueled by financial gain, resulting in meals with lower nutritional value (i.e. high in sodium with few vegetables). Lifestyle or cultural experience traits are also important to consider. Microwave meals are 'analog' in comparison to meal subscription boxes, which require the user to be comfortable in online environments. It is important to note that despite the lack of technology involved in microwave meals, they are not exclusively used by the elderly and are also used by a variety of demographics as well. Meals on Wheels was not mentioned at all in any of the interviews or cultural probe kits filled out by older men, which might relate back to product reputation and the points made by Pelham and Clark (1986), and Fisk (1986), that domestic care services unnecessarily stereotype older people as dependent or helpless.

Older men already utilize a variety of cooking alternatives. Microwave meals provide simplicity and ease of use, but are lacking in nutritional value. Wives as primary cooks may be another alternative for some men. While a wife is likely much more inclined to provide meals with decent nutritional value, this alternative may be problematic to the 
wife if she wants support or for the older man if his wife becomes unable to fulfill this traditional role in the future. When considering the design of available alternatives a multisensory approach might support the design of solutions that are positively received by older men.

\subsection{Nutrition and Food}

While more research would need to be conducted to better gauge D2's theory of unbalanced diet due to comfort seeking behaviours, lack of nutritional education may be another theory that may explain the behavioural insights from this study. P4 showed a drastic contrast in his nutritional habits - on one hand he has cut out added salt from his diet and takes additional supplements, all in the name of health; but, on the other hand, he eats several goodies or dessert-type foods throughout lunch and dinner. P4 also mentioned that prior to his wife's passing she was the primary household cook and took on all meal planning and preparation work. This history combined with P4's unbalanced diet today might imply that he does not have the nutritional education needed to fully understand how to support his nutritional health. Nara et al.'s study of nutritional education of African American adults living with chronic disease found that nutrition education classes helped to improve healthy cooking and eating behaviours (2012). The same might apply in the case of someone like P4, who historically has had no need to learn or develop nutritional knowledge. This gap in knowledge might further be highlighted by P5 who not only credited his wife for his balanced diet, but also outright stated that he would not have a balanced diet if his nutritional health was solely up to him. 
Knowledge pertaining to nutrition and building a nutritionally balanced diet might be limited but of interest to older men. Integrating nutritional education or supports into a designed solution might therefore appeal to older men. Designers might want to consider what sort of balanced diet would be well received by older men - considering six out of eight men discussed goodies or desserts during their interviews, it may be beneficial to consider how some treats may fit into a designed solution supporting a balanced diet.

\subsection{Interest as a Support for Designer Empathy}

Interest was only overtly discussed by Focus Group C, who received the Liam and George personas, which were the only personas to outright mention potential interest in learning to cook. The addition of interest as a fact may have helped humanize the personas for the group working with them, resulting in a higher level of empathy - all of the designers in Focus Group C placed a large emphasis on the interest factor and examples from personal experience were used to justify why certain solutions may be successful. Of the three groups, they used the most personal examples to connect with the personas, which might imply that a higher level of empathy was used when proposing solutions to support the personas. While these designers produced the least amount of solutions of any of the paired groups, the solutions they produced were more wellrounded and considered not only whether men might be able to use the solution based on skill and comfort level, but whether they'd be willing to try it and what would motivate them to continue to use the proposed solution. While many of the other proposed solutions from the focus group sessions hold potential to be well-rounded ideas, these ideas were not fully formed enough to know whether they fully succeeded at supporting emotional reactions, such as those proposed by Don Norman (2004). The most well- 
rounded idea produced by Focus Group C, the cooking class for older men, may arguably play into all three of Don Norman's (2004) aspects of design levels (visceral, behavioural, reflective).

Making the class for men only and proposing to teach simple recipes might acknowledge gender dynamics and appeal to older men on a visceral level; the class may cater to historical discomfort and lack of skill in order to attract older men on a more reflective level. The use of positive social experience and hobbies, such as watching sports, might appeal on a behavioural level, adding to older men's experience of enjoyment from attending the class. Last, if the recipes made in class are carefully selected to cater to the tastes of older men, then the class might appeal on a reflective level, wherein memories are evoked.

Unfortunately, due to the limited sample size of the Focus Groups, data patterns regarding whether the addition of interest factors might contribute higher levels of empathy or more well rounded solutions.

As previously mentioned in section 5.6 Feeling Factors, designers from all three of the focus groups also called for more information on the details of the personas' lives outside of just their food related habits. The general consensus was that a broader sphere of information about daily routines, hobbies, and social networks would help designers better understand what each man does with his time and what motivates him.

\subsection{Limitations}

It is easy after the completion of a study to identify factors that could have contributed to better results. In this study the limitations fall into three categories COVID-19 restrictions, reflections about the process, and sample size. 


\subsubsection{COVID-19 Restrictions}

This study was conducted during the Covid-19 global pandemic, which placed research limitations related to both sample size and variety. Aging populations were flagged as atrisk during the Covid-19 pandemic and at the time in which this research began it was reported in United States that every eight out of ten Covid-19 related deaths were individuals 65 years of age or older (NCIRD, Division of Viral Diseases, 2020). The quarantine and isolation measures put in place to protect at-risk populations resulted in difficulty recruiting older men for this study. The majority of men were recruited through digital means, however a select few were recruited through word-of-mouth (the researcher discussed the study with various people who had connections to older men in their communities).

Additionally, the pandemic also placed limitations upon the research methods used to conduct the preliminary study. No in-person methods, such as ethnographic research methods could be used. The comfort levels of older people working on the study also needed to be considered - integrating online tools such as Mural, a digital mind mapping tool, may be realistic to expect designers to be relatively comfortable using, but might not be realistic to expect older people with no previous experience to be comfortable using. Due to the small sample population size (eight older men and eight designers participated in total) this research can only be categorized as a preliminary study. The categorization means that while the study was able to contribute to a foundation of knowledge by identifying key themes about older men cooking, further research with larger sample sizes may contribute to more rigorous findings. 


\subsubsection{Reflections about the Process}

The interviews conducted with older men consistently accomplished what they intended to do - provide data contributing to building a foundational understanding of older men's lived experiences pertaining to food and cooking abilities. While a variety of different experiences and perspectives were shared during interviews, the use of the same questions throughout interviews allowed the direction of conversation to remain relatively similar, making it easy to compare the data collected from each interview during the coding and analysis stage.

While the data from the interviews provided insights about older men's food and cooking experiences, interviews naturally less intimate; even when conducted over the phone in one's own home, the act of interviewing disrupts a participant's daily life and may cause some response bias, wherein the participant responds in a certain way in order to please the researcher (Furnham, 1986).

Similar to an ethnographic study, the cultural probes aimed to integrate the data collection activities a little more naturally within the daily lives of participants. While interviews allowed data to be collected on factors such as past experiences and memories, cultural probes allowed the focus to remain completely within the present. As such, the cultural probes aimed to not only collect more data about the participants' present daily lived experiences beyond that provided during interviews, it aimed to do so in the least invasive way possible (Mattelmäki, 2006).

While the cultural probes continued to build on the narrative of the older men's dailylived experiences, the naturalness of the information received varied among participants. The kit's journal prompts were specifically designed with the idea that daily meal 
routines as they typically are experienced could be recorded. Questions such as "Who was involved in preparing this meal?" were included so that individuals who did not cook any of their own meals could paint a picture of how they received their daily meals, while questions such as "what were the main steps involved in preparing this meal?" were intended to understand not only level of involvement, but also the participant's level of understanding of the cooking process. Instead, many participants misinterpreted the journal prompts to mean they were required to cook three meals. As a result, two participants contacted the researcher to clarify that they do not cook and were not comfortable doing so. Those who contacted the researcher were told the intention of the questions and prompts, and thusly produced journals that reflected their daily-lived experiences. Another four participants did not contact the researcher to clarify, but may have deviated from the daily routine to become more involved in the cooking process. Some participants utilized the barbeque, which they had mentioned being comfortable with in interviews, to accomplish the task of participating in cooking the meals. Other participants tried cooking new meals specifically for the sake study. In all instances of participants cooking new meals the researcher was informed of the deviation in daily routine either directly in the journal ("It was more than I would usually do but I did it for the study!") or via their wife. In two separate instances the wives of participants informed the researcher during the collection process that upon seeing the journal they had encouraged their husbands to be involved in the cooking process. While these deviations from the intended purpose of the cultural probe kit made it so the typical daily experiences weren't always reflected in the completed journals, it contributed to expanding the understanding of experiences and showcased important 
factors in the cooking experience, such as comfort level and motivation. The panicked messages of the men who do not cook, while reflecting their genuine daily lives, also reflected their absolute discomfort in the kitchen, and the men who tried new cooking experiences, reflected not only on the experience of trying something new, but also showcased their willingness to try new things.

Data comparisons between interviews and probes showed that behavioural patterns from the probes were consistent with the responses given during the interviews. While the journals, in some instances, may not have reflected the men's daily experiences towards cooking, they instead seemed to become a reflection of the men's genuine attitudes towards cooking and how these attitudes could impact their daily experiences. The focus groups provided a challenge in consistency. It was important that the richly diverse experiences and perspectives of the older men were reflected in the personas. However, the sample size of the participating designers was limited because there were not enough sessions to allow for each persona to be used over multiple sessions. As previously mentioned, assignment of personas based on the similarity or differences of the personas helped make up for the limitations of the sample size. Additionally, similarity across sessions, by using the same semi-structured questions and prompts during the Mural mind-mapping activity and the same semi-structured questions during the group discussions, created a similar structural direction for data collection. This meant that at the analysis stage, coded data from the two Carl mind-maps could be compared; the coded data from the George and Liam mind-maps could be compared; and the data from each from all of the discussions could be compared. All the coded data could also be examined as whole to understand how different personas may elicit 
different responses from the designers; an important aspect to examine in order to understand the impact of designer thinking on design processes.

While each of the methods used in this study had their own unique advantages, they also had some limitations as well. By utilizing both semi-structured interviews and cultural probes the two methods were able to complement each other and make up for some of the limitations of the methods individually. This crossover is where data triangulation is valuable in qualitative research (Creswell \& Creswell, 2018). The designer focus groups were a necessary additional method for their ability to provide a window into how the design perspective might impact the process of designing for older men cooking. The focus groups did have their own limitations, especially pertaining to the sample size of designers participating.

\subsubsection{Sample Size}

Due to the limited sample size of this preliminary study, and the recruitment limitations (word-of-mouth and digital recruitment were the only methods used) it is difficult to know whether the variations in experiences, opinions, and abilities is reflective of the general population of older men in North America. For example, most men who participated in the study were at least somewhat comfortable using technology (as mentioned above, the majority were recruited through digital means) and none of the men reported any form of physical handicap; it is unknown whether this comfort level with technology or level of physical ability is a true reflection of the general population. Another example of a limitation of this sample size was the lack of any participants who act as main caregivers to a wife or partner who can no longer take care of their traditional household role. A larger study with a broader recruiting opportunities (i.e. community 
centers with senior programming were closed during the pandemic, but could be a good way during normal times to recruit for this population) could contribute to develop a more informed stance on the impact this research has on older men with a broader spectrum of lived experiences.

The small sample size of design participants also served as a limitation. As mentioned in section 5.9, interest was only included in some of the personas. A larger sample size of design participants may allow for more exploration to create a firmer understanding as to whether interest serves as a humanizing factor capable of evoking designer empathy.

\subsection{Quality of Findings}

While the sample size of this study limited the amount of information, it does not reduce the quality of the experiences, opinions, or emotions of the older men who participated in this study. The data from the cultural probe kits, in many instances, reinforced the information provided during interviews, thus reinforcing the understanding of older men's past and present experiences and the influences on their cooking abilities and attitudes. The majority of the cultural probe kits could be confirmed as a reliable telling of men's daily experiences by comparing the data to the participant's corresponding interview data - the interview data confirmed details that supported the claim that the recorded information in the kits was a true reflection of daily experience. While some men deviated from their typical daily experiences when filling out the cultural probes kits, in all such instances these deviations were disclosed, either by directly disclosing in the journal ("I feel good about making a tasty lunch. It was more than I would usually do, but I did it for the study!" -P7) or disclosed by the participant's wife (P2) during the process of organizing the cultural probe kit pick-up. While these deviations resulted in 
information that did not necessarily reflect the daily experiences of the participants, they did reflect a genuine experience in the kitchen (including thoughts and emotions thanks to the journal prompts and rating scales) and were treated as such.

Furthermore, the addition of the design focus group allowed for an understanding of how valuable the voices of the older men discussing their experiences, opinions, or emotions may be in influencing a design process aimed at supporting older men's cooking abilities. The value of deeper insights, such as the ones found by focusing two of the methods on the older men participating in the study, may contribute to a more empathetic design process (Walters, 2020., Chen, R., Nivala., \& Chen, C-B., 2011., Nielsen, 2019). Focus Groups $\mathrm{A}$ and $\mathrm{C}$ both showcased features of an empathetic design mindset through the designer's interactions with the personas. These groups placed an emphasis on the humanizing features of the personas that they could identify with best (as seen by the use of designer's personal examples when working with the personas). Additionally, they also voiced a desire for more information relating to hobbies, social circles, and daily routines outside of cooking and food (Focus Group B also voiced this desire). Making these personal links or humanizing connections would make the personas what Nielsen (2019) would consider a success and a measurement of empathy. The understanding developed through the three methods emphasizes how the data from the first two methods of research, interviews and cultural probes, might be used in future design scenarios.

\subsection{Revisiting the Research Questions}

As a result of conducting this preliminary study and synthesizing the subsequent data, insights were made that help to answer the research questions. In this section, the two 
sub-questions, which combined together help to at least partially answer the main question, are presented first, followed by the main question.

\subsubsection{How might insights into older men's daily cooking rituals or routines further support independence for this population?}

Insights that helped to answer this question all explored a factor that impacts ritual or routine in some way that may ultimately impact independence as well.

1. Insights into how traditional household roles impact ritual or routine also lead to insights regarding independence.

For married men, traditional household roles result in their wife being the primary cook. Additionally married men typically participate in joint rituals pertaining to food, such as washing the dishes and their wife cooking the meal. These traditional household rituals can impact older men's independence because they do not have the opportunity to build the cooking skills. Rituals take on a higher meaning than just basic need fulfillment, so designers may want to consider ways to add to preexisting rituals rather than change the rituals altogether (Lévy, 2015.,

Lévy \& Hengeveld, 2016., \& Lévy, 2018). For married men, adding to preexisting rituals may mean design solutions that encourage men to help their wives in the kitchen, which will help them to build the cooking skills needed to be capable of independence if needed, while recognizing the value of the preexisting joint rituals.

2. As is seen in the available alternatives, independence is about being fed - not necessarily about an enjoyable experience. 
When examining the cooking alternatives preferred by older men it can be understood that men often prefer methods that are fast and easy to use such as microwave meals, or, other words, routines over rituals. This preference is further highlighted by time being perceived as a limited resource best spent doing things other than cooking. Routines utilizing meal alternatives, such as microwave meals, already support independence in the sense that older men with little cooking experience are able to feed themselves. However, autonomy over what the meal is and how nutritional that meal is impacted by the amount of choice amongst the meal alternatives. Designers might want to consider how routines pertaining to available alternative may support independence while also impacting autonomy (arguable just a more complex form of independence.

\section{Nutritional education may positively impact cooking and food rituals and} routines to include higher value nutrition.

Like in the study conducted by Nara et al. (2012), which showed an increase of nutritionally balanced diets after providing nutritional education, older men may also benefit from nutritional education. If designers understand the nutritional concerns of older men and tailor educational elements in their solutions towards these concerns the resulting design solutions might contribute to older men feeling independent in their ability to provide themselves a nutritionally balanced diet. 


\subsubsection{How might the design of kitchenware further support older men's independence?}

The process of designing kitchenware that is accepted and regularly used by older men supports independence because older men using kitchenware regularly implies they are building the experience and skill they need in the kitchen in order to support themselves. Insights in this section show considerations that might help designers develop a successful solution that older men readily embrace, therefore supporting their independence.

1. Designing kitchenware that embeds into preexisting activities may increase willingness to use the kitchenware as well as build confidence.

As has been previously discussed, older men already positively receive embedded activities in cooking and meal experiences, which is to the advantage of designers. For example, many older men already use a barbecue in a traditional way (flipping meat), so there may be design opportunity to embed other kitchenware tools into the barbecue experience in order to expand upon the cooking abilities of older men. This embedding could apply to activities that are not necessarily currently cooking related as well - for men who are interested in gadgets or tech, integrating new gadgets that cater to this interest into the cooking process might be an approach worth exploring. Integrating new kitchenware into activities men are already comfortable with might help to build confidence in cooking abilities.

\section{Designing kitchenware that separates cooking from the association with} feminine experience may help to interest older men. 
For older men, who are used to cooking being a traditionally feminine experience, kitchenware that appears outwardly feminine may be dismissed before the first use. Due to the women in their lives are often perceived as the superior and/or primary cooks by older men, kitchenware with a feminine aesthetic may appear exclusive to a group older men are not a part of, alienating them before they can even use the tool. Designing to aesthetically appeal to older men might help attract the men to the kitchenware and have more willingness to try using the kitchenware.

\section{Important design interventions may emerge in forms beyond just} kitchenware.

Kitchenware is not the only solution that might help to support independence for older men in terms of their cooking abilities and experiences. During the interviews, seven out of eight men discussed at least one available alternative to traditional cooking (see table 28 in section 4.7.1) and all of the designers discussed at least one alternative to traditional cooking as well (see tables $30 \& 31$ in section 4.7.3). Available alternatives, such as pre-prepared meals or food services offer a valid way for older men to sustain themselves while remaining independent. The form of design intervention that is most suitable for older men may vary depending on their attitude towards cooking. For older men that are open to cooking, kitchenware design interventions may help to support the men in their cooking process. Alternatives to kitchenware may do a better job acknowledging disinterest as well as past negative experiences. For example, P4, who explained that while he knew how to cook he had no intention to do so, 
would likely be more attracted to an alternative solution to kitchenware (which implies a need to cook in at least some capacity). User experience design processes may help to design kitchenware or identify more appropriate design outcomes.

4. The design process is just as important as the resulting design intervention. "The design of kitchenware" is very final, it is the outcome of a design process. The design process is an important step in reaching any outcome and helps the designer to evaluate the target users and consider all necessary factors that may impact the final design intervention. After the first design research method of this study was conducted, the interviews, service design was added as an element to the designer focus groups. These additions were made as a result of the data from the interviews that illustrated higher levels of disinterest in cooking as well as positive discussion regarding available alternatives to traditional cooking methods.

\subsubsection{How might design interventions support the facilitation of positive cooking experiences?}

Insights answering this question can be split up into two different areas - insights into the specific design interventions that may support design pursuits for positive cooking experiences; and insights into the considerations that might contribute to developing positive cooking experiences.

\section{Considerations Contributing to Positive Cooking Experiences}

1. Designers may want to consider the interest levels of older men in the design process. 
Positive cooking experiences can only be facilitated for older men if they are interested and engaged with the way in which these experiences might be facilitated. In considering interest levels designers may begin to explore ways to motivate men with low or no interest to participate in cooking experiences.

\section{Designers may want to consider the past experiences of older men in the}

\section{design process.}

The older men in this study recalled many past experiences that impacted not only their opinions of cooking, but also their openness to developing new cooking skills and experiences. By taking the time to understand these past experiences, designers may find solutions that acknowledge these experiences and communicate an aim to move away from past negative cooking experiences, thus helping to move towards positive experiences.

\section{Designers may want to consider embedded activities or experiences as a part} of their design solutions.

Various forms of embedded activities or experiences appeared repeatedly throughout all three study methods. In interviews and cultural probes the older men discussed how hobbies or social experiences that are embedded within their daily cooking or food experiences positively impacted these experiences. Designers in the focus groups also recognized the potential value of embedded activities or hobbies to both evoke positive cooking experiences, help build confidence (which would also contribute to positive cooking experiences as well), and motivate older men to want to allocate time toward cooking experiences.

\section{Design Process}




\section{Designers may want to consider taking an inclusive design approach.}

The range of technological abilities between the small sample size in this preliminary study emphasizes why an inclusive design approach may be important. This approach may push designers to consider a broader range of users and their varied abilities as design criteria (Wright, 2004., \& Shinohara, \& Wobbrock). There are a diverse range of skills and abilities amongst older men that will impact how a designed solution may be received. A good example of this range would be looking at the aforementioned technological abilities. While some older men, like P8, are uncomfortable with all digital technology, others, like P3, enjoy it and seek out new technology to engage with. If a designer caters only to men like P8 they run the risk of alienating men like P3 from their design solution and vice versa. An inclusive design method, which aims to include many age demographics with a range of different abilities, can help to encourage a designer to think expansively about the variety of skills and abilities of older men (Wright, 2004., \& Shinohara, \& Wobbrock).

\section{Designers may consider an emotional design lens supported by personas.}

An emotional design lens provides a framework that may help to guide designers towards impactful designs that are well loved and well used by pushing the designer to consider the design aspects, such as reflective design, that may be positively received by users (Norman, 2004., Walters, 2020., Desmet \& Pohlmeyer, 2013). In order for these designs to be truly impactful, however, empathy is needed (Walters, 2020). Personas can be used as a tool to successfully communicate information about a group of people in a way that evokes empathy 
(Nielson, 2019., Cooper et al., 2014). Some of the concerns designers may have pertaining to the use of personas can be addressed right away. By creating personas using real information, as was recommended by Cooper et al. (2014), concerns about a lack of buy-in due to the use of fictitious information would no longer apply (Vincent \& Blandford, 2014). When creating personas, Cooper advises that personas can be 'humanized' in order to help designers to connect and empathize with the personas (Cooper et al., 2014). As was seen in the Designer Focus Groups, personal quotes may be one method of humanizing, as well as careful consideration into the content of personas. Certain traits, such as interest levels, may help to evoke empathy. Designer Focus Groups showcased the advantages of the persona-fueled empathy when they began making personal connections in order to support and strengthen the design solutions they were recommending.

\section{A multisensory approach might support design solutions that are positively} received by older men.

Due to the fact that older men in this study held simplicity and familiarity in such high regard, it is perhaps a good idea to consider how any solutions to supporting cooking experiences might be experienced on a multisensory level for inexperienced cooks. Experiences engaging multiple senses stimulate a stronger experience (Ranne, 2019). As such, if the multisensory experience is too overwhelming it may not support the simplicity older men desire from a cooking experience. 


\subsection{Summary}

All the insights from the two sub-questions (5.11.1 \& 5.11.2) contribute to the main question (5.11.3) in some way.

Many of these insights help to answer the main question. Insights into ritual and routine lead to insight regarding independence as well as positive cooking experiences. Both rituals and routines have traits (respectively, assigned higher meaning and regularity) that contribute to positive experiences (Lévy, 2015., Lévy \& Hengeveld, 2016., \&Lévy, 2018). To use insight to build upon preexisting rituals or routines may help to contribute to continuing to facilitate these rituals with higher involvement from older men.

Designers who consider nutritional concerns, embedded activities, and masculine product aesthetics in their solutions may find motivating factors for older men to contribute to their design interventions. Motivating factors are key to facilitating cooking experiences for older men who may not initially be interested in cooking.

There were also some insights from the sub-questions that challenged the main-question. These insights regarded the meaning of independence to older men as well as available alternatives. Both of these insights challenge whether a traditional cooking experience is always the most appropriate solution. Solutions that provide an alternative to the traditional cooking experience, such as pre-prepared foods or food services may be more accepted by some men who are completely closed off to the idea of cooking and provide a more positive experience. As a result of this insight, designers may want to consider what they define as a cooking experience and broaden that definition to include nontraditional methods of cooking or even alternatives to cooking. 


\section{Chapter 6: Conclusion}

In this study an understanding of older men's cooking experiences has led to a wealth of insights that may support future designers aiming to facilitate positive cooking experiences through design intervention for this population.

\subsection{Overview of the Study}

This study aimed to gather insight into older men with little to no cooking experience in order to understand how design might support positive cooking experiences for this demographic. It was also believed that positive cooking experiences for older men may help to support independence in situations where they do not have a spouse capable of caring for their dietary needs. These aims and beliefs helped to form the main research question, which directly explores how design can support positive cooking experiences for older men, as well as the two sub-questions, which looked at more specific ways independence may be supported through cooking experiences.

The literature that was available related to the topic of older men and cooking as well as design approaches or ways of thinking helped to provide a foundation of information to help kick-off the study. The information from the literature review helped to formulate the final research questions that were used for this study. Additionally, it also contributed to what pre-formulated questions were asked in the semi-structure interviews.

The design research methods: semi-structured interviews; cultural probe kits; and designer focus groups utilizing personas; each helped to produce targeted data. The semistructured interviews and cultural probe kits aimed to collect insights into older men with little to no cooking experience. The designer focus groups utilized personas and the data from the first two methods to focus in on how the design process may utilize insights 
about older men with little to no cooking experience. The emerging themes that resulted from the coded data of all three methods are what ultimately produced the insights answering the research questions for this preliminary study.

\subsection{Primary Contributions}

This preliminary study has primary contributions in two areas - contributions to a knowledge foundation (literature) and contributions to support designers aiming to develop design interventions for older men with little to no cooking skills.

\subsubsection{Understanding how older men experience cooking}

The understanding of how older men experience cooking that was developed through this study contributes to social science or sociology literature about older men's experiences. The discussion of themes in chapter 5 provided a compilation of insights into the experiences, attitudes, and perspectives of older men on the topic of cooking. Of these, there are three primary themes that may be most relevant to design and all the common insights contribute to the three primary themes in some way. The themes are as follows, with the top three primary themes bolded and the complimentary themes proceeding each primary:

1. Cooking Interest and Experience are important because understanding the interest and experience levels of older men may greatly impact which design interventions are accepted or embraced.

- Resource Allocation contributes to cooking interest and experience because willingness to allocate time and food may be tied to interest and motivation levels. 
2. Cultural Experiences are important because insights into this theme found that men might be more likely to accept design interventions that embed preexisting cultural experience factors into cooking experiences.

- Gender Dynamics may contribute to cultural experiences because the way in which older men's past and/or present lives and cultural experiences are structured will be impacted depending on whether they follow traditional household roles or not.

- Technology may contribute to cultural experiences because technological literacy is a contributing factor of cultural experience and may impact what design interventions are accepted.

- Feeling Factors may contribute to cultural experiences because emotions and feelings impact the way the world is experienced and may also impact willingness to try new things impacting preexisting cultural experience.

\section{Available Alternatives are important because understanding what} alternatives are available and why they might be a success, a failure, or potentially problematic is valuable information to guide future designs.

- Nutrition \& Food may contribute to available alternatives because nutrition may be a motivating factor for older men to embrace innovative design solutions. Additionally, regardless of interest for nutritious food, available alternatives with little nutritional value may be chosen due to lack more attractive choices. 


\subsubsection{Providing insight for designers aiming to facilitate older men's cooking experiences through design intervention}

The final insights of this study provide recommendations for designers to be able to design interventions (products, services, processes and rituals, or environments) that could facilitate older men's positive cooking experiences. These recommendations fall into two, equally important categories: recommendations for design processes and recommendations supporting cooking experiences.

The design opportunities that support cooking experiences that emerged from this study could draw from these key motivational factors:

1. Traditional household roles contribute to the cooking rituals or routines that will impact future adaptability to designed solutions.

2. The important thing for an independent older person living on their own is the ability to feed themself - enjoyment comes second. As such, alternative methods of cooking could address these factors on various levels.

3. Nutritional education may positively impact cooking and food rituals and routines to include higher value nutrition.

4. Designing kitchenware that embeds into preexisting activities may increase willingness to use the kitchenware as well as build confidence.

5. Designing kitchenware that incorporates a masculine aesthetic may help to interest older men and contribute to a sense of familiarity.

The design processes that support the facilitation of positive cooking experiences could include the following considerations: 
1. Important design interventions may emerge in forms beyond just kitchenware because studying people's experiences, rituals, and/or routines may benefit from a broader scope of design solutions and processes, such as experience design.

2. An inclusive design approach may encourage willingness to use designed solutions because a broader range of skills and abilities will have been considered and the risk of alienation may have also been reduced.

3. An emotional design lens supported by personas might evoke more evoke empathy from designers, which is important because it may create more impactful design solutions that consider all the contributing factors that may interest, motivate, and/or support older men.

4. A multisensory approach might support design solutions that are positively received by older men because combinations of different sensory factors could contribute to how something is experienced.

\subsection{Recommendations for Future Research}

Larger samples of older men (ages 65 years or older) may help to develop a broader understanding of interest and motivations for cooking, cultural experience influences, and general emotions and attitudes towards cooking experiences. The older men who participated in this study led interesting and enriched lives - amongst this small group, one restored cars, some were involved in sports, and another enjoyed trying new foods while travelling. Gaining a firmer understanding about this life experience (including hobbies, technological capabilities, physical abilities, preexisting daily rituals and routines, and social experiences and networks) data may provide a broader context to 
better understand how factors outside of cooking may impact cooking interest, motivation, and skills.

An additional, larger study working with designer focus groups may also serve useful in examining the potential impact the different features of the constructed personas could have on the design solutions produced. As mentioned in section 5.9, designers in this preliminary study who had the personas that included interest factors produced seemingly more empathetic and well-rounded design solutions. A future study replicating these focus group sessions on a much larger scale, with all focus groups consisting of at least four designers and more variation in persona assignment (i.e. one focus group receives George and Carl, another Carl and Liam, and third Liam and George, etc.) may help to identify potential patterns influenced by the interest factors and any potential empathy evoked.

\subsection{Concluding Thoughts}

Through the process of conducting this research I heard so many stories of older men just like my grandfather - and not just from the older men participating in the study! Whenever I explained my research to anyone there was a high chance I'd hear a story of a grandfather or father just like my grandfather. It is my hope that the contributions of this research will help to support older men in future positive cooking experiences, so that future men like my grandfather may explore a rich amount of options to enjoy food (and maybe even some cooking as well). 


\section{References}

Adlin, T., \& Pruitt, J. (2010). The essential persona lifecycle your guide to building and using personas. Morgan Kaufmann.

Angus, J., \& Reeve, P. (2006). Ageism: a threat to "aging well" in the 21 st century. Journal of Applied Gerontology, 25(2), 137-152. Retrieved from https://proxy.library.carleton.ca/login?url=http://search.ebscohost.com/login.aspx?dire $\mathrm{ct}=$ true $\& \mathrm{db}=\mathrm{cin} 20 \& \mathrm{AN}=106361387 \&$ site $=$ ehost-live

Cagan, J., \& Vogel, C. (2002). Creating breakthrough products: innovation from product planning to program approval. Upper Saddle River, NJ: Financial Times/Prentice Hall.

Charles, N., \& Kerr, M. (1988). Women, food, and families. Manchester University Press.

Chen, R. C. C., Nivala, W. C.-Y., \& Chen, C.-B. (2011). Modeling the Role of Empathic Design Engaged Personas: An Emotional Design Approach. In Universal Access in Human-Computer Interaction. Users Diversity (22-31). Springer Berlin Heidelberg. https://doi.org/10.1007/978-3-642-21663-3_3

Cooper, A., Reimannm, R., Cronin, D., \& Noessel, C. (2014) About Face : the Essentials of Interaction Design (4th ed.). John Wiley \& Sons, Inc.

Corso, J. (1981). Aging sensory systems and perception. Praeger.

Creswell, J. W., \& Creswell, J. D. (2018). Research design : qualitative, quantitative, and mixed methods approaches (5th ed.). SAGE Publications, Inc.

Daniels, S., Glorieux, I., Minnen, J., \& van Tienoven, T. P. (2012). More than preparing a meal? Concerning the meanings of home cooking. Appetite, 58(3), 1050-1056. https://doi.org/10.1016/j.appet.2012.02.040

Desmet, P., \& Pohlmeyer, A. (2013). Positive Design: An Introduction to Design for Subjective Well-Being. International Journal of Design, 7(3).

Diller, S., Shedroff, N., \& Rhea, D. (2006). Making Meaning: How Successful Businesses Deliver Meaningful Customer Experiences (1st ed.). Peachpit Press.

Erlich, R., Yngve, A., \& Wahlqvist, M. L. (2012). Cooking as a healthy behaviour. Public Health Nutrition, 15(7), 1139-1140. https://doi.org/10.1017/S1368980012002662

Fisk, M. (1986). Independence and the elderly. London;: Croom Helm. 
Furnham, A. (1986). Response bias, social desirability and dissimulation. Personality and Individual Differences, 7(3), 385-400. https://doi.org/10.1016/0191-8869(86)90014-0

Gaver, W., Dunne, A., \& Pacenti, E. (1999). Design: Cultural Probes. Interactions, 6, $21-$ 29. https://doi.org/10.1145/291224.291235

Gilbert, R. (2019). Inclusive Design Research. In Inclusive Design for a Digital World. https://doi.org/10.1007/978-1-4842-5016-7_6

Goodwin, K. (2009). Designing for the digital age: how to create human-centered products and services (1st ed.). John Wiley \& Sons, Inc.

Heskett, J. (1980). Industrial design. Thames and Hudson.

Holtzblatt, K., \& Beyer, H. (2016). Contextual design: design for life (2nd ed.). Elsevier.

Interaction Design Foundation (2020). The principles of service design thinking building better services. interaction-design.org. [URL] https://www.interactiondesign.org/literature/article/the-principles-of-service-design-thinking-building-betterservices

Interaction Design Foundation (N.D.). User Experience (UX) Design. interactiondesign.org. [URL] https://www.interaction-design.org/literature/topics/ux-design

Keller, H., Gibbs, A., Wong, S., Vanderkooy, P., \& Hedley, M. (2004). Men Can Cook: Development, Implementation, and Evaluation of a Senior Men's Cooking Group. Journal of Nutrition For the Elderly, 24(1), 71-87. https://doi.org/10.1300/J052v24n01_06

Kirkham, P., \& Blecksmith, A. (2003). Industrial design. In Oxford Art Online. https://doi.org/10.1093/gao/9781884446054.article.T041254

Kullberg, K., Bjorklund, A., Sidenvall, B., \& Aberg, A. (2011). "I start my day by thinking about what we"re going to have for dinner'- a qualitative study on approaches to food-related activities among elderly men with somatic diseases (Report). Scandinavian Journal of Caring Sciences, 25(2), 227-234. https://doi.org/10.1111/j.1471-6712.2010.00813.x

Lévy, P. (2015). Exploring the challenge of designing rituals. In 6th International Congress of International Association of Societies of Design Research, IASDR 2015. Brisbane, Australia: Queensland University of Technology.

Lévy, P. (2018). The beauty of making hot chocolate: an inquiry on designing for everyday rituals. In DRS : Design Research Society 2018, 25-28 June 2018, Limerick, United Kingdom. https://doi.org/10.21606/dma.2017.514 
Lévy, P., \& Hengeveld, B. (2016). What matters for ritual visualization: towards a design tool for the description and the composition of rituals. 6th International Kansei Engineering and Emotion Research Conference, KEER 2016. Leeds.

Mattelmäki, T. (2006). Design probes. [Doctoral Thesis, Aalto University, School of Arts, Design and Architecture]. http://urn.fi/URN:ISBN:951-558-212-1

Monk, A., \& Cox, C. B. (1991). Home care for the elderly: an international perspective. Auburn House.

Morgan, J. (1979). Becoming old: an introduction to social gerontology. New York: Springer Pub. Co.

Nara, D., Thompson, L., Johnson, A., Ntekim, O., Castor, C., \& Ngwa, J. (2019). A "Food as Medicine" Program and It's Effects on Healthy Eating and Cooking Confidence (P04-021-19). Current Developments in Nutrition, 3(Suppl 1). https://doi.org/10.1093/cdn/nzz051.P04-021-19

National Center for Immunization and Respiratory Diseases (NCIRD), Division of Viral Diseases. (2020, June 25). Coronavirus Disease 2019 (Covid-19); Older Adults. Retrieved July 2, 2020, from https://www.cdc.gov/coronavirus/2019-ncov/need-extraprecautions/older-adults.html

Neuman, N., Gottzén, L., \& Fjellström, C. (2017). Masculinity and the sociality of cooking in men's everyday lives. The Sociological Review, 65(4), 816-831. https://doi.org/10.1111/1467-954X.12420

Nielsen, L. (2019). Personas - User Focused Design (2nd ed.). Springer London. https://doi.org/10.1007/978-1-4471-7427-1

Norman, D. A. (2004). Emotional design: why we love (or hate) everyday things. Basic Books.

Norman, D., \& Nielsen, J. (N.D.). The Definition of User Experience (UX). Nielsen Norman Group; world leaders in research-based user experience. [URL] https:/www.nngroup.com/articles/definition-user-experience/

Palmore, E. (1970). Normal aging; : reports from the Duke longitudinal study. Durham, N.C., Duke University Press.

Pelham, A. O., \& Clark, W. F. (1986). Managing home care for the elderly: lessons from community-based agencies. Springer Pub.

Ranne, J. (2019). Designing for Multi-sensory Experiences in the Built Environment. [Master's Thesis, Aalto University School of Arts].

DOI: 10.13140/RG.2.2.26244.35208 
Rozendaale, M.C. (2007). Designing engaging interactions with Digital Products. [doctoral thesis, Technische Universiteit Delft]. PrintPartners Ipskamp B.V

Saldaña, J. (2009). The coding manual for qualitative researchers. SAGE publications Ltd.

Schifferstein, H., \& Desmet, P. (2008). Tools Facilitating Multi-sensory Product Design. The Design Journal, 11(2), 137-158. https://doi.org/10.2752/175630608X329226

Shephard, R. J. (1997). Aging, physical activity, and health. Human Kinetics.

Shinohara, K., \& Wobbrock, J. (2011, May 7). In the shadow of misperception: assistive technology use and social interactions. In D. Tan \& G. Fitzpatrick (Chairs), [conference paper] CHI: Conference on Human Factors in Computing Systems. 705714. https://doi.org/10.1145/1978942.1979044

Sidenvall, B., Nydahl, M., \& Fjellström, C. (2000). The Meal as a Gift: The Meaning of Cooking Among Retired Women. In Journal of Applied Gerontology (Vol. 19, Issue 4, 405-).

Short, F. (2006). Kitchen secrets : the meaning of cooking in everyday life. Berg.

Smith, J., \& Ryan, L. H. (2016). Chapter 16 - Psychological Vitality in the Oldest Old. In K. W. Schaie \& S. L. Willis (Eds.), Handbook of the Psychology of Aging (8th ed.) (303-319). https://doi.org/https://doi.org/10.1016/B978-0-12-411469-2.00016-9

Svanborg A. (1984) Ecology, Aging and Health in a Medical Perspective. In: Robinson P.K., Livingston J., Birren J.E., Regnier V.A., Small A.M., Sterns H.L. (Eds.) Aging and Technological Advances. NATO Conference Series (III Human Factors), vol 24. Springer, Boston, MA. https://doi.org/10.1007/978-1-4613-2401-0_15

Szabo, M. (2014). Men nurturing through food: Challenging gender dichotomies around domestic cooking. Journal of Gender Studies, 23(1), 18-31. https://doi.org/10.1080/09589236.2012.711945

Trees, R., \& Dean. (2018). Physical and emotional nourishment: Food as the embodied component of loving care of elderly family relatives. European Journal of Marketing, 52(12), 2405-2422. https://doi.org/10.1108/EJM-11-2017-0840

Vincent, C. J., \& Blandford, A. (2014). The challenges of delivering validated personas for medical equipment design. Applied Ergonomics, 45(4), 1097-1105. https://doi.org/10.1016/j.apergo.2014.01.010

Walter, A. (2020). Designing for Emotion (2nd ed.). A Book Apart. 
Wright, E. (2004). Designing for an ageing population: an inclusive design methodology. Art, Design \& Communication in Higher Education, 2(3), 155-165. Retrieved from http://10.0.5.106/adch.2.3.155/0

Yoxall, A., Langley, J., Musselwhite, C., Rodriguez-Falcon M.J., and Rowson, J. (2010). Husband, Daughter, Son \& Postman, Hot-water, knife and towel: Assistive Strategies for Jar Opening. In Langdon, P., Clarkson, P. J., Robinson, P. (Eds). Designing

Inclusive Interactions. London: Springer. 187-196 


\section{Appendices}

\section{Appendix A Cultural Probe Kit Journal}

\section{Hello!}

In this journal you will find 4 different sections: Breakfast, Lunch, Dinner, and Camera Contents. These sections will help you to record your daily experiences with food and cooking.

In each of the first 3 journal sections please record 1 meal experience (for a total of 3 recorded meals: 1 breakfast, 1 lunch, and 1 dinner). Each section includes writing prompts and scales to support you in recording your meal experiences.

In your probe kit you will find writing implements to aid you in your journal entries, although you are also welcome to use your own tools. Additionally, there is a disposable camera. You may use this camera to record your cooking and/or dining experiences. The use of the camera is optional, and is used to add an extra dimension of understanding about your experiences. If you choose to use the camera, please use the final section of the journal, titled Camera Contents, to describe the content of each photograph you took. 


\section{Breakfast}


Describe what your breakfast included:

Who was involved in preparing this meal?

What did the planning process look like for this meal (At what point did you determine to have this meal? How did you acquire the ingredients?)? 
What were the main steps involved in preparing this meal?

What cooking tools, utensils, or equipment were used to prepare this meal? 
Circle any favorite tools/equipment mentioned in your last response.

Rate your mood while preparing this meal $(1=I \mathrm{am}$ not experiencing this emotion at all and $5=\mathrm{I}$ am mostly experiencing this emotion) :

Happy

$$
1
$$

2

3

Relaxed

1

2

3

4

Neutral $\quad 1$

2

3

4

5

Anxious

1

2

3

4

5

Frustrated 1

2

3

4

Angry

1

2

3

Comments:

Where did you eat this meal? 
Rate how enjoyable this meal was:

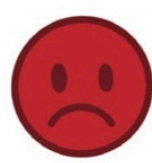

5

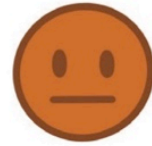

4

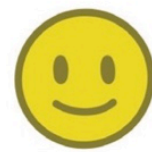

3

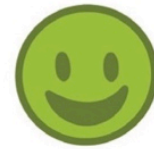

2

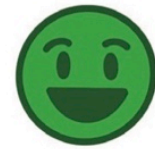

1

This meal This This meal This meal This meal was awful, meal was was okay, was good, was one I did not okay, but I wouldn't I would of the best enjoy it at I wouldn't mind enjoy eat- meals I've all want to eat eating it ing it again ever had it again occasion-

ally

What factors influenced your rating (taste, location, social factors)?

Rate how filling you found this meal:

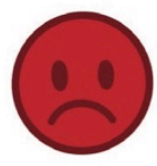

5

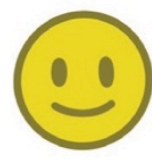

4

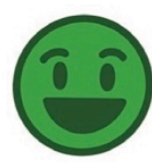

3

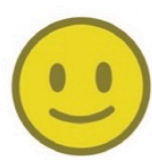

2

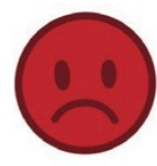

1

I am still I am still a I am I am a little I am very little comfort- too full uncomforthungry hungry ably full ably full

Comments: 
Describe the cleanup process after this meal:

Please add any additional comments about your meal experience: 
Lunch 
Describe what your lunch included:

Who was involved in preparing this meal?

What did the planning process look like for this meal (At what point did you determine to have this meal? How did you acquire the ingredients?)? 
What were the main steps involved in preparing this meal?

What cooking tools, utensils, or equipment were used to prepare this meal? 
Circle any favorite tools/equipment mentioned in your last response.

Rate your mood while preparing this meal $(1=I \mathrm{am}$ not experiencing this emotion at all and $5=\mathrm{I}$ am mostly experiencing this emotion) :

Happy

$$
1
$$

2

3

Relaxed

1

2

3

4

Neutral $\quad 1$

2

3

4

5

Anxious

1

2

3

4

5

Frustrated 1

2

3

4

Angry

1

2

3

Comments:

Where did you eat this meal? 
Rate how enjoyable this meal was:

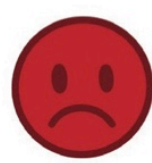

5

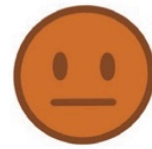

4

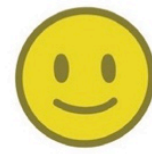

3

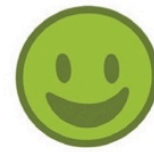

2

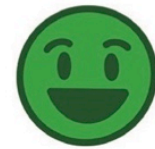

1

This meal This This meal This meal This meal was awful, meal was was okay, was good, was one I did not okay, but I wouldn't I would of the best enjoy it at I wouldn't mind enjoy eat- meals I've all want to eat eating it ing it again ever had it again occasion-

ally

What factors influenced your rating (taste, location, social factors)?

Rate how filling you found this meal:

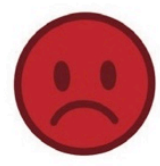

5

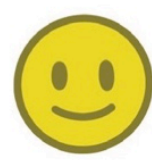

4

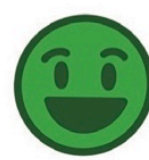

3

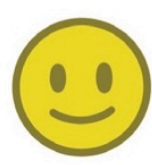

2

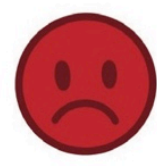

1

I am still I am still a I am I am a little I am very little comfort- too full uncomforthungry hungry ably full ably full

Comments: 
Describe the cleanup process after this meal:

Please add any additional comments about your meal experience: 


\section{Dinner}


Describe what your dinner included:

Who was involved in preparing this meal?

What did the planning process look like for this meal (At what point did you determine to have this meal? How did you acquire the ingredients?)? 
What were the main steps involved in preparing this meal?

What cooking tools, utensils, or equipment were used to prepare this meal? 
Circle any favorite tools/equipment mentioned in your last response.

Rate your mood while preparing this meal $(1=I \mathrm{am}$ not experiencing this emotion at all and $5=\mathrm{I}$ am mostly experiencing this emotion) :

Happy

$$
1
$$

2

3

Relaxed

1

2

3

4

Neutral $\quad 1$

2

3

4

5

Anxious

1

2

3

4

5

Frustrated 1

2

3

4

Angry

1

2

3

Comments:

Where did you eat this meal? 
Rate how enjoyable this meal was:

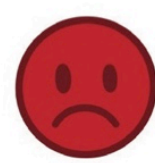

5

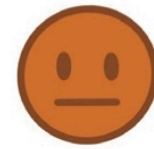

4

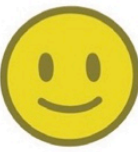

3

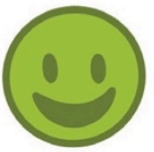

2

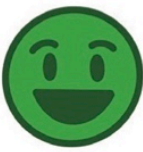

1

This meal This This meal This meal This meal was awful, meal was was okay, was good, was one I did not okay, but I wouldn't I would of the best enjoy it at I wouldn't mind enjoy eat- meals I've all want to eat eating it ing it again ever had it again occasion-

ally

What factors influenced your rating (taste, location, social factors)?

Rate how filling you found this meal:

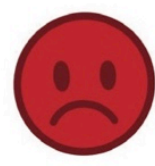

5

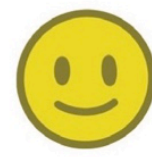

4

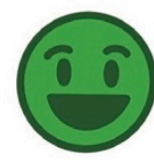

3

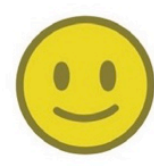

2

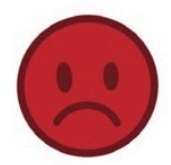

1

I am still I am still a I am I am a little I am very little comfort- too full uncomforthungry hungry ably full ably full

Comments: 
Describe the cleanup process after this meal:

Please add any additional comments about your meal experience: 


\section{Camera Content}

If you choose to take pictures with the camera tool in the
kit as an additional method of recording your cooking and/or
dining experiences, please use this section to keep a written
record of each photo you took.
In order to keep track of your photographs we recommend
you record a description of each photograph directly after it
is taken, so that records are kept in order (i.e. the first
description will correspond with the first photograph taken on
the camera).




\section{Picture 1:}

\section{Picture 2:}

\section{Picture 3:}

Picture 4:

\section{Picture 5:}


Picture 6:

Picture 7:

Picture 8:

Picture 9:

Picture 10: 
Picture 11:

\section{Picture 12:}

Picture 13:

\section{Picture 14:}

Picture 15: 
Picture 16:

\section{Picture 17:}

\section{Picture 18:}

Picture 19:

\section{Picture 20:}




\section{Appendix B Mind-Mapping Activity Templates}

\section{Appendix B.1 Carl Activity Template}
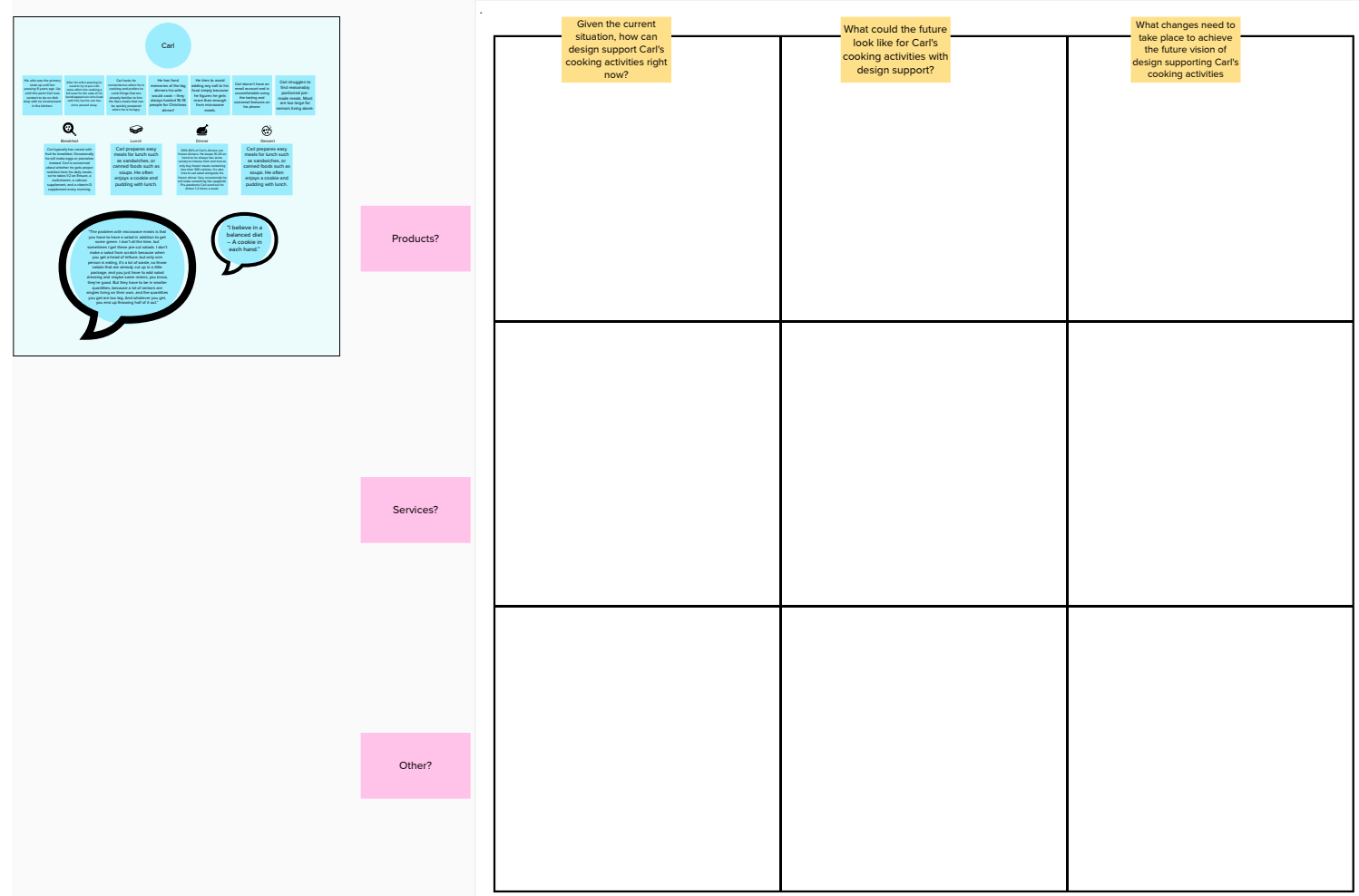

In the blue box a copy of Carl's persona is available. The three yellow stick notes above the chart read in order from left to right: "Given the current situation, how can design support Carl's cooking activities right now?," "What could the future look like for Carl's cooking activities with design support?," and "What changes need to take place to achieve the future vision of design supporting Carl's cooking activities?" The three pink sticky notes on the side of the chart read in order from top to bottom: "Product?," "Service?," and "Other?" 


\section{Appendix B.2 George Activity Template}

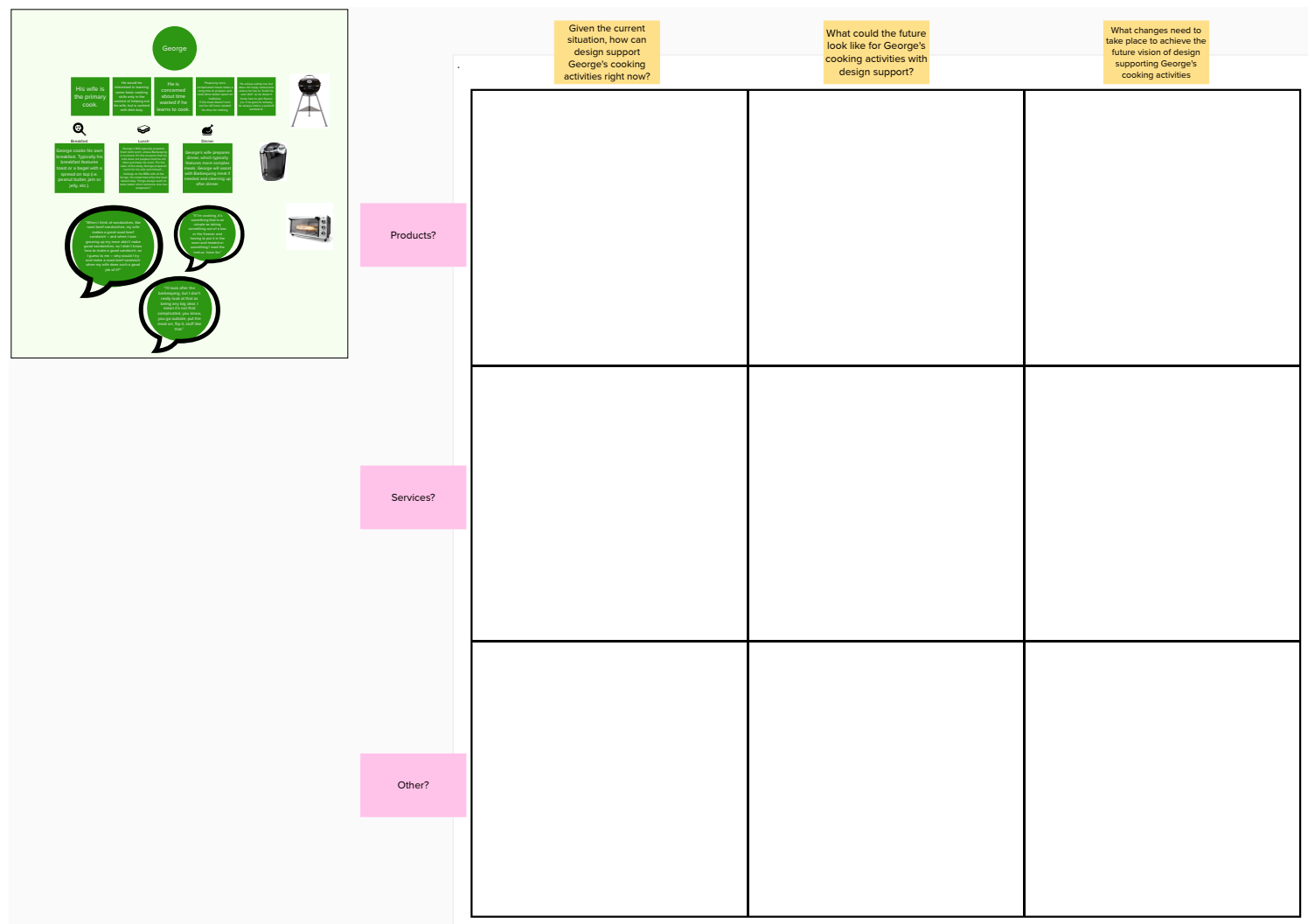

In the green box a copy of George's persona is available. The three yellow stick notes above the chart read in order from left to right: "Given the current situation, how can design support George's cooking activities right now?," "What could the future look like for George's cooking activities with design support?," and "What changes need to take place to achieve the future vision of design supporting George's cooking activities?" The three pink sticky notes on the side of the chart read in order from top to bottom:

"Product?," "Service?," and "Other?" 


\section{Appendix B.3 Liam Activity Template}

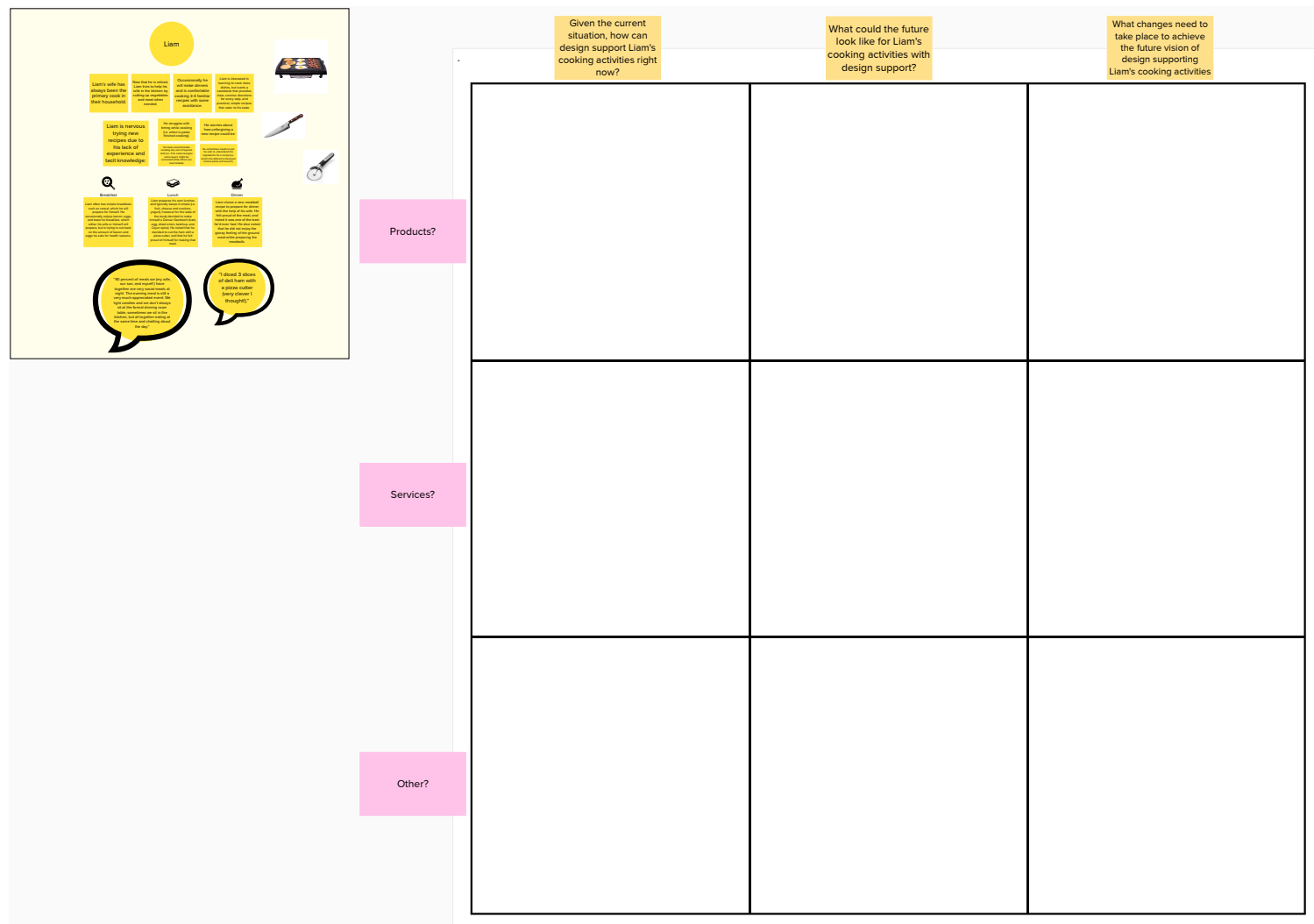

In the yellow box a copy of Liam's persona is available. The three yellow stick notes above the chart read in order from left to right: "Given the current situation, how can design support Liam's cooking activities right now?," "What could the future look like for Liam's cooking activities with design support?," and "What changes need to take place to achieve the future vision of design supporting Liam's cooking activities?" The three pink sticky notes on the side of the chart read in order from top to bottom: "Product?," "Service?," and "Other?" 


\title{
Appendix C Ethics Clearance
}

\author{
F) Carleton \\ Canada's Capital University \\ Office of Research Ethics \\ 4500 ARISE Building | 1125 Colonel By Drive \\ Ottawa, Ontario K1S 5B6 \\ 613-520-2600 Ext: 4085 \\ ethics@carleton.ca \\ CERTIFICATION OF INSTITUTIONAL ETHICS CLEARANCE
}

The following research has been granted clearance by the Carleton University Research Ethics Board-B (CUREB-B). CUREB-B is constituted and operates in compliance with the Tri-Council Policy Statement: Ethical Conduct for Research Involving Humans (TCPS2).

Ethics Clearance ID: Project \# 114589

Project Team Members: Ms. Samantha Schneider (Primary Investigator)

Lois Frankel (Research Supervisor)

Study Title: Design, Cooking, and Older Men

Funding Source: (If applicable):

Effective: November 19, 2020

Expires: November 30, 2021

This certification is subject to the following conditions:

1. Clearance is granted only for the research and purposes described in the application.

2. Any modification to the approved research must be submitted to CUREB-B via a Change to Protocol Form. All changes must be cleared prior to the continuance of the research.

3. An Annual Status Report for the renewal or closure of ethics clearance must be submitted and cleared by the renewal date listed above. Failure to submit the Annual Status Report will result in the closure of the file. If funding is associated, funds will be frozen.

4. During the course of the study, if you encounter an adverse event, material incidental finding, protocol deviation or other unanticipated problem, you must complete and submit a Report of Adverse Events and Unanticipated Problems Form.

5. It is the responsibility of the student to notify their supervisor of any adverse events, changes to their application, or requests to renew/close the protocol.

6. Failure to conduct the research in accordance with the principles of the Tri-Council Policy Statement: Ethical Conduct for Research Involving Humans 2nd edition and the Carleton University Policies and Procedures for the Ethical Conduct of Research may result in the suspension or termination of the research project. 
IMPORTANT: Special requirements for COVID-19:

If this study involves in-person research interactions with human participants, whether on- or offcampus, the following rules apply:

1. Upon receiving clearance from CUREB, please seek the approval of the relevant Dean for your research. Provide a copy of your CUREB clearance to the Dean for their records. See Principles and Procedures for On-campus Research at Carleton University and note that this document applies both to on- and off-campus research that involves human participants. Please contact your Dean's Office for more information about obtaining their approval.

2. Provide a copy of the Dean's approval to the Office of Research Ethics prior to starting any inperson research activities.

3. If the Dean's approval requires any significant change(s) to any element of the study, you must notify the Office of Research Ethics of such change(s).

Upon reasonable request, it is the policy of CUREB, for cleared protocols, to release the name of the $\mathrm{PI}$, the title of the project, and the date of clearance and any renewal(s).

Please email the Research Compliance Coordinators at ethics@carleton.ca if you have any questions.

CLEARED BY:

Date: November 19, 2020

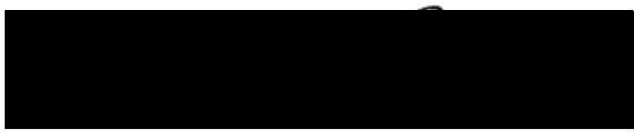

Bernadette Campbell, PhD, Chair, CUREB-B

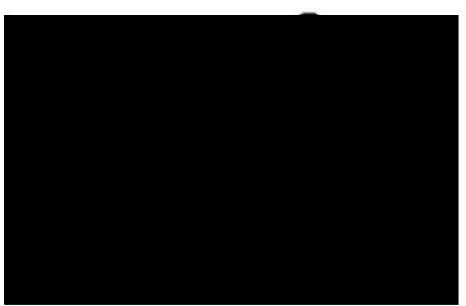

Natasha Artemeva, Co-Chair, PhD, Vice Chair, CUREB-B 